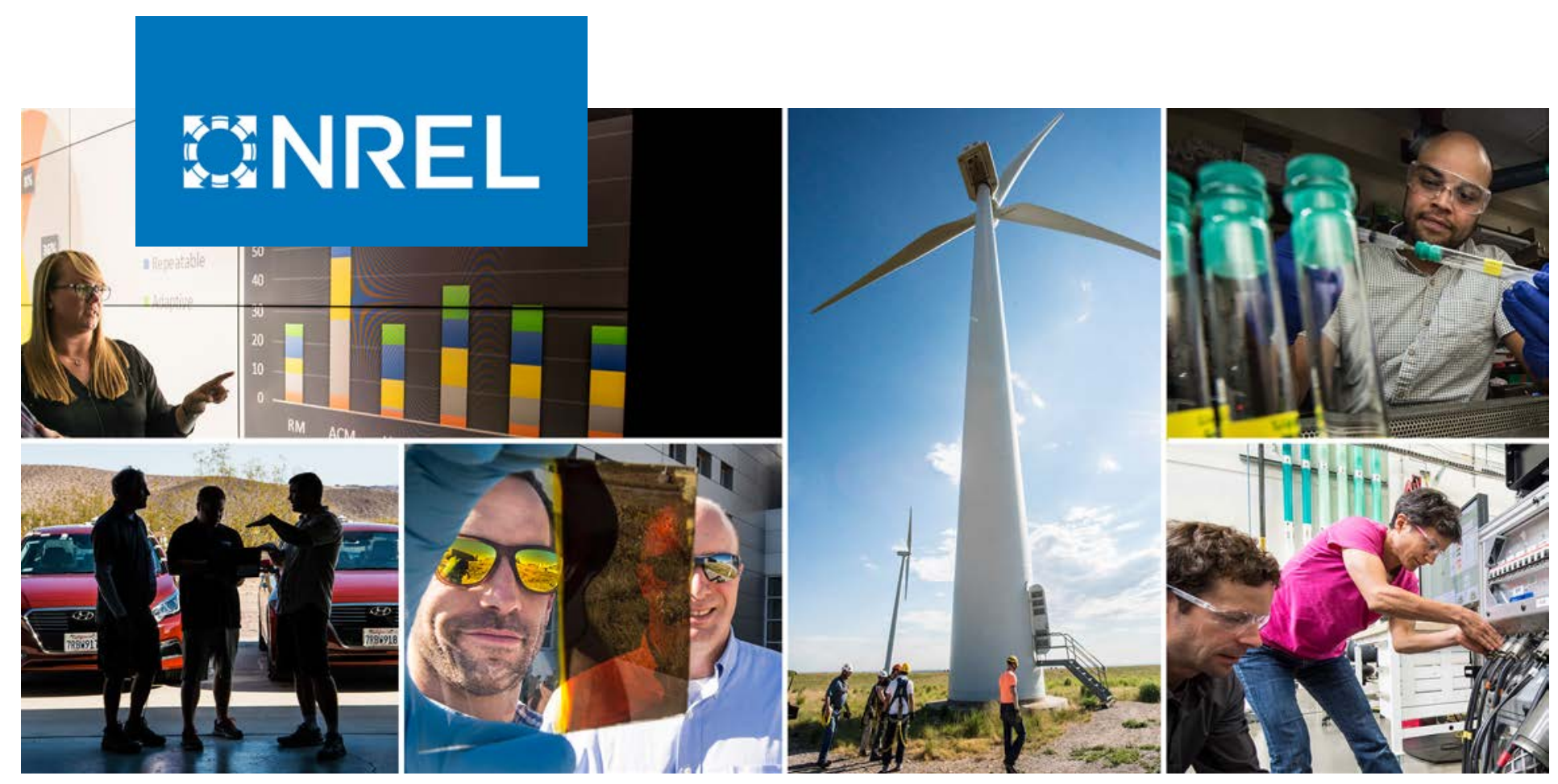

\title{
Opportunities for Research and Development of Hybrid Power Plants
}

Katherine Dykes, Jennifer King, Nicholas DiOrio, Ryan King, Vahan Gevorgian, Dave Corbus, Nate Blair, Kate Anderson, Greg Stark, Craig Turchi, and Patrick Moriarty

National Renewable Energy Laboratory

NREL is a national laboratory of the U.S. Department of Energy Office of Energy Efficiency \& Renewable Energy

Operated by the Alliance for Sustainable Energy, LLC

This report is available at no cost from the National Renewable Energy Laboratory (NREL) at www.nrel.gov/publications.
Technical Report

NREL/TP-5000-75026

May 2020 


\section{GNREL}

\section{Opportunities for Research and Development of Hybrid Power Plants}

Katherine Dykes, Jennifer King, Nicholas DiOrio, Ryan King, Vahan Gevorgian, Dave Corbus, Nate Blair, Kate Anderson, Greg Stark, Craig Turchi, and Patrick Moriarty

National Renewable Energy Laboratory

\section{Suggested Citation}

Dykes, Katherine, Jennifer King, Nicholas DiOrio, Ryan King, Vahan Gevorgian, Dave Corbus, Nate Blair, Kate Anderson, Greg Stark, Craig Turchi, Pat Moriarity. 2020. Opportunities for Research and Development of Hybrid Power Plants. Golden, CO: National Renewable Energy Laboratory. NREL/TP-5000-75026.

https://www.nrel.gov/docs/fy20osti/75026.pdf.

NREL is a national laboratory of the U.S. Department of Energy Office of Energy Efficiency \& Renewable Energy Operated by the Alliance for Sustainable Energy, LLC

This report is available at no cost from the National Renewable Energy Laboratory (NREL) at www.nrel.gov/publications.

Contract No. DE-AC36-08GO28308
Technical Report NREL/TP-5000-75026 May 2020

National Renewable Energy Laboratory 15013 Denver West Parkway Golden, CO 80401 303-275-3000 • www.nrel.gov 


\section{NOTICE}

This work was authored by the National Renewable Energy Laboratory, operated by Alliance for Sustainable Energy, LLC, for the U.S. Department of Energy (DOE) under Contract No. DE-AC36-08GO28308. Funding provided by the U.S. Department of Energy Office of Energy Efficiency and Renewable Energy Wind Energy Technologies Office. The views expressed herein do not necessarily represent the views of the DOE or the U.S. Government.

This report is available at no cost from the National Renewable Energy Laboratory (NREL) at www.nrel.gov/publications.

U.S. Department of Energy (DOE) reports produced after 1991 and a growing number of pre-1991 documents are available free via www.OSTI.gov.

Cover Photos by Dennis Schroeder: (clockwise, left to right) NREL 51934, NREL 45897, NREL 42160, NREL 45891, NREL 48097, NREL 46526.

NREL prints on paper that contains recycled content. 


\section{Acknowledgments}

This work was authored [in part] by the National Renewable Energy Laboratory, operated by Alliance for Sustainable Energy, LLC, for the U.S. Department of Energy (DOE) under Contract No. DE-AC36-08GO28308. Funding provided by the U.S. Department of Energy Office of Energy Efficiency and Renewable Energy Wind Energy Technologies Office. The views expressed in the article do not necessarily represent the views of the DOE or the U.S. Government. The U.S. Government retains and the publisher, by accepting the article for publication, acknowledges that the U.S. Government retains a nonexclusive, paid-up, irrevocable, worldwide license to publish or reproduce the published form of this work, or allow others to do so, for U.S. Government purposes. 


\section{Executive Summary}

Hybrid power plants show promise to provide significant value to the electric grid system, especially as shares of renewable energy in systems increase from $10 \%$ to $20 \%$ or more and costs of wind, solar photovoltaics, and battery storage all continue to decrease. Many manufacturers and developers are proactively developing hybrid power plant strategies to ensure plant profitability in markets where it is important to provide energy that is more predictable and controllable, with higher capacity values, as well as various ancillary services to the grid system. However, there still are many questions about whether hybrid power plants make sense versus leaving it to the larger grid system to ensure low cost and reliable supply by engaging directly with all individual assets. Alternative opportunities exist by adding another technology to an existing interconnect, such as adding solar to wind.

This report summarizes literature on state-of-the-art research concerning hybrid power plants from multiple perspectives, including: (1) resource and market opportunities, (2) technology selection and sizing, (3) physical design, and (4) operation and control. The emphasis was placed on wind and solar hybrid power plants (with or without storage), but additional technologies were considered and merit further investigation.

In addition, findings from a 2018 National Renewable Energy Laboratory workshop titled, "Design and Development of Hybrid Power Plants," on these same topics are included, and the combination of information can be used to help provide a general recommendation for research. Overall, the first question that needs to be answered is under what (if any) market and resource conditions do hybrid power plants make sense. Second, there are questions around what the detailed performance, revenue, and costs of such plants look like under different contexts. Closely related is the question of how to design such plants for the best possible economic performance. Finally, there is a need to continue research and demonstrate and validate the ability of hybrid power plants to provide services to the grid on multiple timescales. As a result, we recommend the following actions:

1. Survey and analyze market and resource conditions to evaluate hybrid power plant performance and cost (with a focus on wind and solar), using sizing tools such as the Renewable Energy Integration and Optimization (REopt ${ }^{\mathrm{TM}}$ ) model or similar toolset. The following steps are included as part of this action item:

- Select number of cases based on market archetypes and associated revenue streams (see Section 2).

- Select number of cases based on resource availability and cross-resource correlation (see Section 2).

- Compare overall profitability of individual technologies vs. multiple co-located technologies.

- Provide general guidance regarding the contexts in which hybrid solar and wind power plants are or are not profitable.

- Project results across national level to estimate overall potential of hybrid power plants. 
2. Consider cases where hybrid power plants show promise and perform a more detailed analysis of design for such plants, using the System Advisor Model and Wind-Plant Integrated System Design and Engineering Model (WISDEM ${ }^{\circledR}$ )-based toolset. The following steps are included as part of this action item:

- For a selection of cases, develop a detailed design of a power plant, including of the layout and collection system with varying levels of co-location (from adjacent plants with a common collection point to a fully interwoven design).

- Investigate specific challenges and opportunities associated with the designs (e.g., economies of scale, technology innovation).

- Investigate alternative technologies, such as different types of storage (e.g., solar panels).

- Evaluate the subset of resulting designs in a production model (like the System Advisor Model) to validate economic performance.

- Evaluate the subset of resulting designs in a larger system model to assess not just the profitability of hybrid power plants, but their impact and potential to support the larger system operation (especially under contingency scenarios).

- Provide recommended best practices on the physical design of hybrid power plants.

3. In parallel, advance research in control and operation of hybrid power plants in areas of grid code compliance, ability to provide ancillary services to the grid, and more.

All these activities are major research efforts, and additional work is needed to prioritize, clarify, and refine the scope of work. This will be the focus of follow-up activity within the National Renewable Energy Laboratory and in collaboration with the larger hybrid power plant stakeholder group. The goal will be to provide an objective suite of research, analysis, and demonstration related to the hybrid power plants' screening, design, operation, and control. 


\section{Table of Contents}

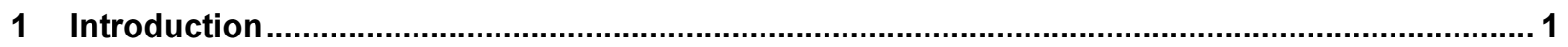

2 Hybrid Power Plant Overview, Resource, and Market Opportunities .......................................... 4

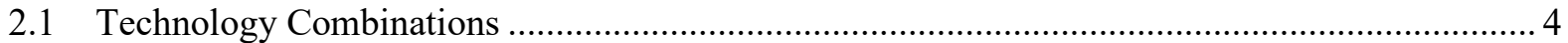

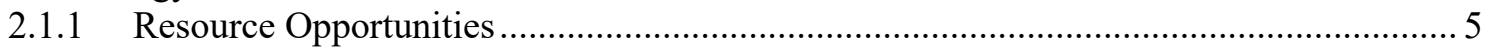

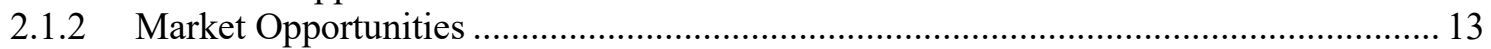

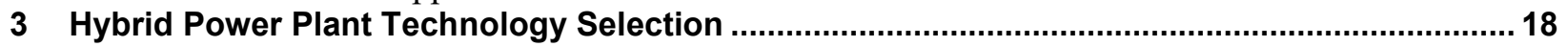

3.1 Research and Software Tools for Hybrid Power Plant Screening ............................................. 20

4 Hybrid Power Plants' Physical Design and Optimization ............................................................ 23

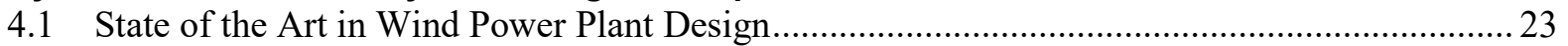

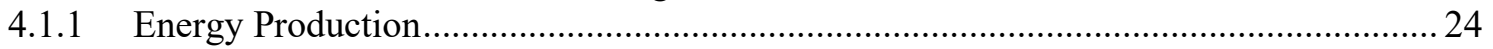

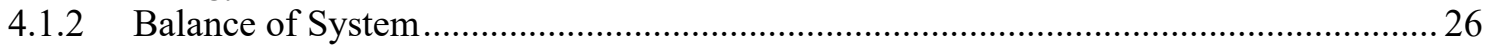

4.2 Example Wind Power Plant Design Case Study …................................................................. 28

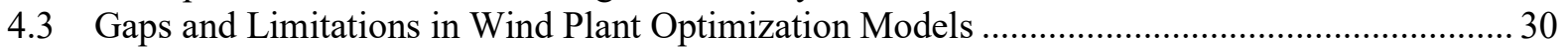

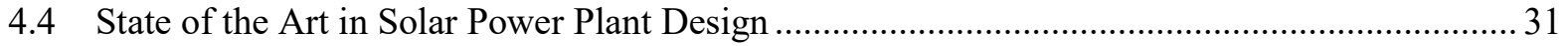

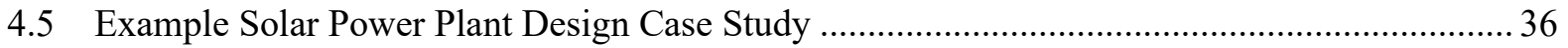

4.6 Gaps and Limitations in Solar Plant Optimization Models......................................................... 40

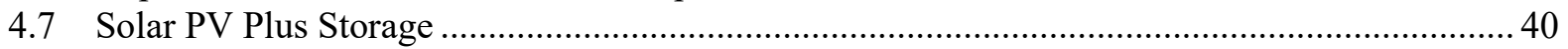

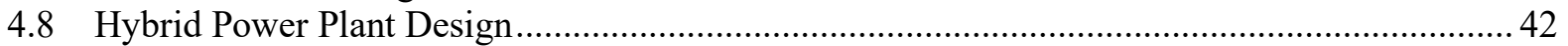

4.8.1 Research in and Software Tools for Physical Design Optimization of Hybrid Power

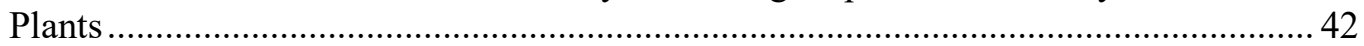

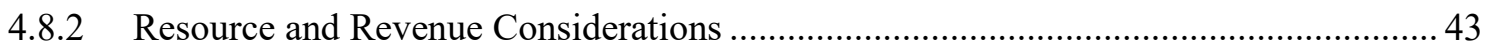

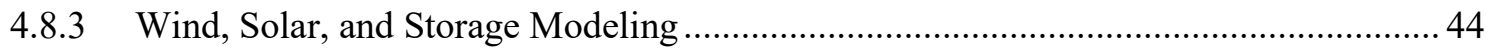

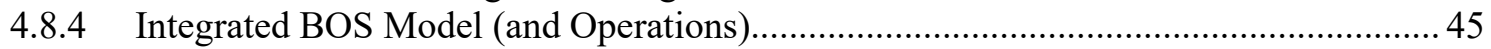

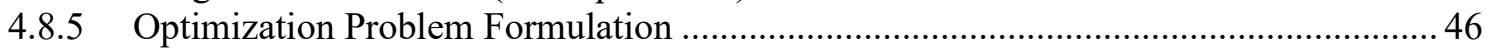

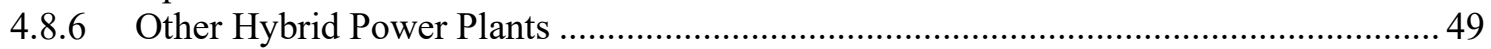

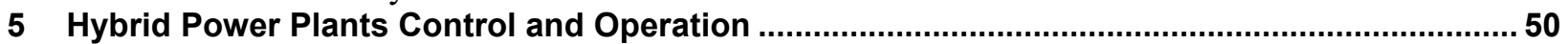

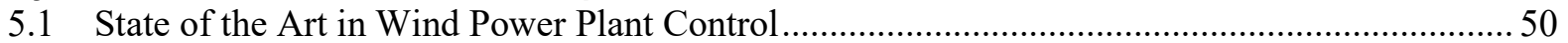

5.2 State of the Art in Solar Power Plant Control ........................................................................... 52

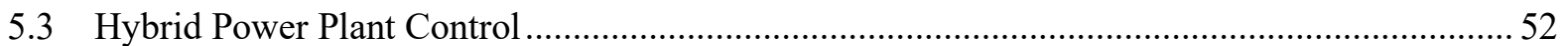

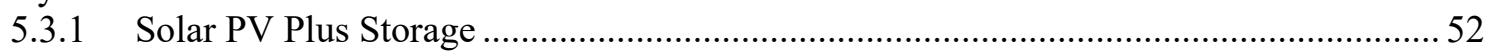

5.3.2 Research in and Software Tools for Hybrid Power Plant Operation and Control........... 53

6 Insights from NREL Workshop on Hybrid Power Plant Design, Development, and Operation . 54

6.1 Specific Questions on Sizing and Design............................................................................. 55

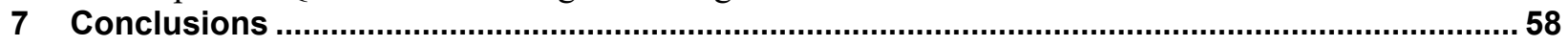

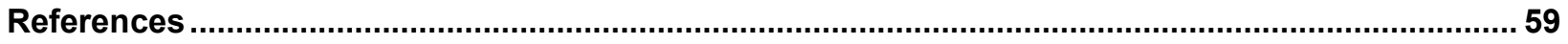




\section{List of Figures}

Figure 1. Example average daily solar resource for Phoenix in four different months ............................ 6

Figure 2. Example average daily wind resource for eastern Arizona in four different months ................... 7

Figure 3. Hydropower in the United States (Samu 2018) .............................................................. 8

Figure 4. Geothermal annual average resource availability across the United States ("Geothermal

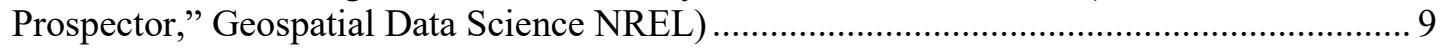

Figure 5. Solar annual average resource availability across the United States ....................................... 10

Figure 6. Wind annual average resource availability across the United States...................................... 10

Figure 7. Changes in capacity factor at higher hub heights across the United States. Source: Lantz et al.

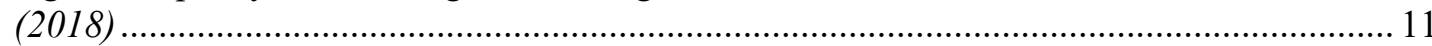

Figure 8. Changes in capacity factor at higher hub heights across the United States. Source: Lantz et al.

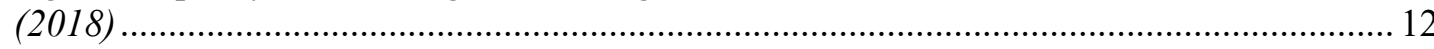

Figure 9. Northern California solar and wind October monthly profile, sourced from NSRDB and Wind

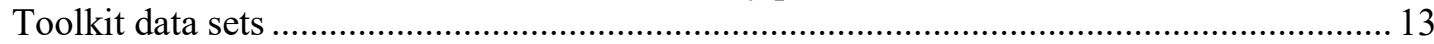

Figure 10. The morphing electricity market system. Source: NREL, based on Ahlstrom et al. (2015)...... 15

Figure 11. REopt energy planning platform key inputs and outputs. Source: NREL ............................ 21

Figure 12. Wind energy as a large-scale complex technical system. Illustration by Al Hicks, NREL....... 23

Figure 13. Wind rose for the eastern Arizona data set described earlier illustrating the distribution or frequency of wind speeds for each wind direction for a wind project set normalized over the course of a year. This wind rose illustrates that the wind resource is predominantly from the southwest. Wind speeds are in meters per second. .25

Figure 14. Example output of FLORIS, a wind farm model that computes the velocity at each turbine in a wind farm and can be used to estimate power production in a wind farm. This model

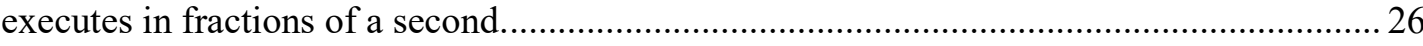
27

Figure 15. Standard topologies for electrical infrastructure design including radial (or daisy-chain) (topleft), double-sided ring (top-right), star (bottom-left), and branched (bottom-right). Source:

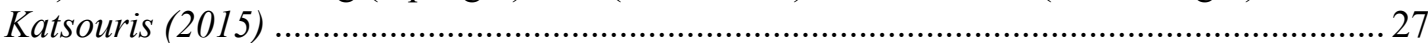

Figure 16. WISDEM toolset for design of wind turbines and plants. Source: NREL ............................ 29 Figure 17. Original Princess Amalia plant boundary relative to the position and yaw-optimized boundary as well as the overall cable length for the final optimized case. Source: Fleming et al. (2015)

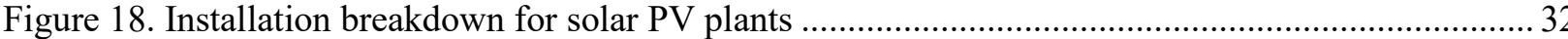
Figure 19. Utility-scale solar trends. The inverter load ratio (ILR) is the ratio between the DC solar array

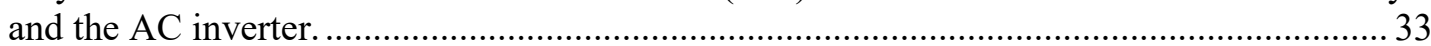

Figure 20. Tracking systems and tilt and azimuth definition. Source: Gilman et al. (2018) ...................... 33

Figure 21. Ground coverage ratio. Source: Gilman et al. (2018) ............................................................. 34

Figure 22. Workflow to optimize PV system design ......................................................................... 35

Figure 23. Basic architecture of SAM for preliminary design and site prospecting of renewable electricity generation plants including solar PV, CSP, wind, and more. Source: NREL ...................... 36

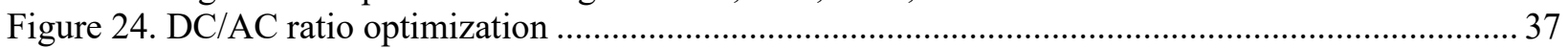

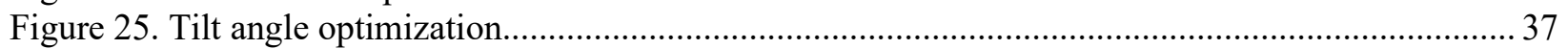

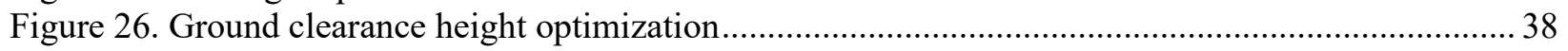

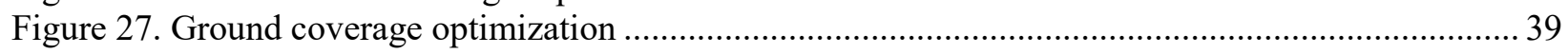

Figure 28. Coupling architectures of solar with storage systems (left) independent coupling, (center) AC coupling, (right) DC coupling. Source: Denholm et al. (2017) ............................................. 41

Figure 29. Generic elements of a hybrid wind and solar PV design optimization problem formulation. Source: NREL

Figure 30. Example of wind-plant-level controls. The top plot shows turbines operating under normal conditions (i.e., each turbine is operating individually to maximize its performance). The 
bottom plot shows some of the turbines operating in misaligned conditions. These conditions are suboptimal for the individual turbine, but the power production of the whole wind plant can be increased by more than $10 \%$.

\section{List of Tables}

Table 1. Market Archetypes for Consideration in Hybrid Power Plant Design..... 16

Table 2. Results of Select Wind Power Plant Control and Layout Design Optimization Cases (Source:

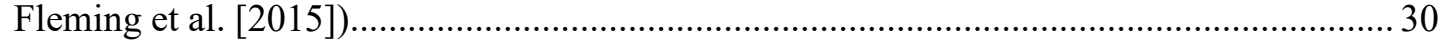

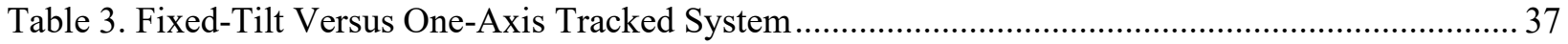

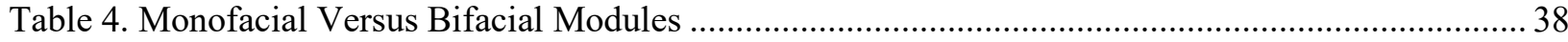

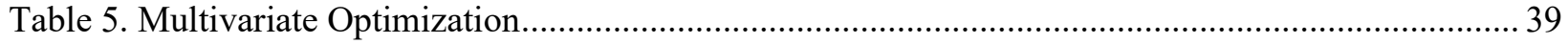

Table 6. Overall Characteristics of Technology Selection, Sizing, and Design of Wind, Solar, and Wind-

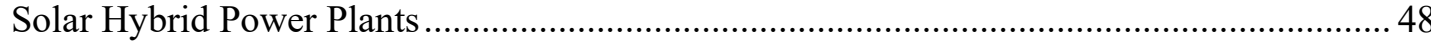




\section{Introduction}

For decades, wind, solar, and other renewable energy technologies have had minimal deployment with respect to fossil-fuel, hydropower, or nuclear-based generation assets in electric power systems. However, driven by consideration of environmental impacts, policy decisions, and significant cost reductions in wind, solar photovoltaic (PV), and energy storage (particularly battery) technologies; new installations of electricity generation have been dominated by renewables in the United States, Europe, and globally (Bloomberg New Energy Finance 2017; BP Energy Economics 2018; International Energy Agency [IEA] 2018). Specifically, the cost of energy for wind and solar PV technologies has fallen to the point where these technologies are cost-competitive with conventional thermal generation in many markets (Haegel et al. 2018; Dykes et al. 2019). "Energy Transition Outlook 2018" has led integrated studies, which forecast that wind energy and solar PV technologies will each make up $30 \%$ of global electricity production by 2050 , in a system with significant electrification of the global energy system (“Energy Transition Outlook 2018”). NREL's 2018 Standard Scenarios indicate significant growth in renewable penetration of the electric sector as well by 2050 (Cole 2018). As we look toward the future grid dominated by renewable energy, a paradigm shift is underway where the traditional model of energy-based revenue streams for wind and solar PV using power purchase agreements or feed-in tariffs is changing (Wiser and Bolinger 2018). With renewable energy growing to $10 \%-20 \%$ or more of overall electricity generation (Wiser and Bolinger 2018; Wingfield 2017; Kleckner 2017; Nelson 2015), design objectives are shifting from producing energy at the lowest levelized cost and using the levelized cost of energy calculator (LCOE) to also include other design objectives that maximize profitability from revenue streams associated with time-varying energy pricing, ancillary services, and capacity markets.

Wind, solar, and storage technologies can take part in a limited way in some of these markets today but, because of their uncertainty and variability, not to the same degree as traditional power plants. To ensure profitability of these assets in the future, developers would like wind, solar, and other renewable energy plants to have the ability to operate more like traditional power plants, in terms of capacity value, dispatchability, ancillary services, and reliability. To ensure profitability at an individual asset level, developer/owner/operators are designing "hybrid power plants" that combine wind, solar, storage, and other renewable technologies together.

By combining generation assets together, including storage, solar, wind, and other renewable generation, into "hybrid power plants," an individual plant owner can 1) develop economies of scope in terms of land usage, electrical and physical infrastructure, and operational expenditures, and 2) increase their system value to capitalize on revenue streams through forward capacity markets (where present), "dispatchable" operation in markets with time-varying energy pricing, and ancillary service markets (where present).

This is a substantial shift from historical approaches to solar and wind energy power plant development and operation. Until recently, renewable power plants in many markets had a design objective to produce as many kilowatt-hours as possible, because all were awarded the same fixed income stream (whether through a power purchase agreement or other form of fixed energy payment). In this case, such power plants only curtail when necessary, and commanded to do so from the system operator to support the larger grid. Looking forward, hybrid power plants 
act more like conventional generation, where they consistently produce less than full capacity and focus on providing energy at specific times (i.e., dispatchable energy) as well as services that support the reliability and stability of the grid system. This new paradigm creates an opportunity to critically consider how hybrid power plants should be designed and controlled, and which technology assets should be used in what configuration.

In the recent Xcel "2017 All Source Solicitation 30-Day Report," 30\% of the wind and solar bids included some form of hybrid plant offering by including storage (Deign 2018). Vestas, one of the oldest wind turbine manufacturers still operating, has made hybrid power plants part of its core strategy going forward with a demonstration plant already in the works (Vestas 2018a, 2018b). General Electric has announced similar plans ("GE” 2018). This topic is highly relevant to industry because it is intuitive to combine wind, solar, other renewables, and storage to minimize the risks of renewable energy variability and at the same time maximize revenue in evolving markets. However, after consulting industry, it is apparent that there is still a lot of uncertainty around the economic viability of hybrid power plants in general, and under what resource and market conditions these plants may or may not make sense.

To understand the current landscape of hybrid power plants and associated research and technology development needs, a workshop was held in December 2018 to bring together perspectives from across a large stakeholder group including original equipment manufacturers, developer/owner/operators, utilities, consultancies, government, laboratories, and universities. Through a series of presentations and breakout sessions, speakers and participants described current practice in hybrid power plant design and development and discussed gaps and challenges. Topics addressed included:

1. Technology Combinations, Markets, and Sizing of Hybrid Power Plants:

- Representing uncertain resource availability and revenue streams

- Sizing of wind/solar/storage elements and consideration of different technology options

- Integrating with other systems (hydropower and geothermal)

- Transmission considerations

- Co-location versus virtual hybrid power plants.

2. Physical Design Considerations and Innovation Opportunities for Hybrid Power Plant Design

- Electrical infrastructure

- Combining balance-of-system elements for an integrated development process

- Practical design considerations

- Design and optimization methodologies and approaches.

3. Considerations of Hybrid Power Plant Operation and Control

- Existing and emerging control capabilities at the individual technology level

- Integrating hybrid power plant controls wind/storage, solar/storage, wind/solar and wind/solar/storage

- Forecasting for hybrid power plant operation

- Integrating hybrid power plants into power system operations. 
This report summarizes the literature and workshop findings in each of the three topic areas above. Sections 2 and 3 focus on resource and market opportunities that inform technology selection and sizing of hybrid power plants. Section 4 considers the detailed physical design of those power plants, and Section 5 then considers their operation and control. Section 6 shares insights that emerged directly from the workshop itself and a brief overall summary and outlook. The report findings will be used to inform National Renewable Energy Laboratory (NREL) research on hybrid power plants. 


\section{Hybrid Power Plant Overview, Resource, and Market Opportunities}

The first point of discussion around hybrid power plants is under what resource, technology, and market conditions do combined assets (potentially virtually coupled or physically co-located) make sense. In this section we provide a general overview of hybrid power plants and their technology configurations as well as a discussion of the complementarity of their respective energy resources.

\subsection{Technology Combinations}

Hybrid power plants are those that combine multiple generation assets in a single power plant. Storage technologies, like batteries, do not generate energy by themselves and instead can shift when energy is produced, to provide more predictable and controllable generation, and to provide services to support grid system reliability. However, storage additions to a generation facility are not considered to create hybrid power plants for the purposes of this report.

\section{Definition: Hybrid power plants are power plants that contain two or more technologies that may potentially include wind turbines, solar PV, solar CSP, storage, geothermal power, hydropower, biomass, natural gas, oil, coal, or nuclear power. These hybrid plants can be used to generate electricity or other products such as hydrogen. This report will focus mainly on electricity generation.}

Throughout this report, we will focus on hybrid power plants using only renewable generation and with emphasis on wind and solar PV hybrid power plants with and without additional storage technology. We also focus on hybrid power plants that produce electricity as their only output (versus producing fuels, hydrogen, or other energy products). Although such hybrid power plants could provide significant potential in terms of the transformation of the energy systems, they are excluded here to reduce the overall scope and would be a good topic for a future effort of similar magnitude.

Electricity generation technologies have different strengths and weaknesses when it comes to supporting the bulk electricity grid system for low cost, secure, stable, and reliable operation over both the short and long term. Past efforts have looked at the different electric grid system needs for low-cost and reliable operation and assessed the ability of different generation technologies to address those needs (Kroposki et al. 2017; Gevorgian, Burra, and Morjaria 2018). The former classifies electricity generation technology according to different grid stability services, while the latter assesses different grid technology and market solutions to address some of the challenges of systems with high shares of variable renewable generation.

Conventional synchronous generation excels at providing high capacity value, predictable and controllable energy supply, and the various grid services needed to ensure stable and reliable operation of the electric grid. This is not surprising because the development of the electric grid system since the early 20 th century has been built on a model that conforms to the nature of the capabilities that these generation technologies embodied. Hughes (1993) provides a detailed account of how early electricity systems evolved around coal-fired, synchronous electricity generation around the turn of the 20th century. Although demand in the system has been considered variable over the course of the evolution of the electricity grid system, supply has 
been dispatchable and readily available when needed. This paradigm afforded significant freedom to the demand side of the electricity system without substantial increase in cost.

Renewable energy from wind and solar PV, especially in the last few years, has provided lowercost energy than the electric grid system has ever seen before, with one significant caveat: that energy is more variable and less controllable than the electricity demand currently. To fully exploit these new energy sources, one of two things must happen: either demand adapts to take advantage of cheaper but more variable energy supply, or the supply adapts to provide more predictable and controllable energy (Dykes et al. 2019). In either case, a system with significantly less synchronous generation than in the past (i.e., with large numbers of wind and solar power plants) will require a paradigm shift to enable the reliable and cost-efficient operation and planning of such converter-dominated systems (see Dykes et al. 2019 for a detailed discussion on converter-dominated electricity systems in terms of their design, and the subsequent requirements imposed on converter/inverter-based generation assets, such as wind and solar power plants).

The former case requires an adaptation of the current paradigm of market design and system operation where demand is relatively elastic, and supply conforms to match demand minute by minute, day by day, week by week, month over month and year after year. Early examples of the formation of the electricity system point to this flexibility where new use cases emerged to take advantage of the availability of electricity generation at off-peak times through electric transportation, proliferation of theme parks, and other technologies (Nye 1992). Increased demand elasticity today is also present through increasing participation in demand-response programs that shift electricity (when needed) as well as through increasing adoption of electric vehicles that may be able to flexibly charge based on pricing signals as well as to serve as systems for distributed storage (Mai 2018; Zahedi 2012).

Hybrid power plants that couple various forms of generation together and/or with storage technology may be able to provide more elastic supply to conform with less elastic demand. Firstly, if there is an anti- or inverse-correlation in the energy production of the technologies, then there is opportunity for enhancing the predictability and controllability of the supply from the plant. For solar PV and wind energy, this depends on the joint distributions of the energy resources themselves and will be discussed further in the next section.

Expanding to other technologies, including solar, concentrating solar power (CSP), geothermal, and hydropower (the latter two are classified as synchronous generation) allows the ability to provide an even more robust buffer against the variability and uncertainty associated with wind and solar PV production. Combining these assets would allow a hybrid power plant to provide capacity, energy, and services in a manner more similar to conventional power plants. An optimal mix of technologies for a given power plant depend, however, on the site-specific environmental resources and local market conditions. The next two subsections explore the impact of resource and market opportunities (including demand profiles) on the economic viability of hybrid power plants.

\subsubsection{Resource Opportunities}

Depending on the specific location, there are different quantities of renewable resources (solar, wind, hydro, geothermal) at different timescales of interest. These will have varied levels of 
correlation at different timescales as well. Farther away from a specific location, the more a resource profile for a given energy source will change, creating geospatial correlation characteristics both for a given resource as well as across different types of energy resources. Below is a brief summary of some of the characteristics of the various energy resources:

- Solar. Solar energy, regardless of its location on the globe, has a diurnal cycle (Lewis 2007). The time of the year and latitude of the location strongly dictate the profile of that diurnal cycle. In addition, weather trends (which influence cloud cover) on a regional scale have a significant influence on the resource, and these are less predictable on shortterm timescales. However, both the weather trends and the impact of time of year/latitude do have predictable influence on the seasonal variability of the resource. Figure 1 is an example of the temporal profiles (diurnal and seasonal) for solar power in Phoenix, Arizona, USA. As shown in the graphic, solar energy potential increases in the morning after sunrise, peaks in the middle of the day, and declines until the sunset. During the night, there is no available solar resource. In addition, the summer months have higher maximum potential irradiance. Solar resource data can be freely obtained for much of the world using public data sets (NSRDB, NREL: Developer Network, Sengupta et al. 2018) or purchased data sets. These resource data were obtained from the NSRDB.

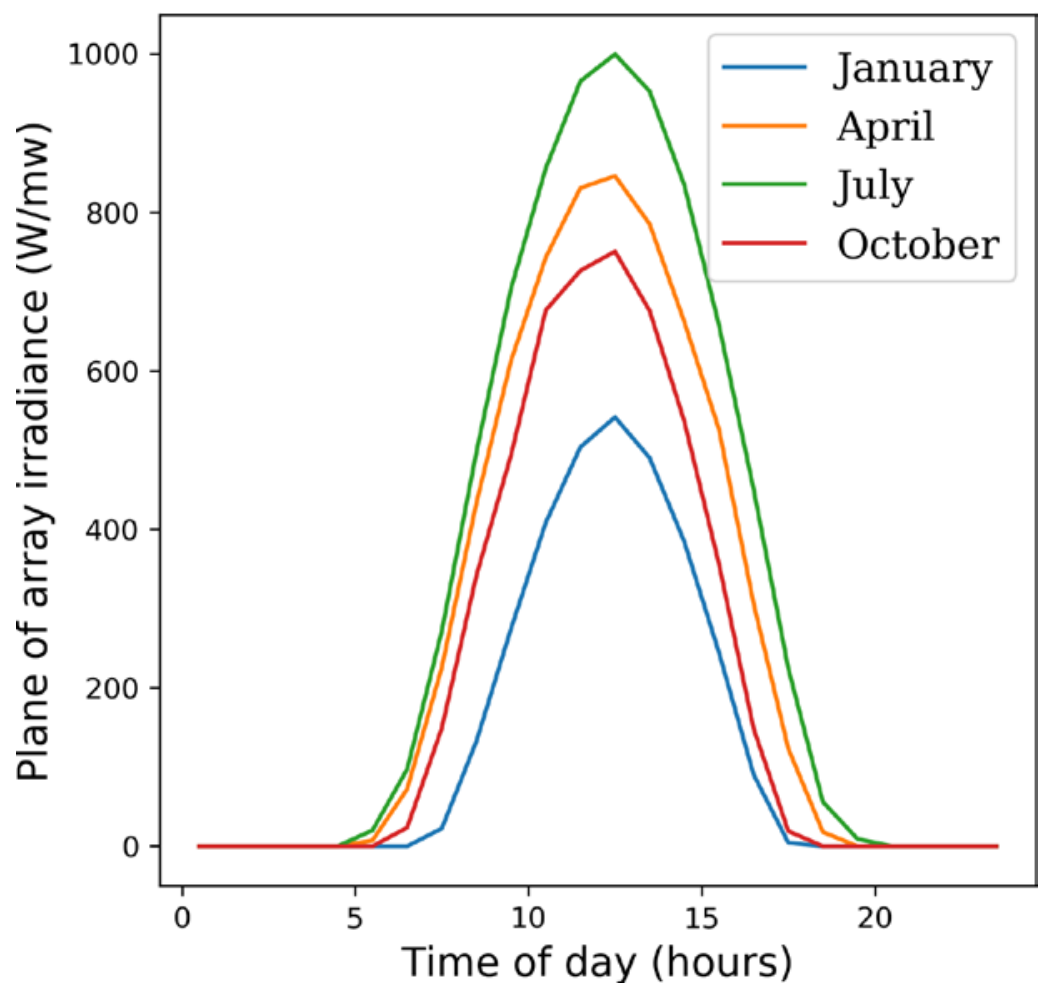

Figure 1. Example average daily solar resource for Phoenix in four different months

- Wind. Wind energy resources vary widely, depending on the global position (see Manwell et al. 2009 for an overview of the basic features of wind energy resource variation and assessment). First, there are the different driving sources for wind energy, including pressure forces because of differential heating of the Earth's regions, Coriolis 
forces because of the Earth's rotation, inertial forces of the wind itself because of largescale circular motions, and frictional forces from interacting with the Earth's surface (Manwell et al. 2009). Variations in topography (forestation, ridges, built environment, offshore areas) strongly influence these frictional forces and the behavior of the local resource at a specific site and even the location within it. Even more difficult to assess and predict is the wind resource variation over time. Although there may be a general diurnal trend to the resource, such as the "sea-breeze effect ${ }^{1}$ " in near-shore wind power plants (both land-based and offshore), there is typically much less correlation of the wind resource with time of day than for solar energy. Seasonal prediction of the resource is similar where there are general trends and correlation, but they are less strong than for solar technology. Below is an example of diurnal and seasonal variation in wind power production in eastern Arizona, USA, with data obtained by the Wind Integration National Dataset (WIND) Toolkit.

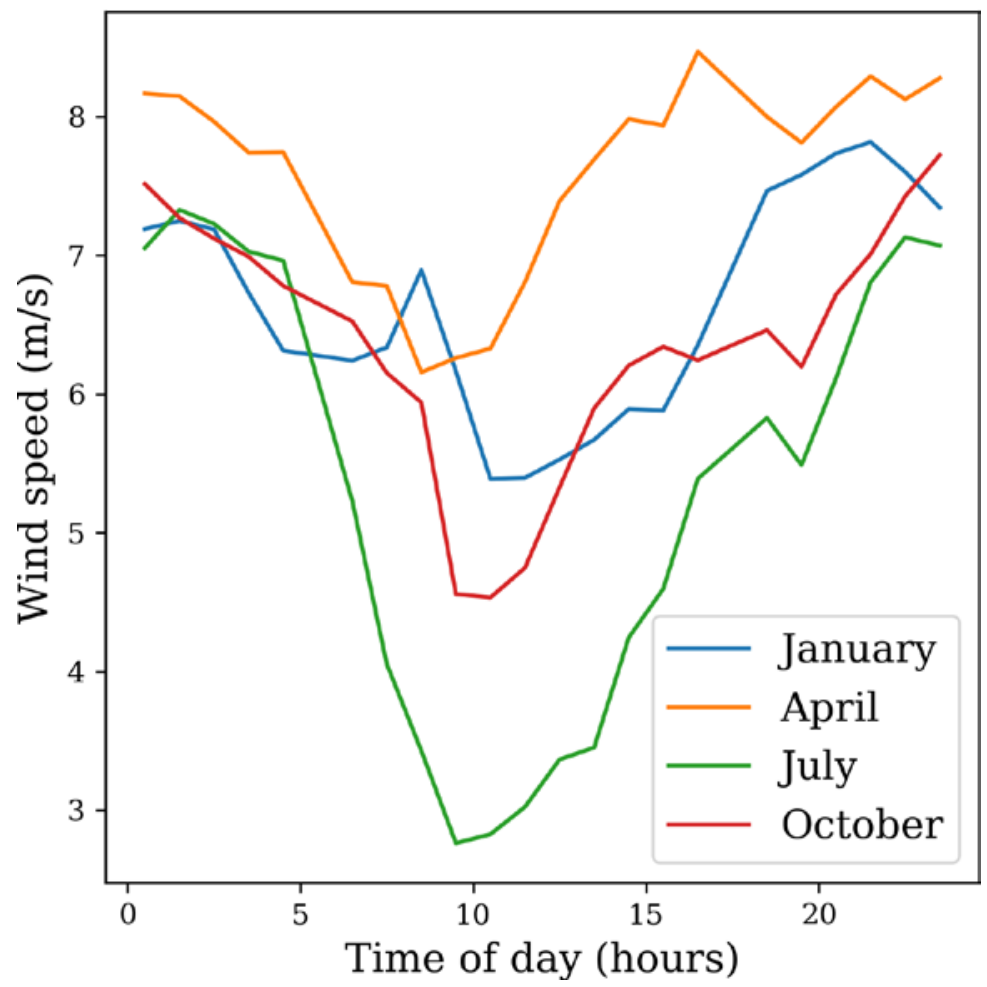

Figure 2. Example average daily wind resource for eastern Arizona in four different months

In contrast to the solar profile discussed earlier, there is a lot more variability in all the cases with a slight trend toward lower production in the middle of the day and higher production at night as well as higher overall production in the winter compared to the summer. However, these profiles are examples only and can vary from day to day and year to year. For access to wind energy resource data in the United States, see the WIND Toolkit at https://www.nrel.gov/grid/wind-

\footnotetext{
${ }^{1}$ The sea breeze effect is caused by differential heating of air over land and sea which causes a relatively predictable pattern to the wind resource depending on the time of the day.
} 
toolkit.html (Draxl et al. 2015), and globally see the Global Wind Atlas at https://globalwindatlas.info.

- Hydropower. Availability of hydropower resources is very site-dependent, based on availability of water basins and potential for dams or different forms of running water (e.g., rivers). Although the availability is very local, the predictability and controllability of the resource is much better than for wind or solar. There is seasonal dependence of hydropower resources based on factors like rainfall or snowmelt, such that the seasonal capacity of the resource varies, but the day-to-day availability of that resource for matching energy production needs is predictable and controllable. An assessment of the hydropower resources (rivers and oceans) can be found here:

https://www.nrel.gov/gis/maps-marine.html.

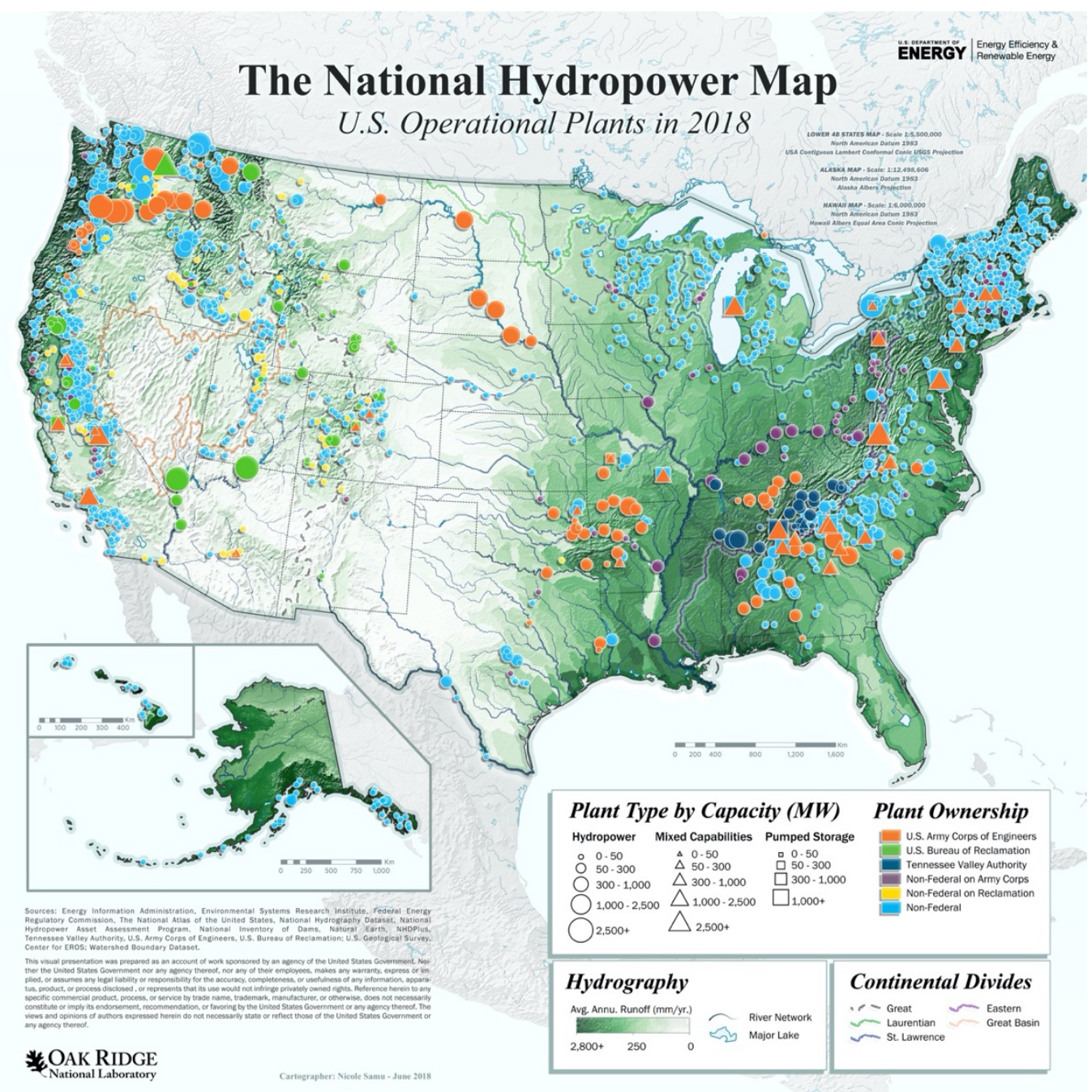

Figure 3. Hydropower in the United States (Samu 2018)

- Geothermal. Like hydropower, the short-term variability and controllability of the resource is low, though there are diurnal trends that can fluctuate more. Seasonally, there are changes in the capacity available from geothermal resources, but they are generally 
predictable and controllable. The major limitation to geothermal resources, like hydropower, are the limited availability of sites with significant natural resources. Engineered or enhanced geothermal technologies may offer ability to allow more widespread application of geothermal technology, but these are still in the lower stages of technology readiness. Geothermal resources across the United States are focused in the Mountain West, as shown in Figure 4. The underlying data for this figure is described in detail (Getman et al. 2015).

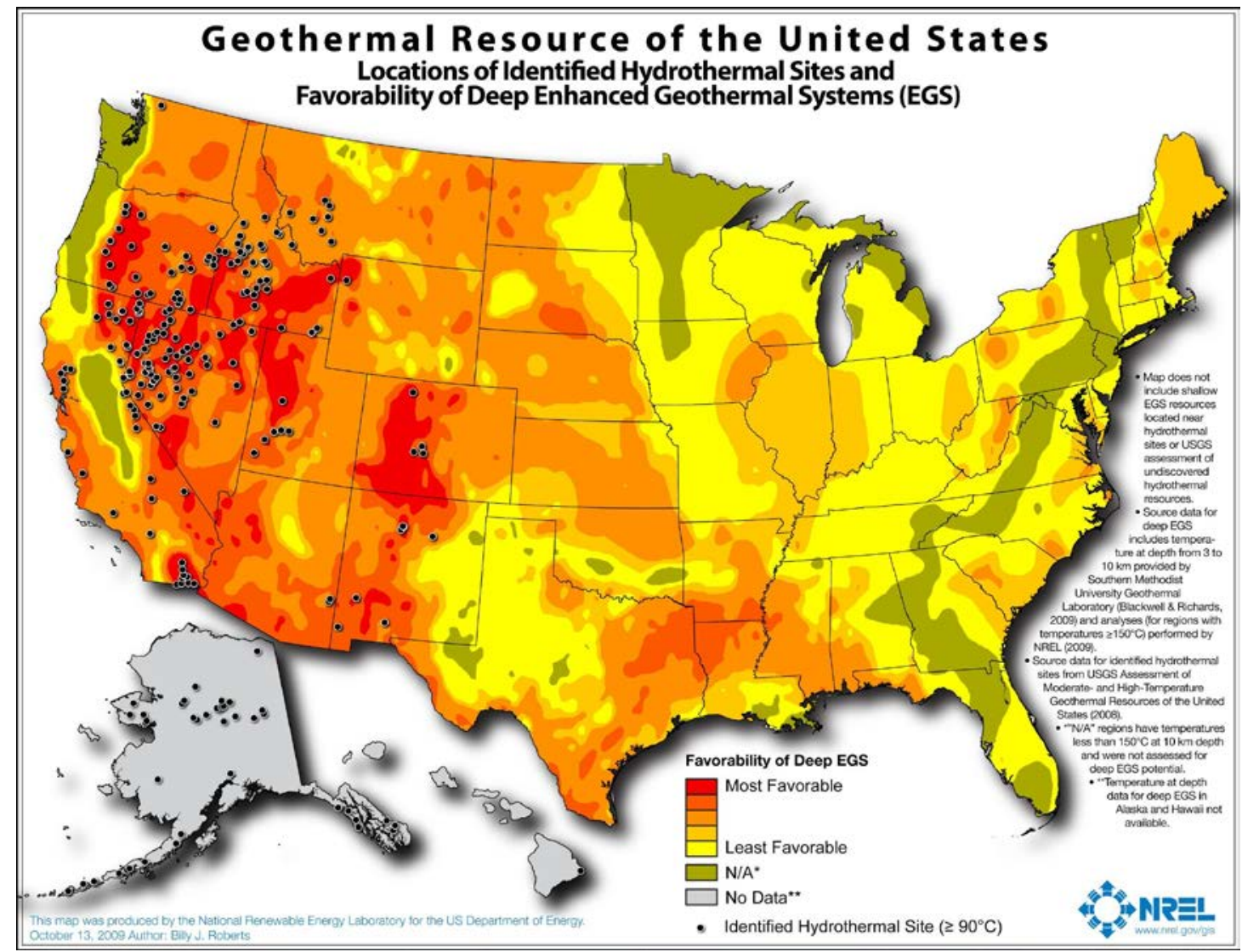

Figure 4. Geothermal annual average resource availability across the United States ("Geothermal Prospector," Geospatial Data Science NREL)

When considering the potential of hybrid power plants, a key element is the complementarity of the different resources at a given location. Figures 4 and 5 show the annual average resource availability of solar irradiance and wind speed across the United States. As shown, there are regions, such as in the southern portion of the United States, where solar irradiance is strong and wind speeds may be lower (for land-based applications in particular), whereas in the interior of the country, there are strong wind speeds and lower solar irradiance (especially in the northern area of the United States). However, there are regions, around west Texas, for example, where solar and wind energy resources are both strong. 


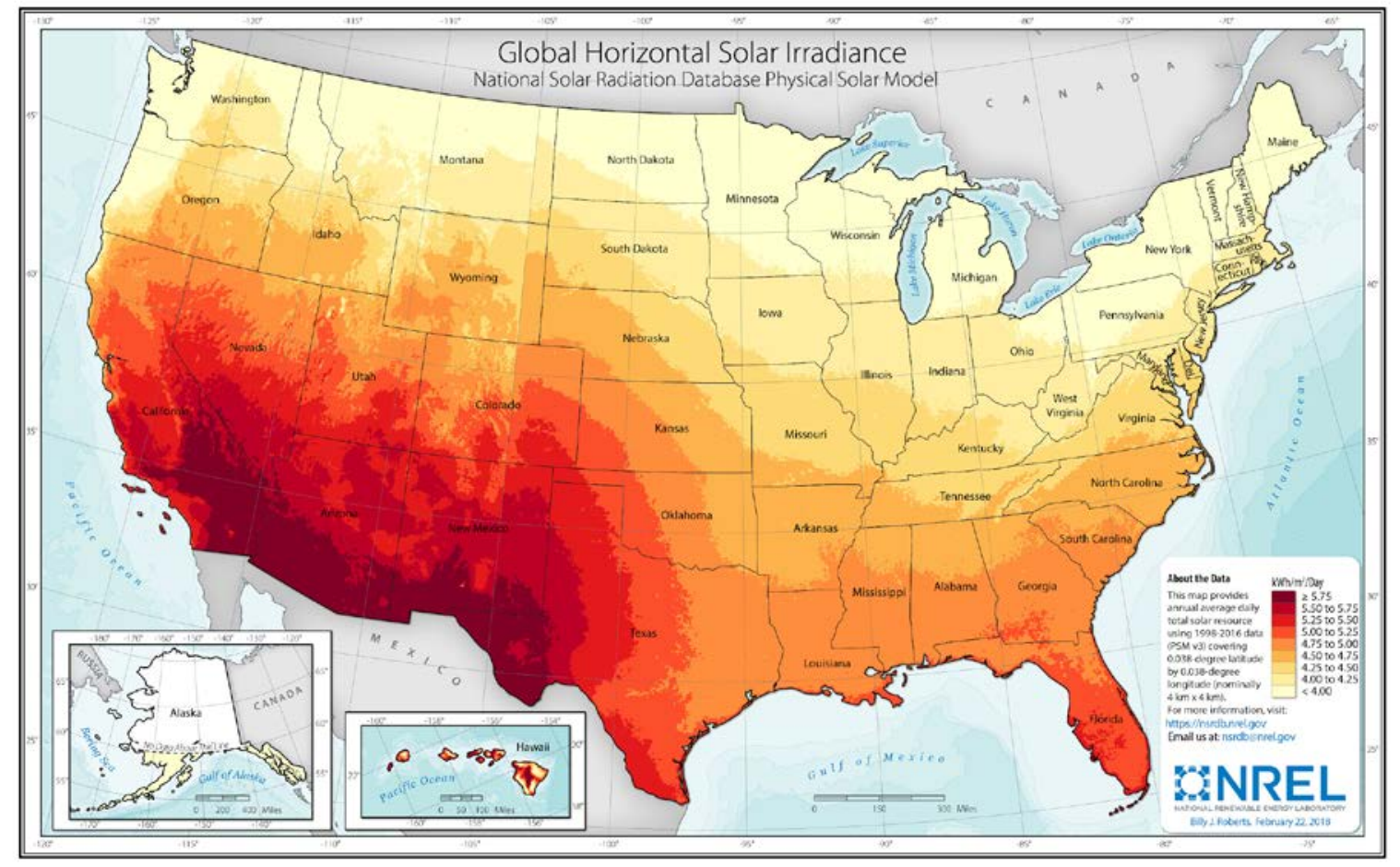

Figure 5. Solar annual average resource availability across the United States

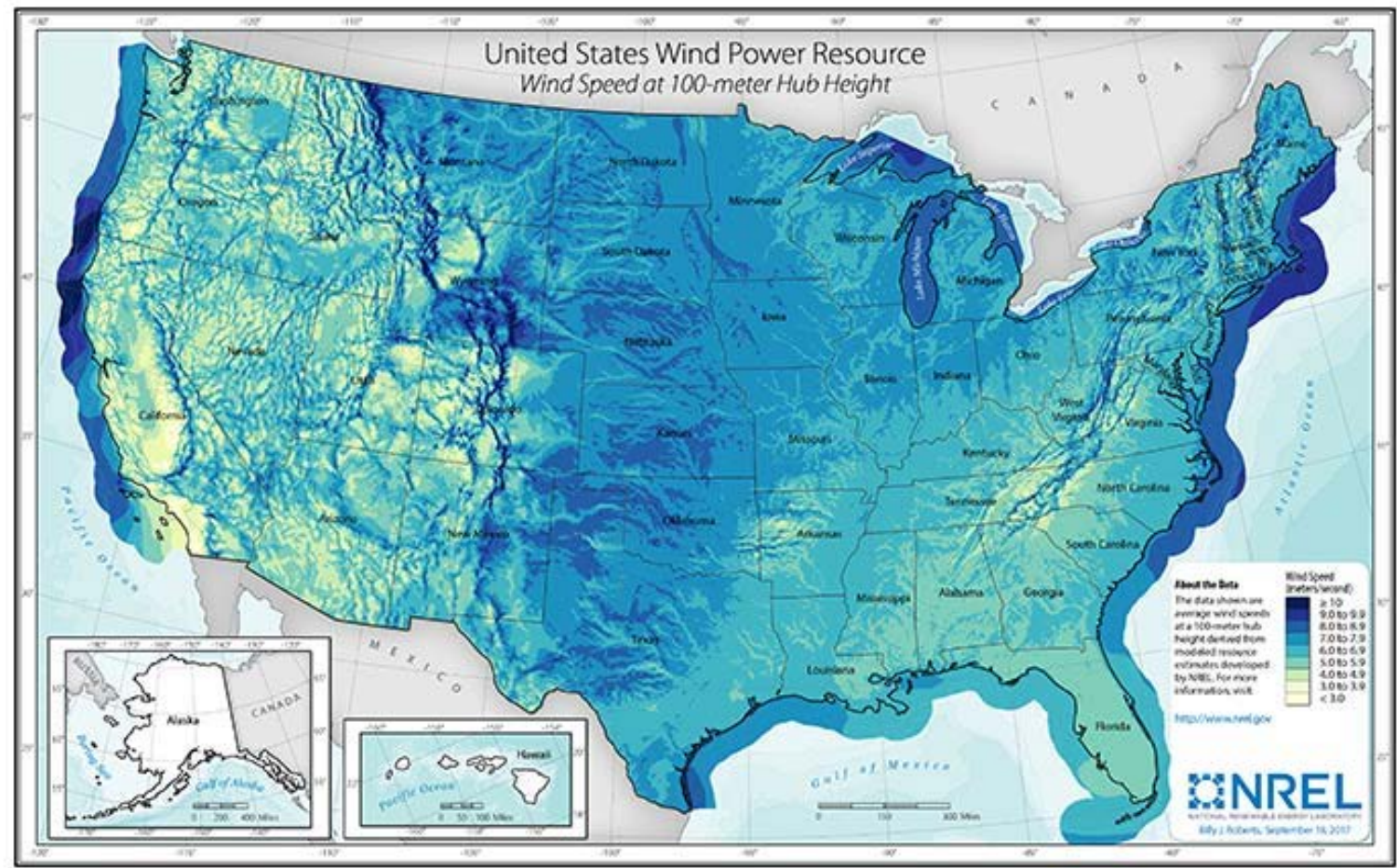

Figure 6. Wind annual average resource availability across the United States 
It is also important to note that the resource for wind energy has a strong dependence on the height of the wind turbine above the ground, caused by "wind shear," where the wind resource tends to increase with height, according to:

$$
v=v_{0} *\left(\frac{Z}{z_{0}}\right)^{\text {shear exponent }}
$$

where $v$, is the velocity at the turbine hub height, $z$, is the hub height and, $z_{0}$, is a reference height (see Manwell et al. 2009 for a discussion). The velocity from the reference height, $v_{0}$, scales to the hub height according to the shear exponent, which is site dependent. Studies have shown that there is a large shear exponent and significant potential for increased wind energy production at higher hub heights (as shown in Figures 6 and 7). As the resource potential increases with height, there is a greater portion of the country with both strong solar and wind energy resources that can be closely located or even co-located.

\section{Change in Net Capacity Factor for Modern 3-Megawatt (MW) Turbines on a 110-m}

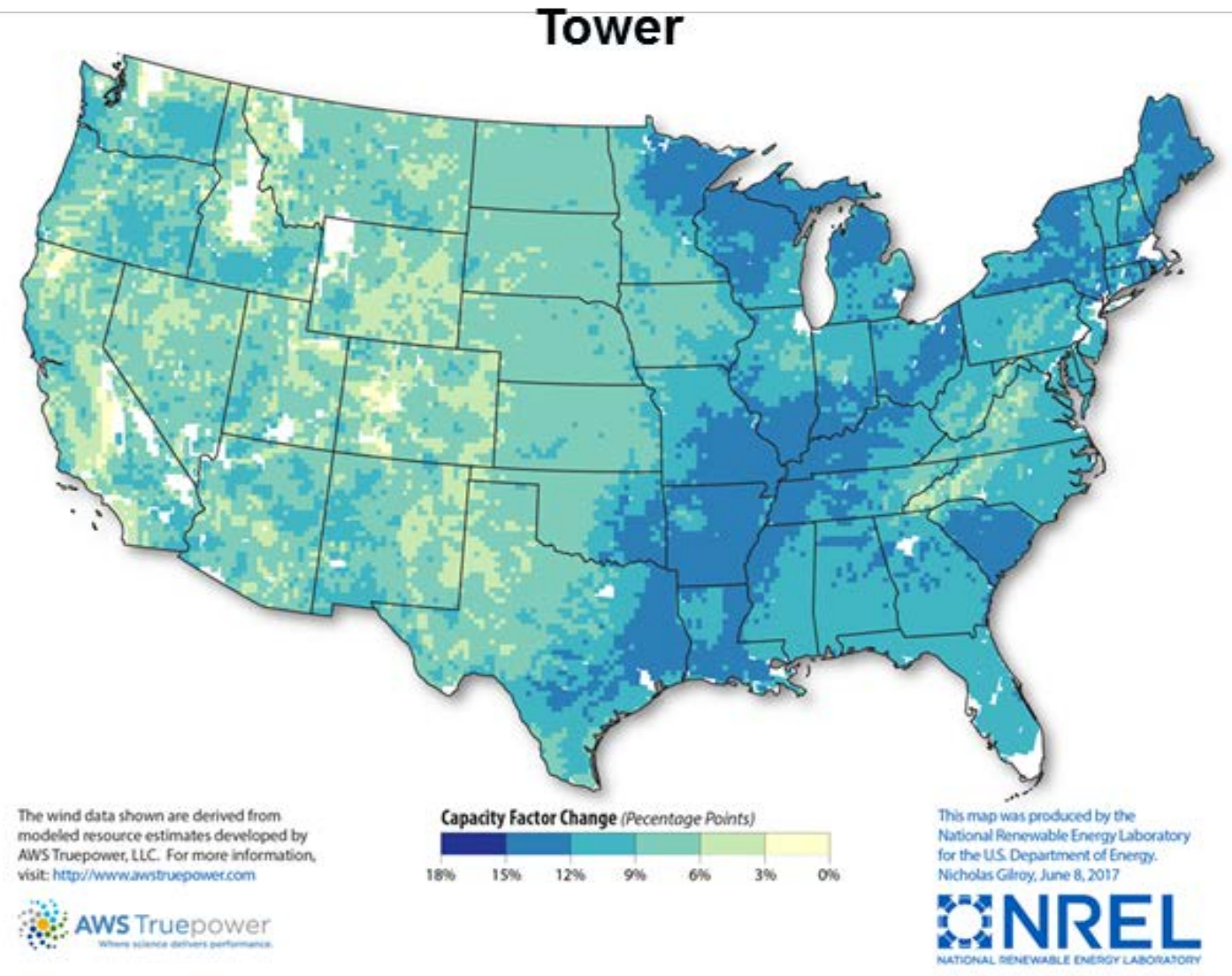

Figure 7. Changes in capacity factor at higher hub heights across the United States. Source: Lantz et al. (2018) 


\section{Change in Net Capacity Factor for Future (2030) Generation 3-MW Turbines and Plants on a 135-m}

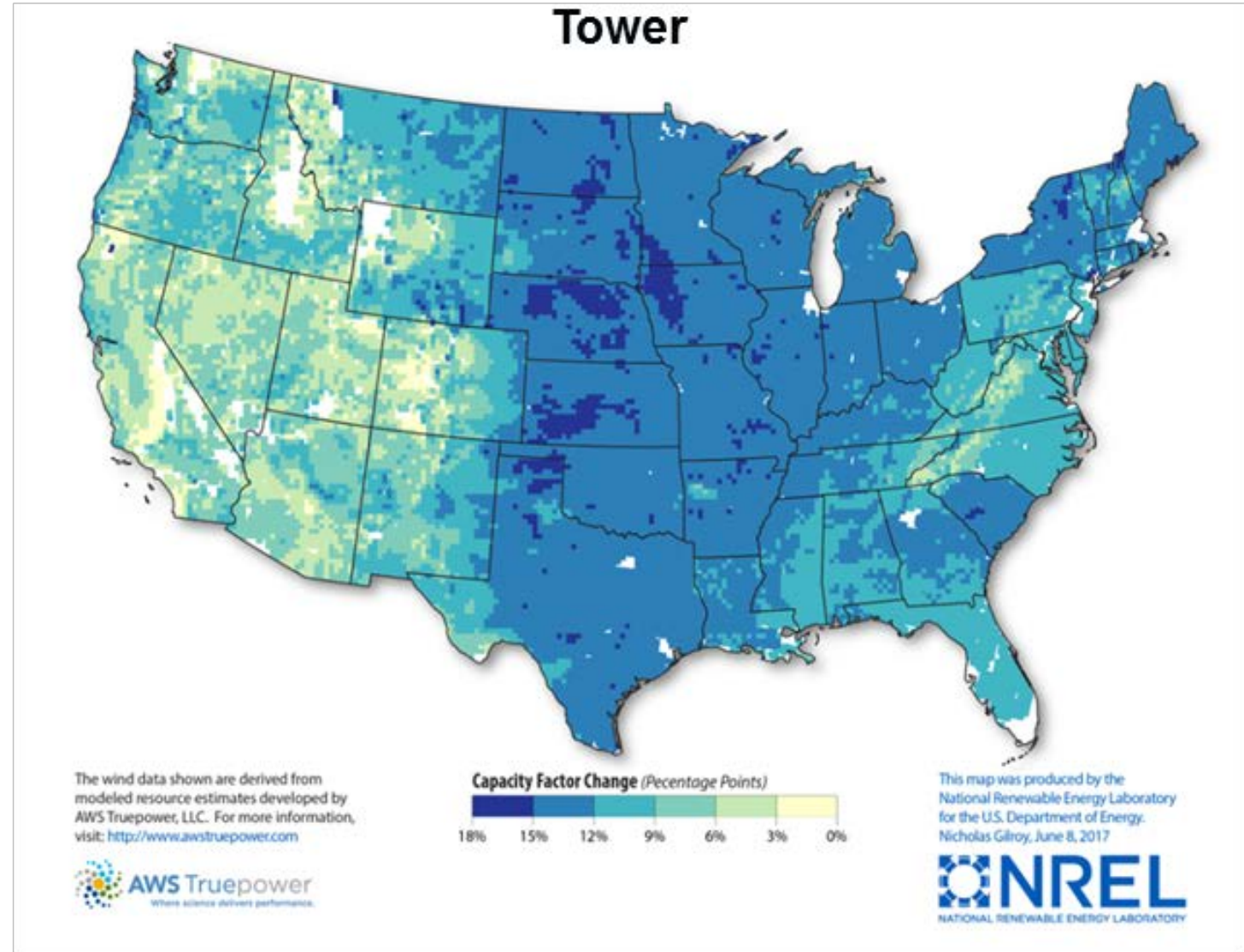

\section{Note: Impacts include advanced, low specific power technology and reduced losses from improved plant design and operation}

Figure 8. Changes in capacity factor at higher hub heights across the United States. Source: Lantz et al. (2018)

For geothermal and hydropower, there are again complementarities that already have been exploited in bulk system operation, such as the pairing of solar and geothermal assets in the Southwest and California (Turchi et al. 2014) and pairing of wind and hydropower in northern California and the Pacific Northwest (MWH 2009; Huertas-Hernando et al. 2017).

However, to really understand the potential complementarity of different renewable assets, it is important to look at their correlation at different timescales. Regardless of the overall annual resource availability, wind, solar, and other renewable resources may have different levels of correlation. Thus, combining these resources into a hybrid power plant at a specific locale may have favorable impacts on the predictability and controllability of the energy supply. In some regions of the world, for example, wind and solar resources are anti- or inversely correlated, so that the combined production is more predictable and controllable. Referring to the examples shown for Phoenix, Arizona, in Figures 1 and 2, there is a trend of inverse-diurnal correlation of the wind and solar profiles, with solar higher in the day and wind higher at night. Similarly, there 
is a seasonal inverse correlation with higher wind energy in the winter and higher solar energy in the summer. However, this is not always the case; there may also be profiles where there is strong correlation of the two resources so that they do not provide a benefit of complementarity and smoothing of variability. One example of resources that do not have a strong inverse correlation is observed in a Northern California location in Figure 9 over the month of October. Although the wind does not strongly vary throughout the day, it peaks at approximately the same time as the solar generation.

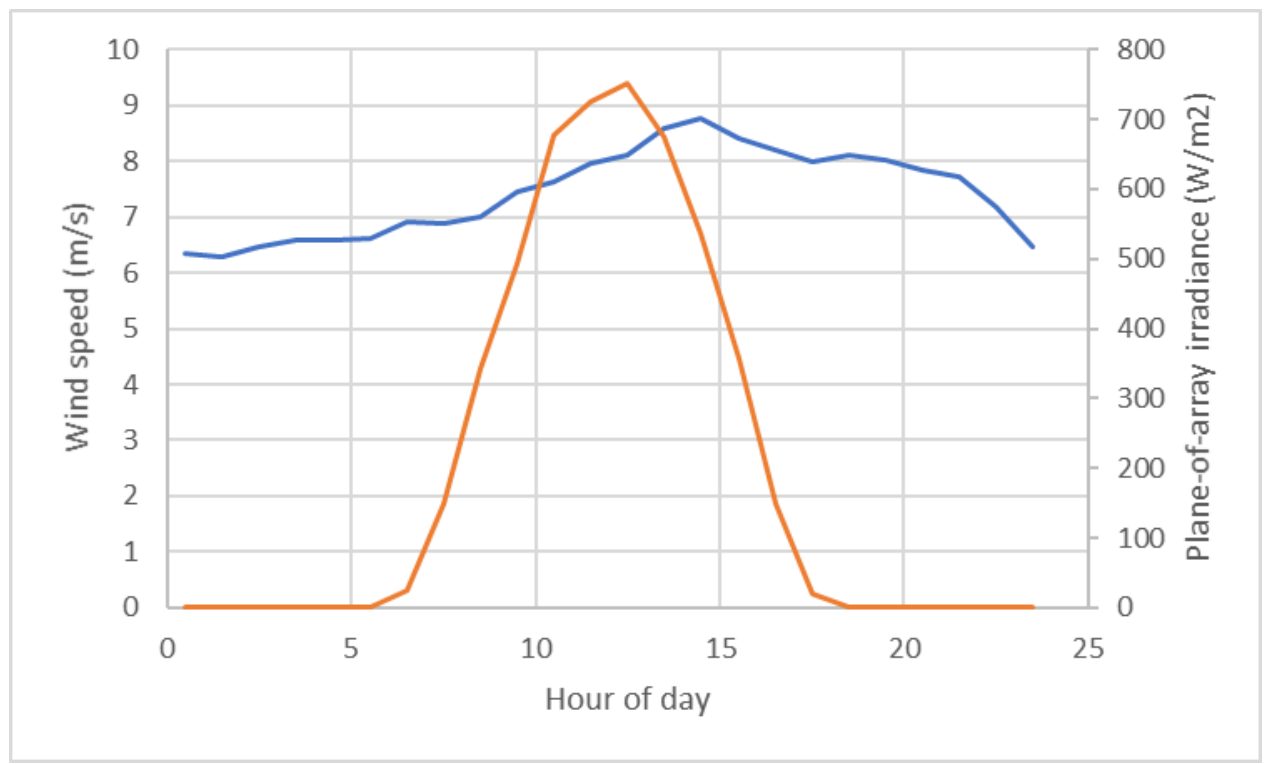

Figure 9. Northern California solar and wind October monthly profile, sourced from NSRDB and Wind Toolkit data sets

To understand the large-scale potential of hybrid power plants across the United States, more research is needed to understand the potential for different resources (wind, solar, hydropower, geothermal) to complement each other, decreasing overall variability of the joint potential energy resource, and, as a result, increasing the predictability and controllability of the joint assets.

The joint probability distributions of different renewable resources at different geospatial and temporal scales (including autocorrelation within and across resources) is key to understanding the potential for hybrid power plants at a single location (if co-located) or virtually connected (if physically separated).

The joint probability distribution of the resources, wind and solar for example, is important to understand at a given site. In addition to annual correlation, the temporal correlation (including autocorrelation across assets) will be important to model in order to support sizing, design, and operation and control of hybrid power plants that include these combined assets. There are several ways to model multiple resources at a site, and these will be discussed in more detail in the next subsection.

\subsubsection{Market Opportunities}

Combining technologies that leverage the complementarity of the different resources may lower the overall power plant cost of energy or increase the value of that energy to the electricity system. The potential of a hybrid power plant, however, depends not only on the resources and 
costs, but also on the market context, including several factors such as: (1) generation mix and transmission infrastructure of the system, (2) demand profile in the system at various timescales, (3) market structure that determines what types of revenue streams are available to which types of assets. Here, we will focus on the market structure. When designing electricity markets today, there are four major components (each of which may be managed differently by different jurisdictions, utilities, and system operators) relating to generation as well as transmission; the three affecting generation assets are briefly described as follows:

- Capacity markets. Based on the correlation of availability of capacity with demand in a specific market, power plants will receive capacity payments. Through capacity markets, operators ensure that there will always be adequate capacity, given expected demand over the course of the year. Traditionally, renewables have either not been able to participate in these markets or can only claim a very small capacity credit (percentage of their rated capacity eligible for capacity payment), caused by the inherent variability and uncertainty of the resource (Midcontinent Independent System Operator [MISO] 2015). In addition, as more variable resources like wind energy assume a larger market share of a given system, the capacity payments to new wind plants decrease, because of the lack of correlation of the wind resource and the demand profile (MISO 2015; Fang et al. 2018a). Coupling renewables with storage increases the system's ability to monetize this value stream (Denholm et al. 2017).

- Energy markets (day ahead and real time). Traditionally, the dominant source of revenue for power plants has come from providing energy (kilowatt-hours) to the electricity grid. In some regions, renewable energy power plants participate directly in energy markets and receive time-varying revenues based on the electricity price fluctuations over time. In many cases, especially looking at historical developments, renewable power plants are provided fixed payments for every kilowatt-hour produced, through power purchase agreements in the United States or feed-in tariffs in Europe. (Ahlstrom et al. 2015).

- Ancillary service markets. These markets pay generators for providing services to ensure grid reliability and stability in the short term. In some regions, these types of services may be required through grid codes rather than awarded as an additional revenue opportunity. There are very few regions where renewable energy resources can actively participate in some ancillary services markets; however, there is increased interest in providing these services (Milligan et al. 2015; Ahlstrom et al. 2015; Kroposki et al. 2017; Fang et al. 2018b; Denholm, Sun, and Mai 2019).

Looking toward the future of the electricity system, there is a consensus within the grid integration community that will likely be a shift in market structures as more variable and uncertain energy sources (such as wind and solar PV) are integrated in the electricity system (Ahlstrom et al. 2015; Helistö et al. 2017; Hirth 2013; Holttinen et al. 2016; Seel et al. 2018; Dykes et al. 2019). In general, as the need increases to ensure sufficient capacity and ancillary services at all times, the market structures may shift toward increasing revenue from capacity and services markets and reduced revenues from energy markets (as indicated in Figure 10). 


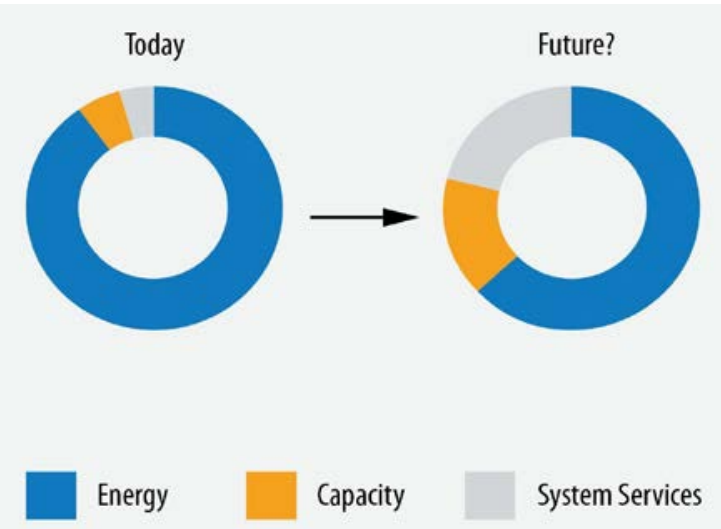

Figure 10. The morphing electricity market system. Source: NREL, based on Ahlstrom et al. (2015)

Some markets, many of which have high wind and/or solar PV concentrations, are already shifting toward models such as that of PJM, where the relative shares of revenue for energy sales have been declining and a larger share has been made up of capacity payments (PJM Interconnection 2017). In places like Ireland and South Australia, where the systems are relatively isolated and less well connected to other balancing areas, regulators and system operators have found that adapting markets, including shorter time intervals for dispatch, encouraging renewables to participate in ancillary markets to support more renewables on the system (Bloom et al. 2017). As markets evolve, the economic potential of hybrid power plants will change. A grid system with very small shares of variable renewable energy and a significant amount of gas or hydropower resources, where the energy markets dominate, would indicate that hybrid power plants will only benefit in terms of economies of scope that can be made through integration of some infrastructure and operational assets. On the other hand, a market that has very high shares of renewable energy, where capacity and service markets are significant, may mean that the profitability of a hybrid power plant may be better than individual technology plants or even individual technology plants with storage.

For evaluation of hybrid power plants, the market context, in terms of what other generation assets are present and what revenue streams are available (and their expected value over the plant lifetime), is critical to assessing the relative performance of the relative sizing of technology assets in the plant and its overall physical design.

For tractable analysis, a reduced number of market contexts (or archetypes) is helpful. These should include representations both for current market archetypes as well as future market archetypes. Based on review of market trends and current conditions, the set in Table 1 are recommended for further exploration. 
Table 1. Market Archetypes for Consideration in Hybrid Power Plant Design

\begin{tabular}{|c|c|c|c|c|c|}
\hline $\begin{array}{l}\text { Defined Market } \\
\text { Archetypes }\end{array}$ & $\begin{array}{l}\text { Share of } \\
\text { Variable } \\
\text { Renewables in } \\
\text { Generation } \\
\text { Mix*}^{*}\end{array}$ & $\begin{array}{l}\text { Energy Market } \\
\text { Revenue }\end{array}$ & $\begin{array}{l}\text { Capacity Market } \\
\text { Revenue }\end{array}$ & $\begin{array}{l}\text { Services } \\
\text { Market } \\
\text { Revenue }\end{array}$ & $\begin{array}{l}\text { Objective } \\
\text { Function }\end{array}$ \\
\hline $\begin{array}{l}\text { Fixed-energy } \\
\text { payment }\end{array}$ & Low $(<10 \%)$ & Fixed per unit & Negligible & Negligible & LCOE \\
\hline $\begin{array}{l}\text { Energy-market } \\
\text { dominant }\end{array}$ & $\begin{array}{l}\text { Moderate } \\
(\sim 10 \%-25 \%)\end{array}$ & Time-varying & Low to negligible & $\begin{array}{l}\text { Low to } \\
\text { negligible }\end{array}$ & $\begin{array}{l}\text { Net present } \\
\text { value ([NPV] } \\
\text { (or other } \\
\text { profitability } \\
\text { metric) }\end{array}$ \\
\hline $\begin{array}{l}\text { Capacity- and } \\
\text { service- } \\
\text { dominant }\end{array}$ & $\begin{array}{l}\text { High }(25 \% \text { or } \\
\text { more) }\end{array}$ & $\begin{array}{l}\text { Time-varying } \\
\text { but low }\end{array}$ & Moderate to high & Moderate & $\begin{array}{l}\text { NPV or } \\
\text { capacity value }\end{array}$ \\
\hline
\end{tabular}

A more detailed description of these scenarios is as follows:

- Fixed-rate energy payment. This market serves as a baseline for investigation and aligns with historical market scenarios where the share of renewable generation in the system is relatively low. In this case, renewable power plants are paid a fixed rate for each unit of energy produced, regardless of time. Capacity and service revenues are low or negligible. In this context, the objective is to minimize the cost of energy produced by the power plant, (similar to current practice for wind and solar PV power plant design).

- Energy-market dominant. This market is similar to many markets today, where shares of renewable generation are reaching higher levels than ever before (up to $25 \%$ or more in several markets [Wiser and Bolinger 2018]). In these markets, renewable power plants typically participate in time-varying energy markets and may receive some payments for capacity value and ancillary services as well, though still much lower than for energy revenues. There may be additional penalties if energy produced does not meet forecasted expectations. As a result, the predictability and controllability of the energy supply is important. In this case, there is a more complex objective needed around maximizing the energy revenues for the plant, while still minimizing the overall cost (in other words, the objective is to maximize the plant profitability given the expected revenues and costs over its lifetime, for instance, using net present value [NPV]). In this type of market, the make-up of the rest of the generation mix is important to understanding what types of trends may affect the energy pricing over time-for example, the share of overall renewables in the generation mix.

- Capacity- and service-dominant. This is representative of future energy systems with high shares of renewable generation, such that energy is abundant and low-cost (Ahlstrom et al. 2015). In this market context, the profitability of the plant depends primarily on its ability to maximize the capacity value it provides to the electricity system and to provide ancillary services on demand. The objective function here would be NPV or a similar profitability metric as well. However, the optimization problem could be simplified by focusing on the main revenue streams from capacity and service markets 
and could be reduced to the capacity value itself or include ancillary service provisions as well.

The optimal design of the plant will depend heavily on the applied market context. In all cases, we assume the perspective of the individual owner-operator of the hybrid power plant, who is a price taker (i.e., a small generator in a much larger system [Sioshansi et al. 2014]). This aligns with the view of the developer/owner/operator stakeholder who is looking at the economic viability and profitability of a prospective project. This also helps simplify the optimization problem, since it avoids the endogenous effect of the plant operation on the potential revenues it receives.

Another key aspect of the market structure is what incentives may be available to different types of technologies. Combining assets into hybrid power plants complicates the matter, since most incentive structures are tied to a single technology power plant configuration. Incentives generally come in forms that are tied to upfront investment or energy produced over time. With the former, various forms of investment tax credits (ITCs), rebates, grants, and loan programs have been used for adoption and deployment of renewable energy across the world. For the latter, production tax credits (PTCs), renewable energy credits or certificates, and feed-in-tariffs have seen widespread usage to support renewable energy adoption globally. Incentives vary with jurisdiction at state/province and national levels. Two current federal incentives are the solar ITC and wind PTC, which are both scheduled to phase out or substantially reduce over time. Statelevel policies and renewable portfolio standards also have a strong impact on market viability. Understanding the available incentives is crucial toward evaluating technology options at a given location. It is also important to consider how hybrid systems can affect incentive structures. For instance, PV plus storage systems may fully monetize the federal ITC for solar, provided the batteries are fully charged from electricity produced by solar; however, storage is eligible for a lower incentive if charged from the grid (Elgqvist et al. 2018). 


\section{Hybrid Power Plant Technology Selection}

For the purposes of this section, we focus on high-level representation of a hybrid power plant in the bulk sizing (in terms of capacity) of the various technology assets in the plant. Much of the work to date looking at the design of hybrid power plants has focused on sizing of the technology, so it is a natural place to start. In addition, this helps simplify the overall context and discussion around the impact of different meta-characteristics of the technology, renewable resources, and the market conditions in which hybrid power plants might operate. This section looks at what types of technologies to select for a given hybrid power plant design, and next at what combination in terms of sizing the capacity of those technologies. Section 4, then, addresses the physical design of the plant in terms of the overall layout of the different technology assets and their interconnection locally and to the larger electric grid system.

Historically, there have been several successfully combined generation and storage power plants that have been deployed globally to support more reliable and resilient electricity supply for a range of applications. In fact, the first wind electric generation systems were almost all hybrids, typically with a connection to batteries to help provide electricity, even when the wind did not blow (Dykes 2016). There was even an early application of using wind power to produce hydrogen through the pioneering work of early Danish wind turbine inventor Poul la Cour (Dykes 2016). Throughout the first half of the 20th century, hundreds of thousands of "wind dynamos" with coupled storage batteries were deployed globally to help provide electricity to rural parts of the United States, Europe, and globally (Dykes 2016). However, with the expansion of the electric grid system across the world, the interest in such systems waned as more and more residences, farms, commercial enterprises, and industrial locations were able to access low-cost and reliable electricity from the centralized utilities. After the oil crisis in the 1970s, there was a significant return of interest in renewable energy, including wind, solar, geothermal, biomass, and more; now for utility-scale applications as well as for off-grid applications.

During the last several decades, a proliferation of combined storage and generation plants for weak-, micro-, or off-grid applications has been developed in distributed, behind-the-meter, electricity-generation applications. Solar and battery storage systems for residential and commercial applications have been widespread since the 1970s (Whittingham 2012; Chen et al. 2009). Another common system for remote and islanded applications has been wind-diesel hybrid power systems (Baring-Gould and Dabo 2009; Baring-Gould et al. 2003). Diesel generation, historically and currently, plays an important role as a back-up electricity generation source for many locations when there are problems with the larger electric grid systems, and is important for supporting resiliency of electricity generation for a variety of end users, including military bases, hospitals, and more. Both solar-battery and wind-diesel applications historically focused on end-user applications.

In contrast, pumped hydro storage coupled with electricity generation has demonstrated value at multiple system levels over a period of several decades. The basic technology for pumped hydro systems has existed for over a century, with the first demonstrations taking place in the early part of the 20th century in Switzerland as well as the United States, consisting of largely separate systems for generation and for pumping (MWH 2009). Key technologies for modern pumped hydro power plants were developed in the second half of the 20th century and introduced into 
commercial projects from the 1980s onward (MWH 2009). Newer pumped hydro storage systems are able to provide storage for shifting energy production over time, but also can provide a variety of services to support the grid, such as load following, frequency regulation, voltage control, and spinning reserves (see MWH 2009 and Krad, Ela, and Koritarov 2014 for a detailed overview of pumped hydro technology capabilities). However, even with such capabilities, existing pumped hydro systems may be underutilized because of market designs that hinder optimal exploitation of pumped hydro in operational markets for commitment and dispatch (Ela et al. 2013b; Stark 2018).

Pumped hydro systems have been applied to a range of system types, including: (1) off-grid and distributed electricity generation (Pali and Vadhera 2018), (2) smaller or islanded grid systems (Norconsult 2013; Coburn et al. 2014), or even (3) very large utility-scale systems (MWH 2009; Huertas-Hernando et al. 2017). The objectives of pumped hydro differ, depending on the type of system of interest. For distributed or even off-grid electricity generation applications, storage serves a key role of providing robustness to fluctuations in variable generation from solar and wind energy to provide a dependable supply of electricity to the end user. In these cases, the enduser customer for the electricity is the primary stakeholder for the system design, and the overall capacity of such systems is relatively small (less than $100 \mathrm{MW}$ but often closer to just a few megawatts or even kilowatts in scale). Pali and Vadhera (2018) provide an example of one type of small-scale system for a rural electrification application, where the wind turbine is used to drive a hydro pump system to feed a reservoir that then provides electricity generation more or less on-demand. For off-grid applications, customers are typically looking to supply their full electricity needs at the lowest system cost, while for grid-connected applications, the customers are looking to either increase their resilience to outages, reduce their electricity costs, meet renewable electricity usage or emissions targets, or some combination of all of these (Simpkins et al. 2014). Several research studies have looked at the sizing of these systems in order to choose the appropriate generation mix and associated rated capacity of each generation technology to optimize one or more of the above-mentioned objectives (see, for example, studies using the Renewable Energy Integration and Optimization [REopt ${ }^{\mathrm{TM}}$ ] model that will be discussed shortly).

For small- to large-scale electricity systems, pumped hydro technology may be valuable again for addressing variability and uncertainty in the generation from wind and solar. In these cases, the size of the pumped hydro systems is typically much smaller than the overall capacity of the system and is used to support short-term operational flexibility and services (Huertas-Hernando et al. 2017). However, depending on the overall sizing of the systems, they can even supply seasonal energy storage capacity, which is a particularly challenging feature of many systems with high wind energy shares, where the capacity factor for that wind energy varies significantly over the course of the year (Huertas-Hernando et al. 2017). In most of these cases, the pumped hydro systems are decoupled from the variable generation resources and are either stand-alone or coupled with a larger hydroelectric power plant. Coburn et al. (2017) investigated the opportunities for co-located wind and pumped hydro energy storage systems in Ireland but found limited potential because either of mismatch of the resource potential or various nontechnical obstacles to their development. However, evaluation of pumped hydro across a broad set geographic regions and markets is still an open area of research. 
Beyond solar and wind with storage, including batteries or pumped hydro, there has been a growing interest in fully hybrid power plant projects that include more than one electricity generation source in a single plant. In addition to wind-diesel systems for distributed electricity generation, these include wind and solar (either PV or CSP), solar CSP and PV, geothermal and CSP, and more. For these systems, sizing all the plant's technology assets is key to meeting their design objectives and is an active area of research.

\subsection{Research and Software Tools for Hybrid Power Plant Screening}

A number of studies have looked at hybrid power plant sizing, including a variety of configurations like the one described earlier, and even applications beyond electricity generation such as "Power-to-X" applications that produce various forms of fuel like hydrogen, ammonia, and so on (Eichman and Flores-Espino 2016). Many of these applications focus on distributed generation and "behind-the-meter" applications, versus commercial- and utility-scale generation, which is the focus of this report. Still, there are many parallels between the prior efforts and the topic of utility-scale hybrid power plant sizing and design. Here we will highlight several comprehensive efforts in this space.

The REopt model developed at NREL has been used for a variety of studies on hybrid power plant sizing. It solves the optimal mix of technologies, their size, and operational profile to minimize lifecycle cost of energy typically for distributed, behind-the-meter systems (Cutler et al. 2017). The technologies considered in REopt include: solar PV of various scales/configurations, energy storage (electrical and thermal), wind power (small, medium, and large turbines), solar water heating, solar ventilation air preheating, ground source heat pump, biomass (thermal, combined heat and power [CHP], electric) waste to energy, (thermal, CHP, electric), landfill gas (thermal, CHP, electric), diesel/natural gas generators and combustion turbines, dispatchable loads/energy conservation measures, and, of course, the utility grid itself (Cutler et al. 2017). The model has also been extended to look at nuclear-renewable hybrid energy systems that leverage the thermal energy and/or electricity from the nuclear power plant, integrated with electricity produced by the renewable asset to provide electricity generation as well as, potentially, storage or other outputs (fuel production including hydrogen, desalination, and more [Ruth et al. 2016, 2017]).

The goal of the REopt model is to find the combination of technologies and dispatch strategy that minimizes lifecycle cost of energy to the site. Depending on the stakeholder, a variety of additional constraints for the overall system design can be added including increasing resilience (ability to sustain critical load using on-site resources during outages of the larger utility system), meeting renewable energy targets, or reducing emissions (Cutler et al. 2017). In all cases, REopt looks at slices of data (typically, one year of hourly data) for different potential revenue streams including capacity, energy, and grid services (including policy incentives associated with each) that are then balanced against the costs of the different technologies. The representation of technology performance is accomplished with pre-generated production profiles that are scaled up or down as part of the solution of an optimization problem. The mathematical optimization approach, using a mixed-integer linear programming algorithm, is powerful for screening sites for potential but is not well suited for detailed physical design of the integrated plants. For a more detailed discussion of REopt's capabilities and optimization algorithm, see Cutler et al. 2017. A diagram of the main REopt architecture components is provided below. 


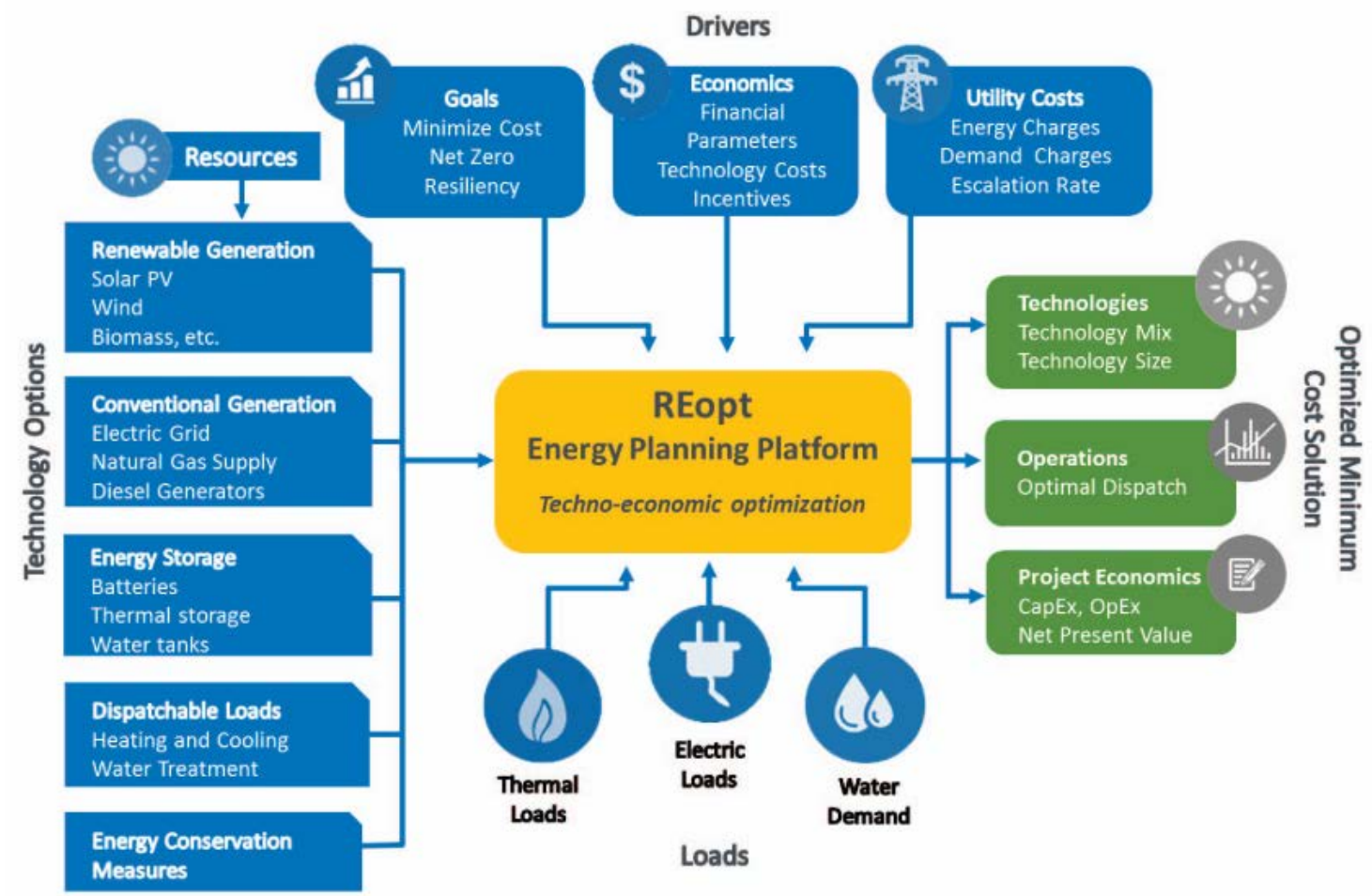

Figure 11. REopt energy planning platform key inputs and outputs. Source: NREL

Two additional tools that have been used for screening and sizing of hybrid power plants include the Hybrid Optimization Model for Electric Renewables $\left(\mathrm{HOMER}^{\circledR}\right)$ and Distributed Energy Resources Customer Adoption Model (DER-CAM). HOMER (HOMER Products 2017) was originally developed at NREL and now developed commercially, is designed to optimize microgrids and distributed energy resources (Sinha et al. 2014). The tool has many capabilities including performing prefeasibility, optimization, and sensitivity analysis for different system configurations. The model takes inputs around the electric load, available resources, system constraints and control, and outputs the optimal sizing, cost, and other system metrics. DERCAM is a model developed by the Lawrence Berkeley National Laboratory to find optimal distributed energy resource investments for buildings or microgrids. The model is formulated as a mixed-integer linear program, determining the optimal technology portfolio, placement, and dispatch. Recent updates have expanded the model to use multinode modeling techniques (Mashayekh et al. 2017), and the model has been used to perform analysis of optimal battery storage operation for PV systems with tariff incentives (Hassan and Cipcigan 2017).

In terms of applications, there have been several one-off studies looking at optimal sizing of geothermal and CSP, solar PV, and CSP, and several looking at wind and solar PV together. For geothermal and CSP, Turchi et al. (2014) investigated the ability to create synergies between the thermal energy produced from both resources in a hybrid power plant. Because solar CSP produces thermal power then used by a turbine, it is similar in many ways to other thermal energy sources such as geothermal, nuclear, and fossil-fuel-based electricity generation facilities. Combined geothermal and CSP were shown to provide more power during hot afternoons, which would generally correspond to periods of higher electricity demand (Turchi et al. 2014). Areas where resource potential for solar PV are high can be (but are not always) places where solar CSP would have good performance and thus present an opportunity for synergy, as CSP 
technology has the ability to time-shift production through short-term storage of the thermal energy produced (with high efficiency).

Finally, several studies have begun to investigate the opportunities for combined solar PV and wind energy into hybrid power plants (Nema et al. 2009; Testa et al. 2010; Badwawi, Abusara, and Mallick 2016). Nema et al. (2009) and Badwawi, Abusara, and Mallick (2016) provide indepth reviews of the state of the art in hybrid wind and solar PV energy system analysis, including sizing applications. The efforts largely focused on distributed or off-grid generation applications and the relative capacity sizing for wind, solar PV, and battery storage with relatively simple representations of the different technology elements, similar to those done in REopt and HOMER. More recently, there has been some interest in utility-scale hybrid wind and solar PV power plants and their optimal sizing. Given the large number of existing wind power plant facilities in the United States, De Azevedo and Mohammed (2015) investigated the potential for retrofitting existing facilities with the addition of solar PV because costs for solar PV have continued to fall substantially. An important aspect of the study was considering the tower shadow from the turbines and the impact to the solar resource potential of the co-located assets. The work also considered wake losses from the wind turbine interactions with the flow, such that the research could be classified not just as a sizing optimization but as a physical design optimization as well. The latter topic will be discussed in more detail in Section 4. 


\section{Hybrid Power Plants' Physical Design and Optimization}

First, we review the state of the art for both solar and wind power plant design, each of which has a substantial associated body of literature and commercial application. Then, we explore the needs for hybrid power plants that combine solar, wind, and storage technologies. Finally, we discuss the opportunity for expanding the set of potential hybrid power plants to include geothermal, hydropower, and concentrated solar power technologies.

\subsection{State of the Art in Wind Power Plant Design}

Design optimization for wind power plants is a subject with an extensive and immense presence in academic literature as well as a proliferation of targeted open-source and commercial software packages. For a detailed review of the state-of-the-art in wind power plant optimization, see Systems Engineering and Optimization of Wind Turbines and Power Plants by Ning, Dykes, and Quick (2019). Here, we provide a high-level overview of wind power plant design optimization including key decisions, models, and an example application.

Wind power plants are large-scale, complex, and technical systems involving many subsystems, science and engineering disciplines, and stakeholders, as shown in Figure 12.

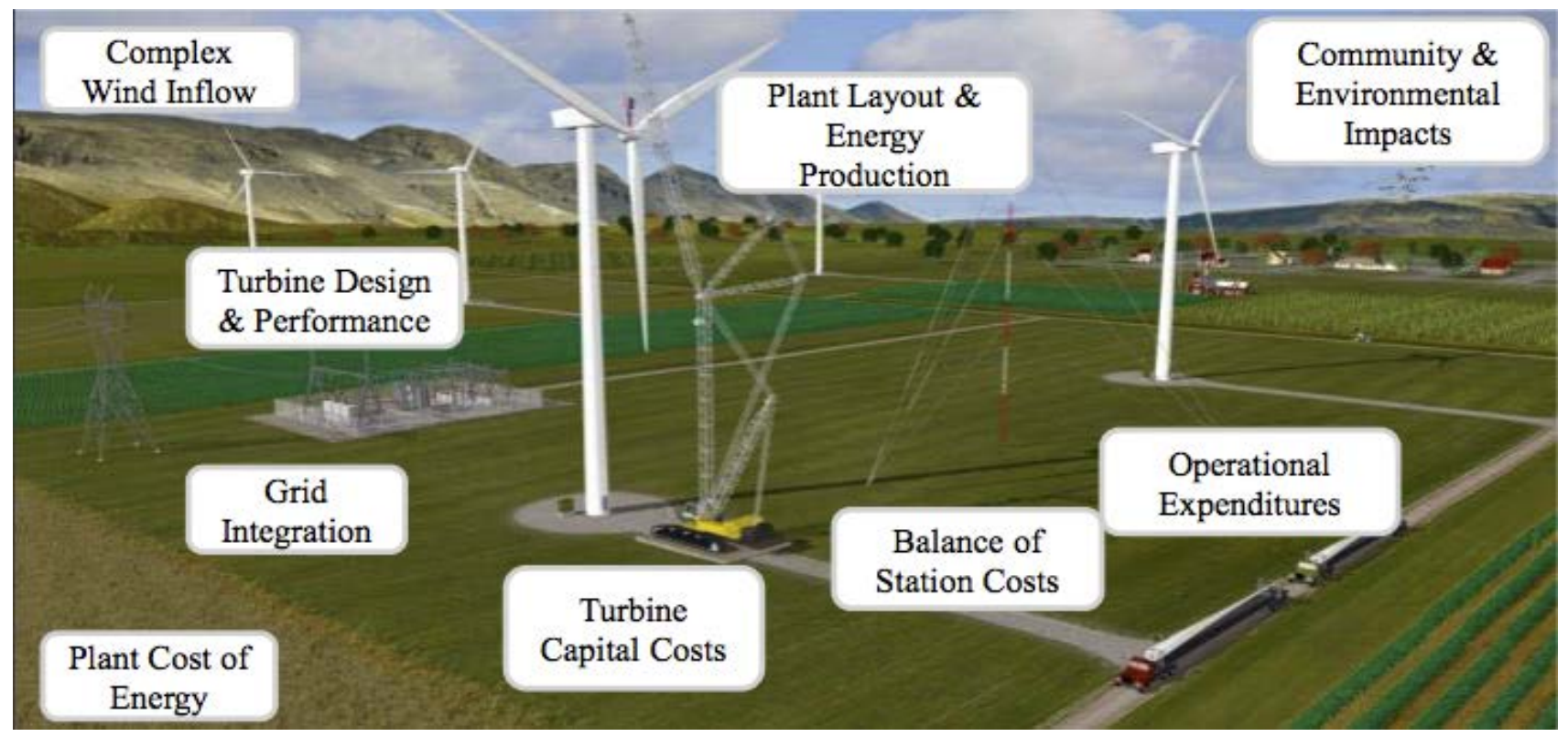

Figure 12. Wind energy as a large-scale complex technical system. Illustration by Al Hicks, NREL

As wind energy moves from very large-scale global and regional weather phenomena, down into and through the wind power plant, it interacts with each turbine to create wakes and low-energy and higher turbulent bodies of flow, as well as potentially complex terrain and other site-specific topographic elements. The physics within and across each of these geospatial scales, as well as the physics of the turbine response over time, involve a large amount of complexity and uncertainty, which pose major research challenges to the scientific community (Dykes et al. 2019). Despite the complexity and uncertainty of the physics, there is still a need to try to design 
wind power plants to be as profitable as possible, to yield the largest quantity of energy possible at the lowest possible cost over the lifetime of the plant.

Historically, wind power plant designers have used a LCOE metric as a global objective for plant design. This metric includes all the upfront capital expenditures (CapEx) of the plant adjusted for a fixed charge rate $(F)$, the expected annual operational expenditures (OpEx) over the plant lifetime, and the expected annual energy production $(A E P)$ delivered to the grid (see Dykes et al. 2017 Appendices B and C for more detail):

$$
L C O E=\frac{F * C a p E x+O p E x}{A E P}
$$

Although the LCOE metric obfuscates details of the financing impacts, it is necessary to create an objective function that can be tractably computed within an optimization design loop. In practice, however, power plant designers and developers perform detailed financial modeling of the plant and may adjust the design to a degree based on the results of those modeling efforts. For the purposes of this paper, we will focus on the simplification of the global objective of LCOE for optimization.

To estimate the LCOE for a given wind power plant design, designers use software packages that contain a combination of several models together that represent different subsystems of the plant, each itself represented by one or more science and engineering disciplines, as well as cost models. The primary subsystems considered for the plant design include energy production, balance of system (BOS; including plant infrastructure and installation), and operations and maintenance. In practice, the community still lacks detailed and accurate models for how plant design affects the latter subsystem, operations, and maintenance because of the very high uncertainty around the reliability of the turbine and BOS equipment components over the lifetime of the plant. Thus, most wind plant design efforts (both in academia and in practice) focus on trade-offs between the BOS costs (affecting capital expenditures) and energy

production. Each of these subsystems involve several components and associated disciplines.

\subsubsection{Energy Production}

For wind energy, a "wind rose" is often used to describe the joint probability distribution of wind direction and wind speed frequencies (see Figure 13 for an example of a wind rose). Wind roses can vary quite a bit from site to site and determine the overall orientation of the site in terms of primary directions and spacing between turbines. 


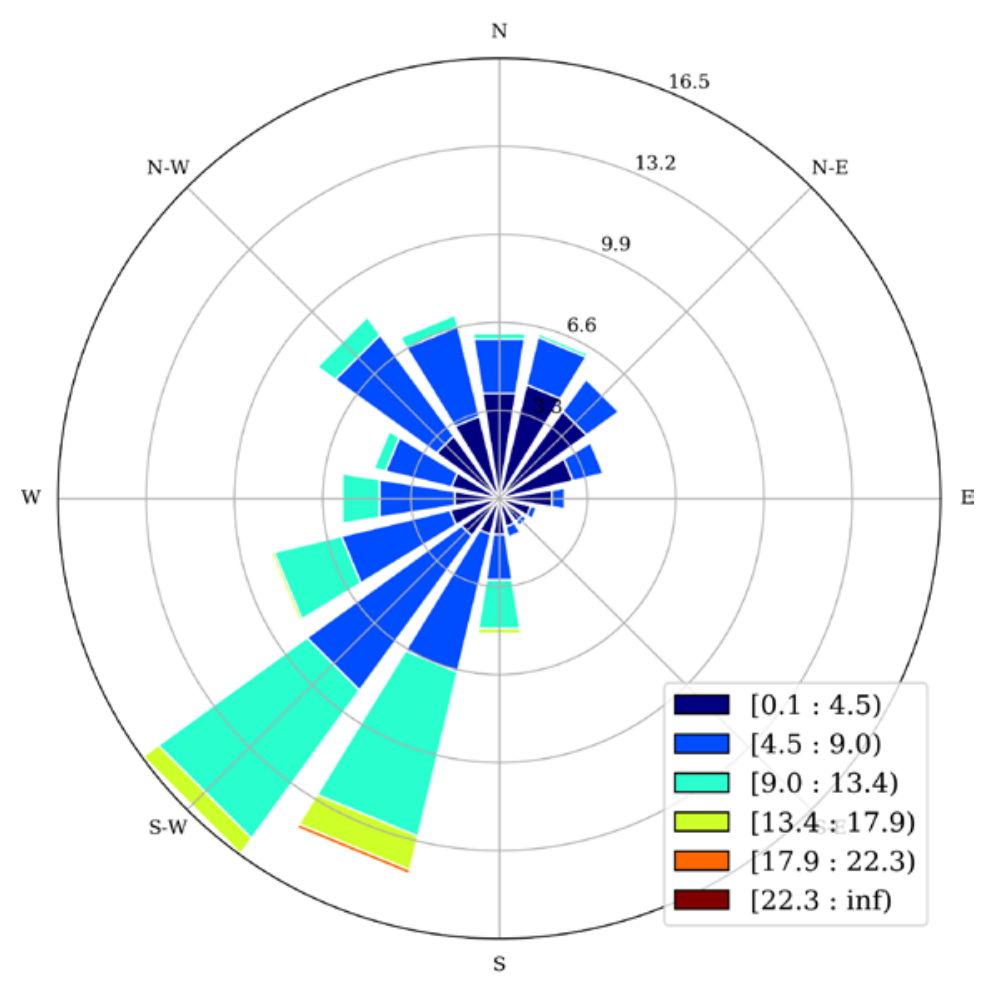

Figure 13. Wind rose for the eastern Arizona data set described earlier illustrating the distribution or frequency of wind speeds for each wind direction for a wind project set normalized over the course of a year. This wind rose illustrates that the wind resource is predominantly from the southwest. Wind speeds are in meters per second.

Each direction of inflow has a vector of frequencies for wind speeds, the integration of which (overall all speeds and directions) sums to 1 . To the distribution of speed and direction, additional site-specific meteorological characteristics can be added, such as the turbulence intensity (defined as the standard deviation over the mean of the wind speed) and wind shear or other properties. These wind roses typically represent long-term trends for the site averaged over many years of historical data and projections, but they may be further resolved into seasonal, monthly, or even diurnal wind roses (or at least wind speed distributions) to address the variation of the resource over those timescales. However, the interdependencies of the resource with time (the autocorrelation) at different timescales is typically not explicitly modeled.

Estimating energy production for a given plant layout includes models of the plant inflow (the wind resource: see prior discussion in Section 2), propagation of the flow through the plant, the response of the turbines to the flow and creation of wakes, and combinations of the background flow with the wakes produced by different turbines as they propagate through the full plant. The wind rose, or wind resource grid, with varying wind roses throughout a site, is used as high-level input to the optimization, each of which is generated by an upstream modeling chain combining data with engineering or potentially mesoscale models. Linearized flow and wake models are used most often in plant design, because they are computationally efficient and have been refined over time through calibration with field data and higher-fidelity model data to reliably estimate energy production for a wide range of types of sites. An example of a collection of wake models and overall wind power plant energy production is NREL's Wind-Plant Integrated System Design and Engineering Model (WISDEM ${ }^{\circledR}$ ) and FLOw Redirection and Induction in Steady 
State (FLORIS) model toolsets (shown in Figure 14), which have been applied to wind power plant layout as well as control strategy optimization (Fleming et al. 2015; Gebraad et al. 2016). Where these models struggle is in capturing nonlinear flow effects that can be introduced by local topography and complex terrain, wake merging, offshore conditions with deep-array wake effects, interplant wake effects, and more.

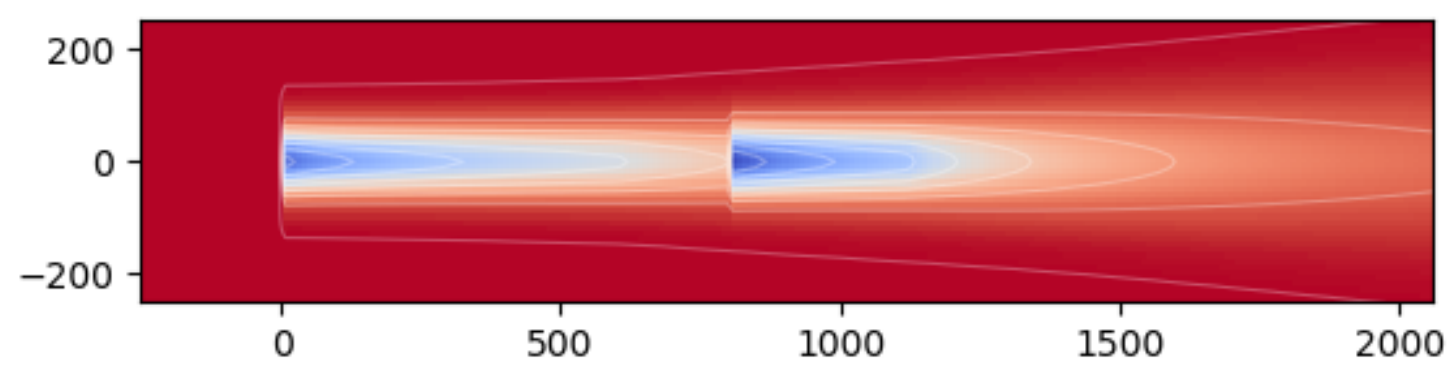

Figure 14. Example output of FLORIS, a wind farm model that computes the velocity at each turbine in a wind farm and can be used to estimate power production in a wind farm. This model executes in fractions of a second.

\subsubsection{Balance of System}

The design of the BOS includes the turbine foundations and infrastructure for roads; the electrical collection system, substation, and interconnection; as well as the erection of the turbines themselves (including crane costs). Many of these elements are not considered in detail in the plant design optimization process. One of the most common elements to include is the layout of the road and electrical collection system infrastructure costs (often co-located) that are strongly dependent on the turbine placement. The substation(s) may also be included as well. Another more common element to include in the optimization process is the foundation. This is particularly important for offshore applications where the support structure costs are much more significant than for land-based power plants.

The electrical infrastructure, particularly the collection system, is important when thinking about hybrid power plant design, as there is potential opportunity for integrated design of this infrastructure with the other generation as well as storage elements of the power plant. There are a small number of basic topologies for the electrical collection system of wind power plants that include: (1) radial or daisy chain (turbines connected in series), (2) ring (turbines connected in series but with a redundant interconnect to the substation), or (3) star (turbines connected in parallel with a common point of interconnection to the substation [Lumbreras and Ramos 2013; Katsouris 2015]). The combination of radial and star topologies into a branched topology (with a main trunk and various branches) has become the dominant topology for most wind power plant electrical system designs, both land-based and offshore (Lumbreras and Ramos 2013; Katsouris 2015). See examples diagrams of these topologies in Figure 15. 

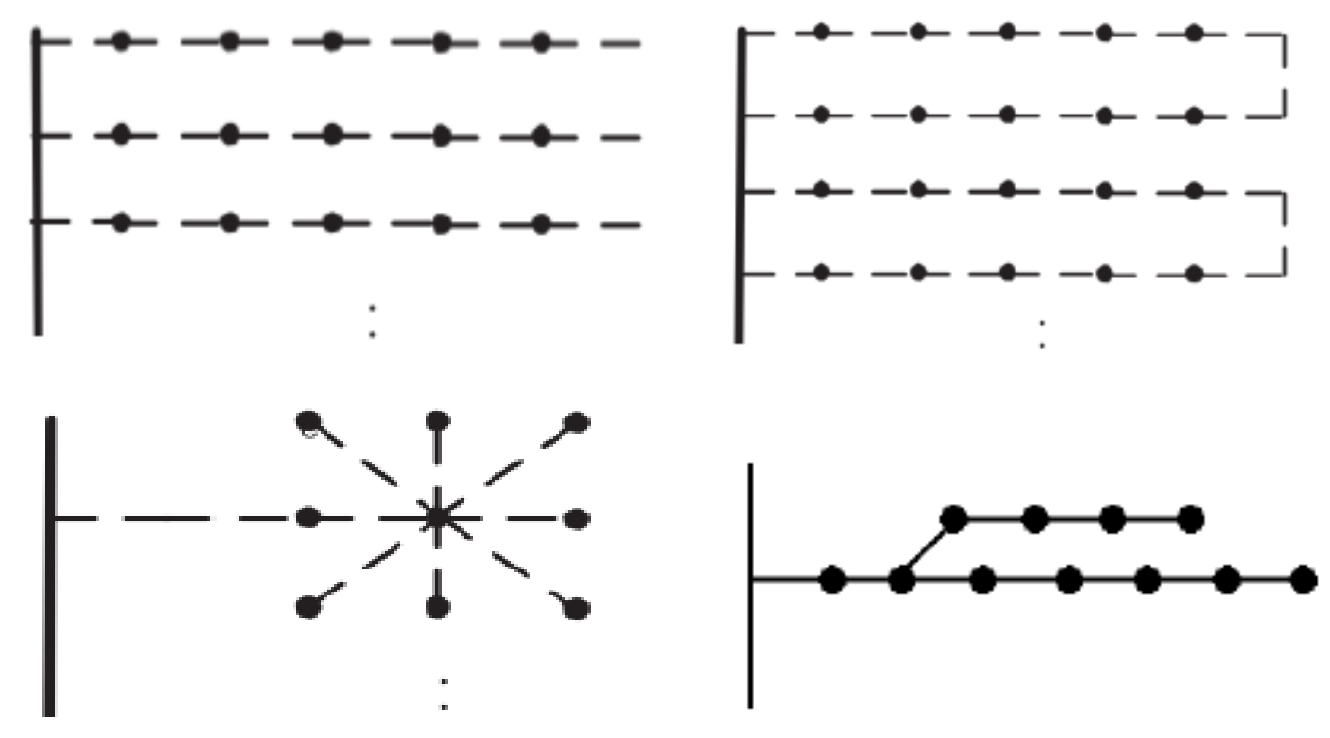

Figure 15. Standard topologies for electrical infrastructure design including radial (or daisy-chain) (top-left), double-sided ring (top-right), star (bottom-left), and branched (bottom-right). Source: Katsouris (2015)

There are benefits to each topology and, depending on the actual layout of the wind power plant, one may use more, or less, cable length, materials, and cost than another. Often, the optimization of the electrical layout infrastructure is a suboptimization within the larger wind power plant design optimization process (Sanchez Perez-Moreno et al. 2017).

Models to consider for integrated wind plant design include models for flow and wakes, the electrical system performance and cost, other infrastructure costs, and civil engineering of the foundation and associated costs. Limiting the design to just this set of models already introduces many potential design variables for consideration (see Dykes et al. [2019] for a more detailed review). The most common design variables include:

- Turbine layout. The position of each turbine in the plant (either on a gridded, semiregular, or irregular layout formation) is the most common design variable for wind power plant design. If gridded, then the spacing between turbines and their orientation is most often used. If semiregular, or irregular, the latitude and longitude of each turbine are typically used. The positions are then often constrained by a plant perimeter that may be convex or may also have exclusion zones based on land leases or topographic elements.

- Turbine number. In many commercial wind power plant optimization software packages, the number of turbines in the plant is not set a priori and is included as a design variable. This introduces a discrete variable, and it is not surprising, then, that most such software packages use gradient-free/meta-heuristic optimization methods that take longer to converge but can handle discontinuities in the design space.

- Topology and sizing of the electrical collection system. Although most wind power plant design models do not address detailed modeling of the electrical system, they will 
often include a suboptimization step to optimize the topology of the electrical collection system and the sizing of various cables. Often, shortest-path algorithms are used to support these optimizations.

- Foundation sizing. Even for the same turbine, the location of the turbine in the plant will affect the loads on the foundation and their design. For land-based wind power plants, local topography and waking from other turbines will affect the loads and sizing. For offshore wind power plants, the depth of the water to the seabed as well as waking from other turbines will affect the loads and sizing. The significant cost of offshore foundations has led to several studies, thereby bringing preliminary design of the foundation into the overall plant design process.

- Types of turbines. A newer area of research has explored using different types of turbines in the same plant with varied hub heights, rotor diameters, and rated powers. Introducing the ability to change the turbine type itself introduces significant computational cost, and the studies in this space have either used a fixed number of predefined turbine designs or surrogate models based on preoptimized turbine designs for a variety of environmental and operating conditions.

- Turbine control strategy. Another novel area of research has focused on wind plant controls that allow the turbines to adjust yaw, pitch, or commanded torque to affect the wakes they produce to increase overall plant energy production or decrease loads and improve turbine component reliability. By using the control settings as part of the upfront plant design, it may be possible to improve plant energy capture while simultaneously reducing overall plant costs. In practice, however, these methods have not been thoroughly validated and are just now being demonstrated at existing wind plants.

Given the number of potential design variables and models that may be addressed in wind power plant design optimization, most research and commercial efforts reduce the design space by focusing on a subset of design variables as well as the use of simplified models (especially early in the design process). Models from different disciplines are connected into a workflow that may be monolithic (all disciplines are solved simultaneously with a single optimizer driving the workflow) or may include suboptimizations of certain disciplines or even more complex architectures. The following workflow comes from an offshore wind power plant layout optimization and includes the energy production models as well as suboptimizations for the electrical cable layout design and the offshore support structure designs at each location of interest (Sanchez Perez-Moreno et al. 2017).

Next, we will walk through an example wind power plant design case study with a fixed number of turbines that considers trade-offs between energy production and electrical infrastructure costs.

\subsection{Example Wind Power Plant Design Case Study}

For wind power plant design, the WISDEM model from NREL couples flow models such as FLORIS with other system performance and cost models (such as BOS cost models) to enable design optimization for LCOE or other system-level objectives (Dykes et al. 2011). WISDEM is a toolset that allows users to flexibly couple models together, depending on the application of interest, and is used both for detailed optimization of wind turbines and their components as well 
as for the design of full wind plants. WISDEM has been used for a broad range of wind power plant optimization problems, including layout with wind plant controls, turbine platform optimization for hub height, rotor diameter, and rated power along with layout, mixed-turbine, and layout optimization with discrete turbine selection, wind plant control optimization under uncertainty, and more (see Ning et al. [2019] for various examples). Figure 16 shows the interaction of the different models in WISDEM.

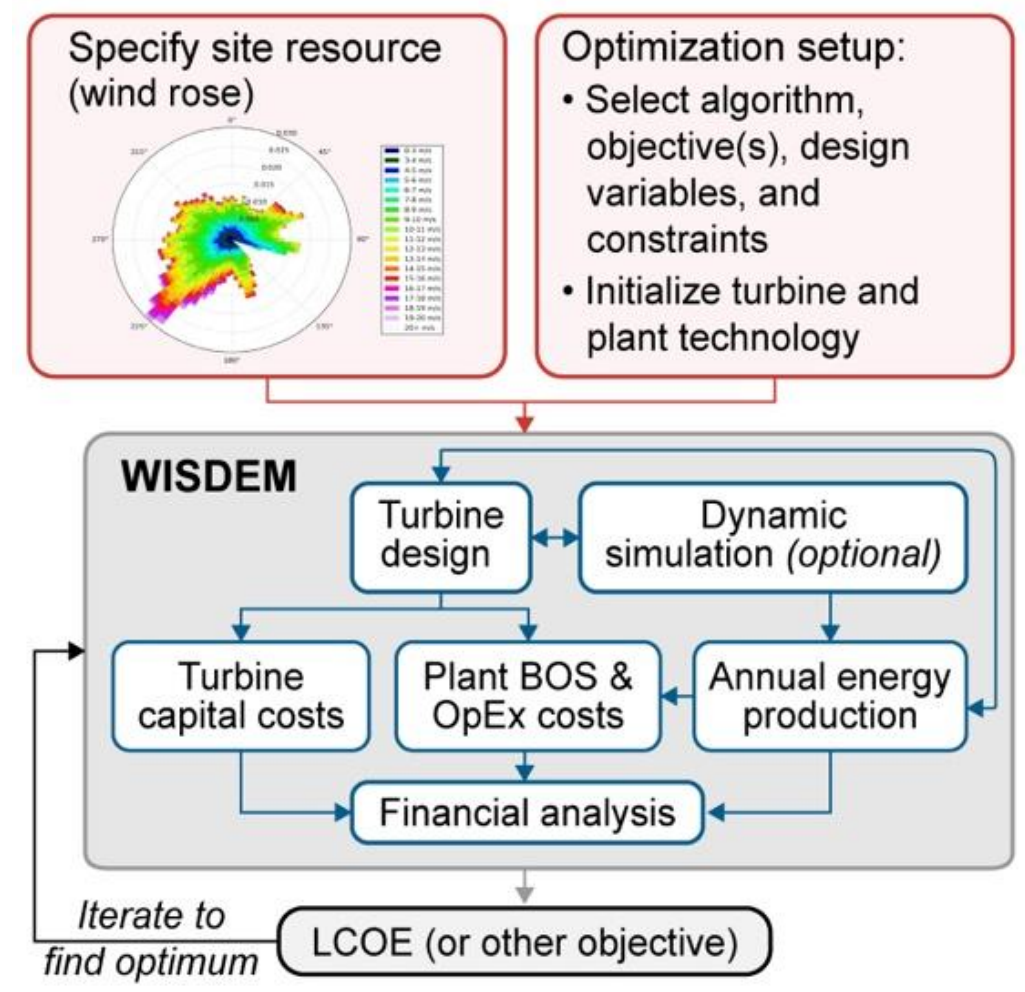

Figure 16. WISDEM toolset for design of wind turbines and plants. Source: NREL

As a recent example of wind power plant design research, Fleming et al. (2015) is of interest for hybrid power plants, because it focuses on integrating a wind plant control strategy into the physical design of the plant. Wake steering was already mentioned as a strategy that has been investigated for improving overall energy production from a wind power plant. By yawing upstream turbines, wakes are steered away from downstream turbines, resulting in increased overall energy production for the plant (Fleming et al. 2016). The primary reason for placing turbines farther away from each other in a wind power plant is to reduce the wake losses that decrease plant energy production. Therefore, by using wake steering strategies, it is possible to get the same energy production with turbines spaced closer together as a wind farm without wake steering where turbines are spaced farther apart. By moving turbines closer together, there are additional benefits in terms of reducing the infrastructure costs of roads and electrical cables.

In Fleming et al. (2015), researchers investigated the optimization of the design of the Princess Amalia offshore wind power plant in the Netherlands. Several cases were compared for energy production and power density (project rating per square meter) with four of the key cases including: (1) the baseline power plant, (2) the baseline power plant design with optimized yaw settings for wake steering, (3) optimal layout of the power plant for maximum density while 
keeping the baseline energy production levels, and (4) combined optimization of the yaw settings and the layout for maximizing power density. In addition, the lengths of electrical cables were also estimated using a minimum spanning tree algorithm. The results are summarized in Table 2. The resulting layout is shown in Figure 17 with a possible cable layout shown in the right figure.

Table 2. Results of Select Wind Power Plant Control and Layout Design Optimization Cases (Source: Fleming et al. [2015])

\begin{tabular}{|l|l|l|l|l|} 
& Baseline & $\begin{array}{l}\text { Baseline Layout / } \\
\text { Yaw Optimized }\end{array}$ & $\begin{array}{l}\text { Position Optimized } \\
\text { for Maximizing } \\
\text { Density }\end{array}$ & $\begin{array}{l}\text { Position and Yaw } \\
\text { Optimized for } \\
\text { Maximizing Density }\end{array}$ \\
\hline Mean power (MW) & 78.86 & 84.91 & 78.86 & 78.84 \\
\hline Area $\left(\mathrm{km}^{2}\right)$ & 14.53 & 14.53 & 12.45 & 8.96 \\
\hline Cable length $(\mathrm{km})$ & 32.74 & 32.74 & 27.50 & 23.88 \\
\hline $\begin{array}{l}\text { Power density } \\
\left(\mathrm{W} / \mathrm{m}^{2}\right)\end{array}$ & 5.43 & 5.84 & 6.33 & 8.80
\end{tabular}
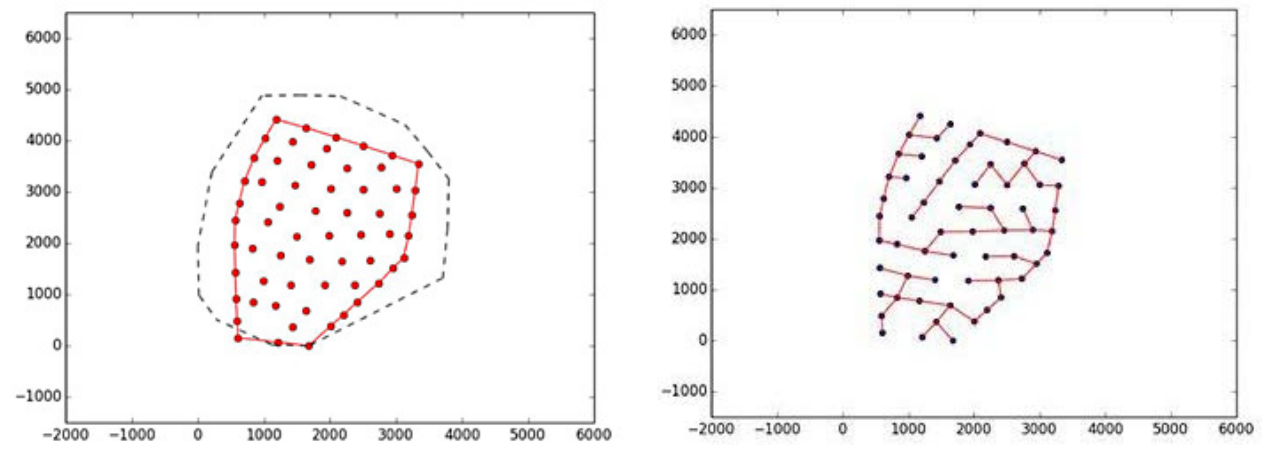

Figure 17. Original Princess Amalia plant boundary relative to the position and yaw-optimized boundary as well as the overall cable length for the final optimized case. Source: Fleming et al. (2015)

Through co-optimization of the plant controls and the layout positions, researchers were able to increase the power density of the Princess Amalia wind power plant by over $60 \%$ while keeping power production at the same levels as the baseline case. At the same time, the resulting overall cable length decreased by nearly $40 \%$. While the costs of the electrical cables were not modeled, this would lead to significant reductions in the cost of energy, especially for an offshore power plant location where electrical cables must reach the sea floor and be buried in the seabed at depths often reaching 20 to $30 \mathrm{~m}$ or more.

Many other optimization studies for wind power plant design have looked at optimizing the layout for energy production and infrastructure costs, site suitability of wind turbines, multiple types of turbines in the same plant, and more (see Dykes et al. [2019] for a detailed review of the state-of-the-art in wind power plant design optimization).

\subsection{Gaps and Limitations in Wind Plant Optimization Models}

Although the body of literature and industry activity around wind power plant optimization continues to grow, there are still significant limitations and remaining research questions in the field. First, because of the size of the system scope involved with wind power plant design 
optimization (involving the full LCOE perspective), the models used for each of the subsystems as well as the disciplines within each subsystem tend to be of lower levels of fidelity:

- Energy production. Current flow and wake models used in design optimization are adequate for some applications (flat terrain such as in prairies and even, to an extent, offshore), but they break down when there are significant nonlinearities in the flow that may be caused by varying atmospheric stability conditions, complex terrain, or interactions of the flow between turbines (Ning et al. 2019; Adcock and King 2018).

- BOS. Electrical infrastructure models are again typically of low fidelity relative to the dynamic behavior of a real operating wind power plant, and ongoing research is looking at improved optimization techniques for a range of different collection system topologies as well as location of substation, interconnection lines, and more (Ling-Ling et al. 2012; Hou et al. 2019). In addition, cost models are typically derived from empirical data and thus do not translate seamlessly to site-specific conditions where there may be complex terrain, heterogeneous soil conditions, or new technologies for which models derived from historical and empirical data are no longer valid (Eberle et al. 2019).

- Operational expenditures. Design of wind power plants all but ignores downstream impacts on operational expenditures. There have been a few studies that consider site suitability in practice (e.g., Graf et al. 2016), and in commercial application developers and turbine manufacturers include models to assess loads and site suitability in their design process (Ning et al. 2020). However, detailed models of the load, reliability and operations, and maintenance impacts of plant design decisions are not yet available. This topic is closely linked to controls, since the optimization of control and operational strategies over the lifetime of the plant can significantly impact lifetime operational expenditures.

In addition, there is increasing interest in other system objectives that go beyond LCOE to include metrics related to the capacity value and potential for ancillary service revenues. These are nascent within the wind plant optimization research community and align well with interests around hybrid power plant design optimization, where a broader set of revenue streams is key to their economic viability.

\subsection{State of the Art in Solar Power Plant Design}

Designing and optimizing a PV plant is a process that entails considering several key design decisions and evaluation of trade-offs. Before examining these factors, it is important to gain context on the state of the United States PV industry, as of 2018. Figure 18 shows a breakdown of installation by market segment and region, illustrating that utility-scale PV projects dominate and, while California still dominates U.S. installations, other regions are seeing considerable installation of PV (Feldman and Margolis 2019). 

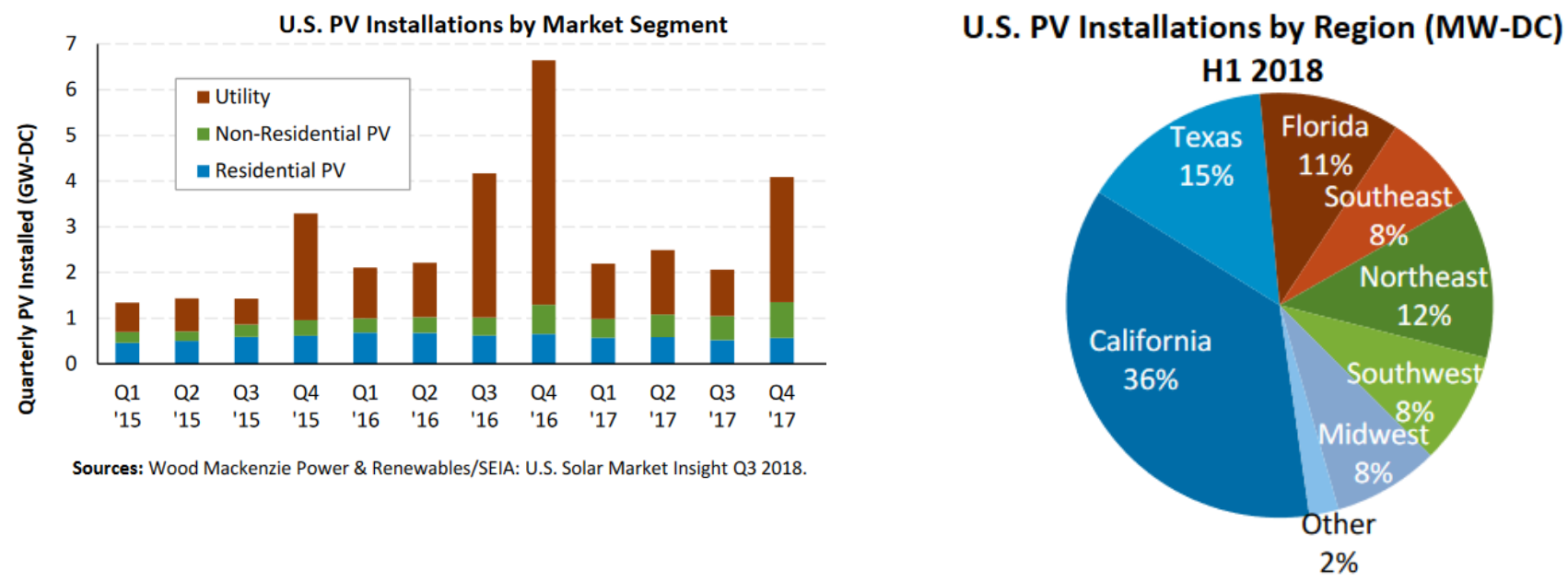

Figure 18. Installation breakdown for solar PV plants

Figure 19 illustrates utility-scale trends that can further inform design decisions and plant optimization. Projects with tracking systems dominate because of their ability to increase output plant production, with fixed-tilt systems primarily being deployed in low-insolation areas. Another trend is the increase of DC to AC ratio because of module price declines and a desire to boost off-peak plant output.

Optimizing plant design has the primary goal of maximizing the value of the plant, typically by maximizing the net-present value or internal rate-of-return, depending on the ownership structure. For utility-scale plants operating under a power purchase agreement (PPA), the traditional source of revenue for a plant is to sell electricity produced by the system at a negotiated rate, which can be fixed or vary by time of day and season. Therefore, a full plant optimization would account for the structure of the PPA and produce electricity at times when it is most valuable within the limits of the system. 

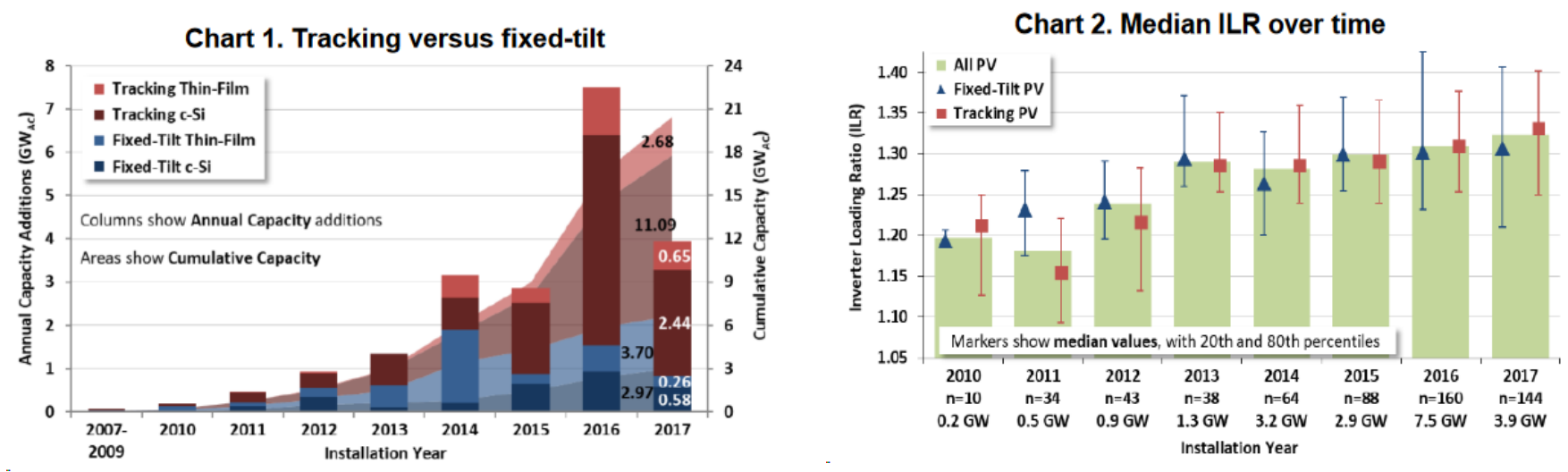

Figure 19. Utility-scale solar trends. The inverter load ratio (ILR) is the ratio between the DC solar array and the $A C$ inverter.

The choice of tracking system and inverter load ratios are two factors to optimize in a PV system. The tracking system is designed to optimize the array tilt and azimuth angles to maximize power production, as shown in Figure 20.

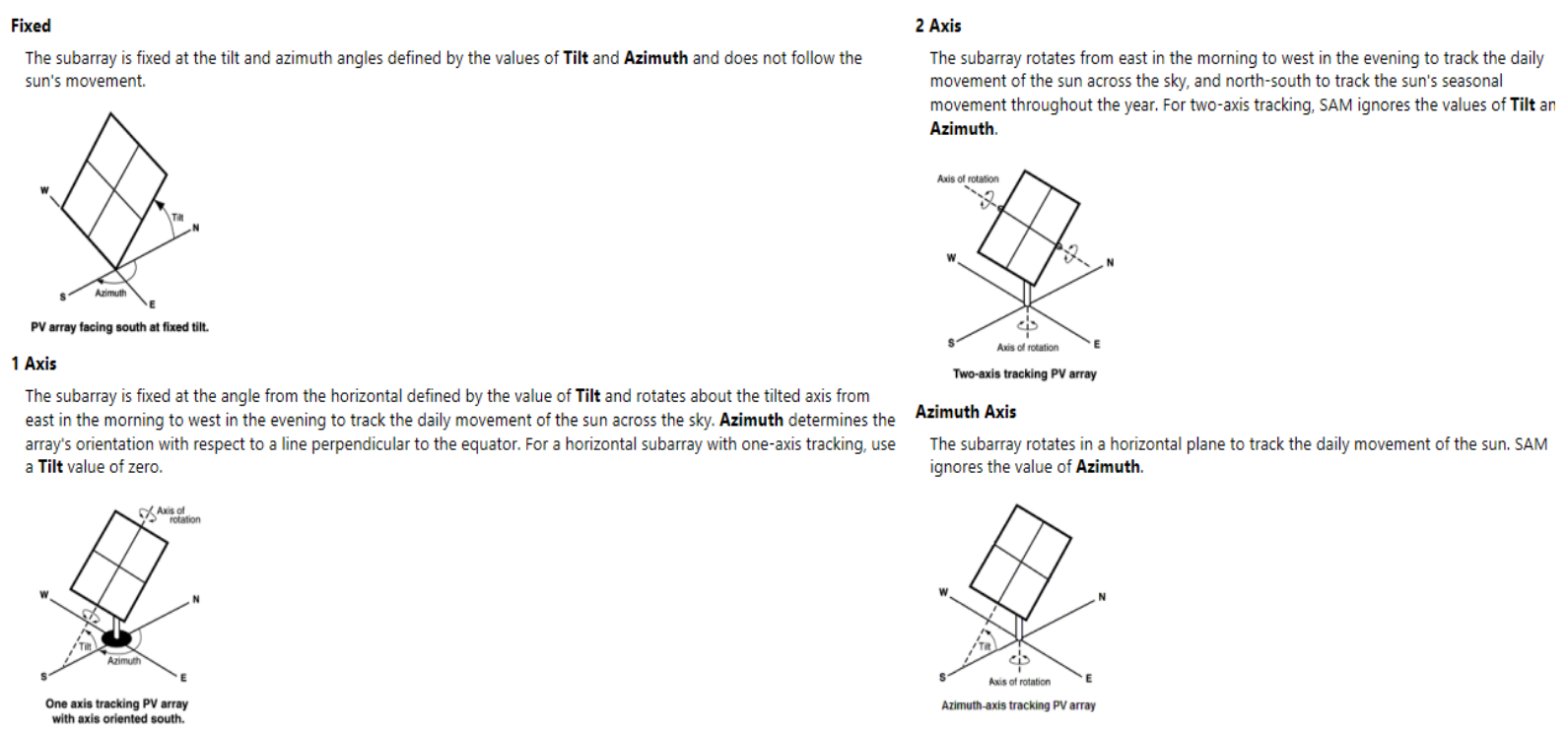

Figure 20. Tracking systems and tilt and azimuth definition. Source: Gilman et al. (2018)

The ground coverage ratio is another important design variable that governs land area usage and module self-shading, as illustrated in Figure 21. 


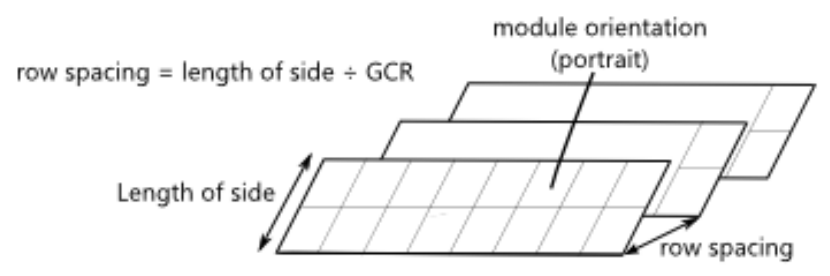

Figure 21. Ground coverage ratio. Source: Gilman et al. (2018)

Other design considerations include:

- Module orientation (portrait versus landscape). The module orientation governs the length of each row and the length of the side of an array, which affects the shadow cast by the array into the next row.

- Row layout (one-up versus two-up). The row layout also affects the length of the side of an array. Rows with only one module will cast a smaller shadow, whereas rows with two or more modules along the length will have larger shadows.

- Bifacial versus monofacial modules. Monofacial modules are those that produce electricity from solar insolation on the front side of the module. Bifacial modules are configured to produce electricity from both the front side and rear side.

- Inverter selection. Inverters are power electronics that convert DC electricity to AC electricity. Each inverter is designed to accept inputs within a certain voltage and power range; therefore, the inverter must be selected with the module string layout in mind. The selection must also be made between different classes of inverters, such as string, central, and microinverters, which offer different benefits and cost trade-offs.

- Module string wiring. PV modules can be wired in series to boost string voltage and added in parallel to boost total capacity. Strings must be designed to conform to the inverter input.

These design variables play a key role in how the system operates, affecting:

- Module shading. PV modules exposed to shading from external objects, including other modules, will experience reduced power output that can vary linearly or nonlinearly as a function of the shadow size, depending on the module type and internal wiring. In utilityscale PV installations, the primary cause of shading is caused by shading from adjacent rows. The row spacing must be designed to simultaneously maximize usage of the land area while minimizing losses from shading.

- Module soiling. PV modules may gather a film caused by dust, pollution, or other particulate matter. This causes reduced insolation and power output.

- Snow coverage. When PV modules are covered in snow, they cannot produce electricity.

- Inverter clipping: 
- AC power limitations. Inverters have restricted AC power capacity. Inputs above the rated capacity are clipped.

- Maximum power point tracker voltage limitations. Inverters have a limited voltage input range. If the voltage input falls below or goes above this range, power loss will occur.

- Module efficiency. The PV module converts irradiance into electricity at an efficiency governed by the properties of the module. Higher efficiency modules can produce more electricity within a fixed land area.

- Inverter efficiency. The inverter converts DC electricity to AC electricity as a function of input power and voltage. At low throughput power, the inverter efficiency is nonlinear and drops precipitously.

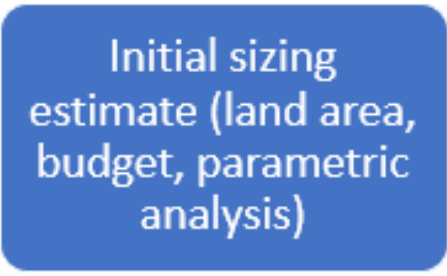

Optimal system

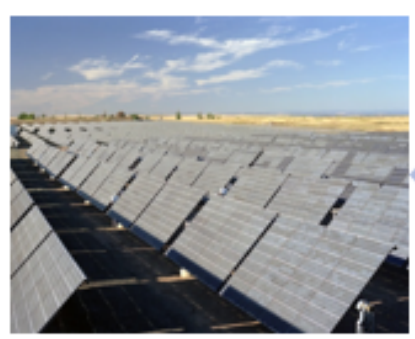

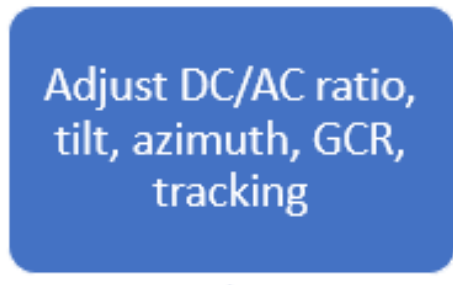
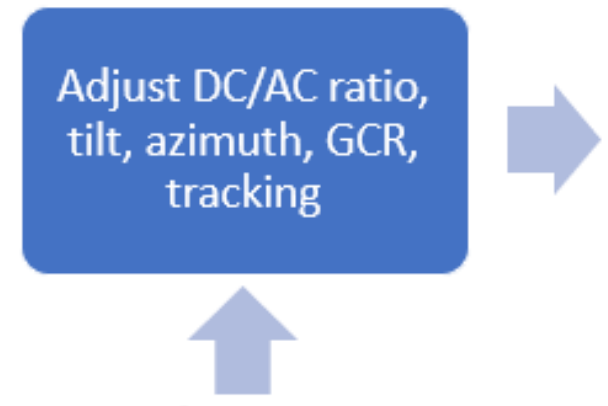

Iterate

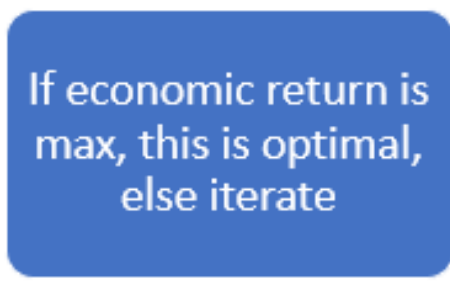

Update system size

if violates land,

budget constraints

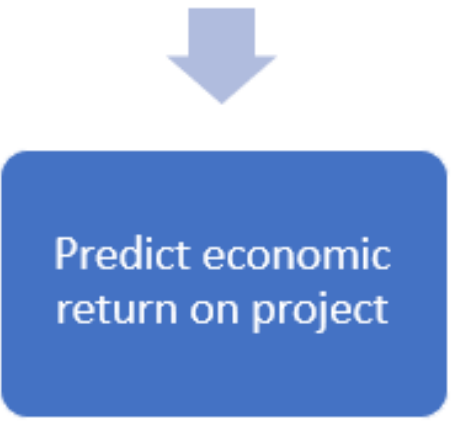

Figure 22. Workflow to optimize PV system design

An example workflow to optimize the design variables is shown in Figure 22, where the general procedure can be determined by:

- Obtain initial sizing estimate based on typical system design assumptions, which are based on land-area, budget constraints, and the desired module and inverter combination.

- Optimize the DC/AC ratio, tilt, azimuth, ground-coverage ratio, and tracking system for that system size by iterating through options, evaluating energy production and value.

- Update the system size if changes to the design require modifying land-area, project budget, or other constraints, and iterate as desired until the overall design converges on an optimal solution. 


\subsection{Example Solar Power Plant Design Case Study}

To illustrate the process of solar power plant design, a powerful toolset is the NREL System Advisor Model (SAM; Blair et al. 2018). SAM is powerful for detailed performance and financial modeling of solar PV, concentrated solar power, and other technologies. It can be used as a site prospecting and preliminary design tool for several technologies with particular emphasis on detailed technical design of a solar power plant (as will be shown). Using timeseries weather data, system specification features including physical layout, and inputs for system losses, SAM can predict the electricity production and costs over time as well as the income from different revenue streams (energy, capacity, incentives) and use them to perform a detailed financial analysis of the system performance for various high-level objectives including LCOE, NPV, payback periods, and more. A general architecture of the SAM tool is shown in Figure 23.

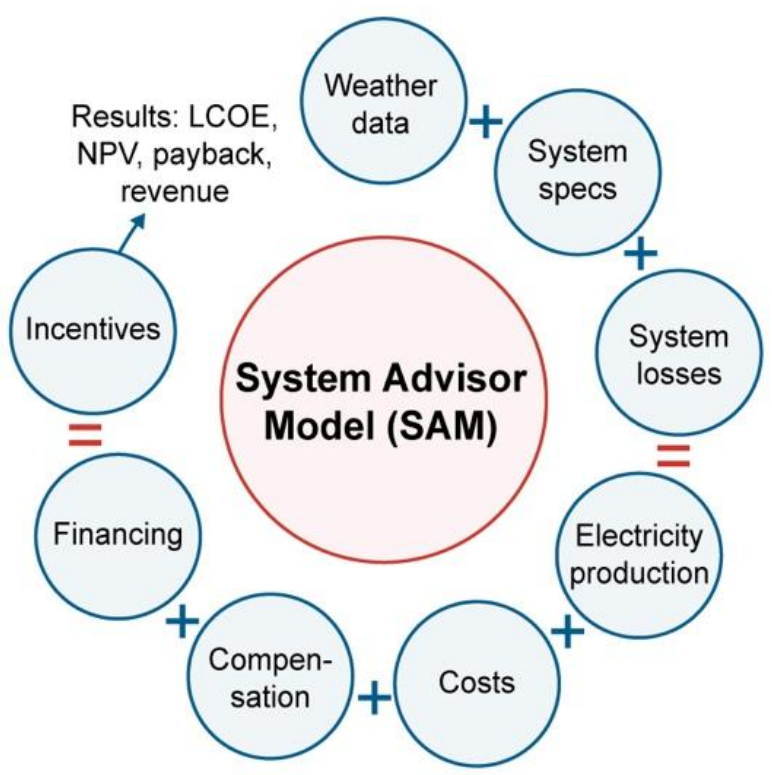

Figure 23. Basic architecture of SAM for preliminary design and site prospecting of renewable electricity generation plants including solar PV, CSP, wind, and more. Source: NREL

SAM will be used to provide an example design of a 20-MW DC PV plant, where the goal is to maximize the NPV in a PPA agreement for a single-owner system. For a given module and inverter, trade-offs for the DC/AC ratio can be considered, as shown in Figure 24. The plot illustrates relatively flat net present value as the DC/AC ratio increases, until a sharp drop occurs above ratios of 1.2. A corresponding increase in inverter clipping is shown, resulting in the tradeoffs of increasing DC capacity without installing additional inverter capacity. 


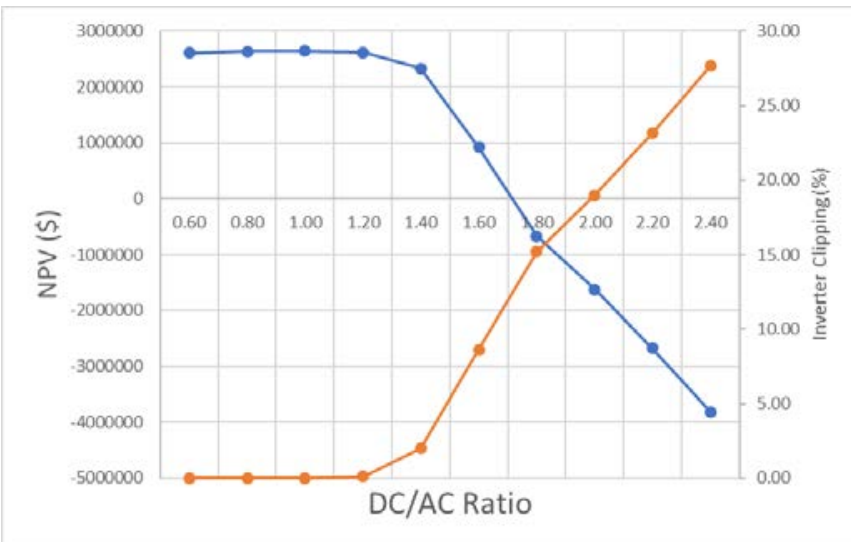

Figure 24. DC/AC ratio optimization

Another key design consideration is the optimization of the tilt angle and whether to install a tracking system. This decision can be made with a similar process, by first considering the optimal tilt angle for a fixed-tilt system, as shown in Figure 25. The NPV is optimized for a tilt of $32^{\circ}$. Comparing the optimal fixed tilt system to a one-axis tracked system is illustrated in Table 3, which shows that for a cost of about $\$ 0.10 / \mathrm{W}$, a one-axis tracker increases annual energy production by $30 \%$ in this case. One additional consideration for tracked systems is the addition of a mechanical component, which requires maintenance, and can be a deterrent for some developers interested in the simplicity of a static system.

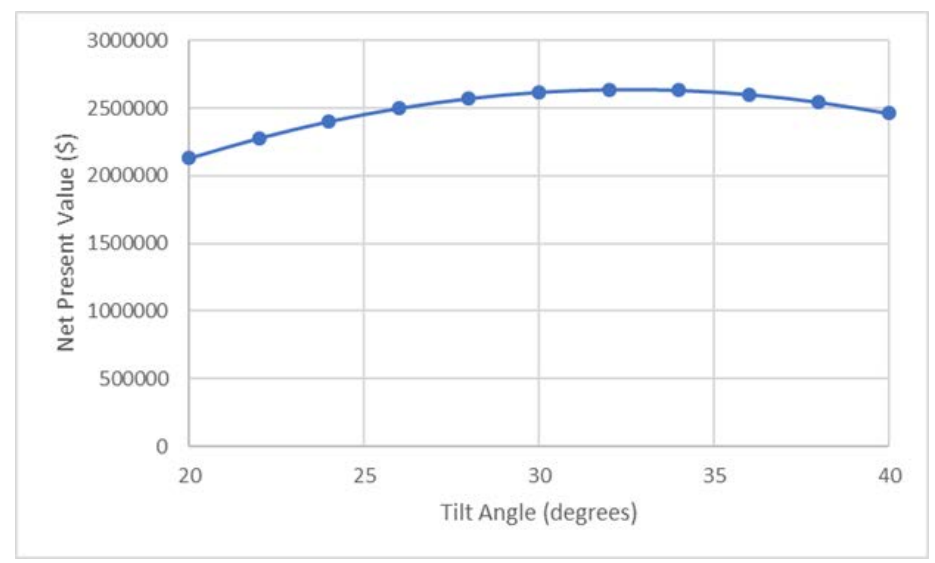

Figure 25. Tilt angle optimization

Table 3. Fixed-Tilt Versus One-Axis Tracked System

\begin{tabular}{|l|l|l|}
\hline & Fixed Tilt & 1-Axis Track \\
\hline Tracking cost & $\$ 0 / \mathrm{W}$ & $\$ 0.10 / \mathrm{W}$ \\
\hline Annual Energy & $37.2 \mathrm{MWh}($ year 1$)$ & 49.0 MWh (year 1) \\
\hline Inverter Clipping & $13.5 \%($ year 1$)$ & $31.1 \%($ year 1$)$ \\
\hline
\end{tabular}

Another design decision is whether to replace monofacial PV modules with bifacial modules, which can capture light on both the front and rear side, potentially boosting plant output with a small additional cost for manufacturing (Stephens 2018; Tillman 2019). Table 4 illustrates an 
analysis considering the energy production of monofacial modules versus bifacial modules with and without tracking systems, illustrating potential gains.

Table 4. Monofacial Versus Bifacial Modules

\begin{tabular}{|l|l|l|l|l|}
\hline & \multicolumn{1}{c}{$\begin{array}{c}\text { Monofacial } \\
\text { Fixed-tilt }\end{array}$} & $\begin{array}{c}\text { Bifacial } \\
\text { Fixed-tilt }\end{array}$ & $\begin{array}{c}\text { Monofacial } \\
\text { 1-axis track }\end{array}$ & $\begin{array}{c}\text { Bifacial } \\
\text { 1-axis track }\end{array}$ \\
\hline $\begin{array}{l}\text { DC Annual Energy } \\
\text { (MWh) }\end{array}$ & 38.4 & 40.4 & 50.6 & $51.9 \mathrm{MWh}$ \\
\hline Energy Gain & $0 \%$ & $5.2 \%$ & $31.7 \%$ & $35.1 \%$ \\
\hline
\end{tabular}

Installing bifacial modules adds more complexity to a project. In addition to optimizing frontside irradiance and energy production, shading of the rear side must be considered, which is affected by multiple factors, including the ground clearance, ground coverage ratio, and module mounting structure. Optimal mounting for bifacial modules is an active area of research (Deline et al. 2017), particularly how to estimate rear shading losses caused by mounting structures and the subsequent mismatch losses because of spatial nonuniformity. Abstracting out these details, it is still possible to consider the ground clearance height and ground coverage ratio, which maximize annual energy and bifacial gain, as shown in Figures 25 and 26.

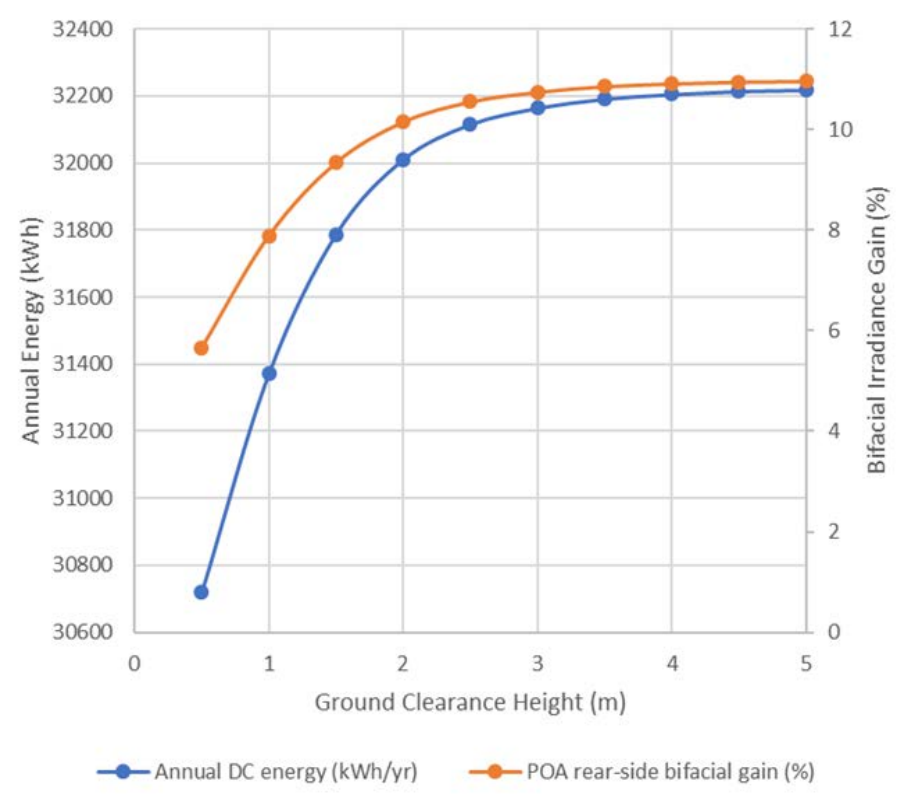

Figure 26. Ground clearance height optimization 


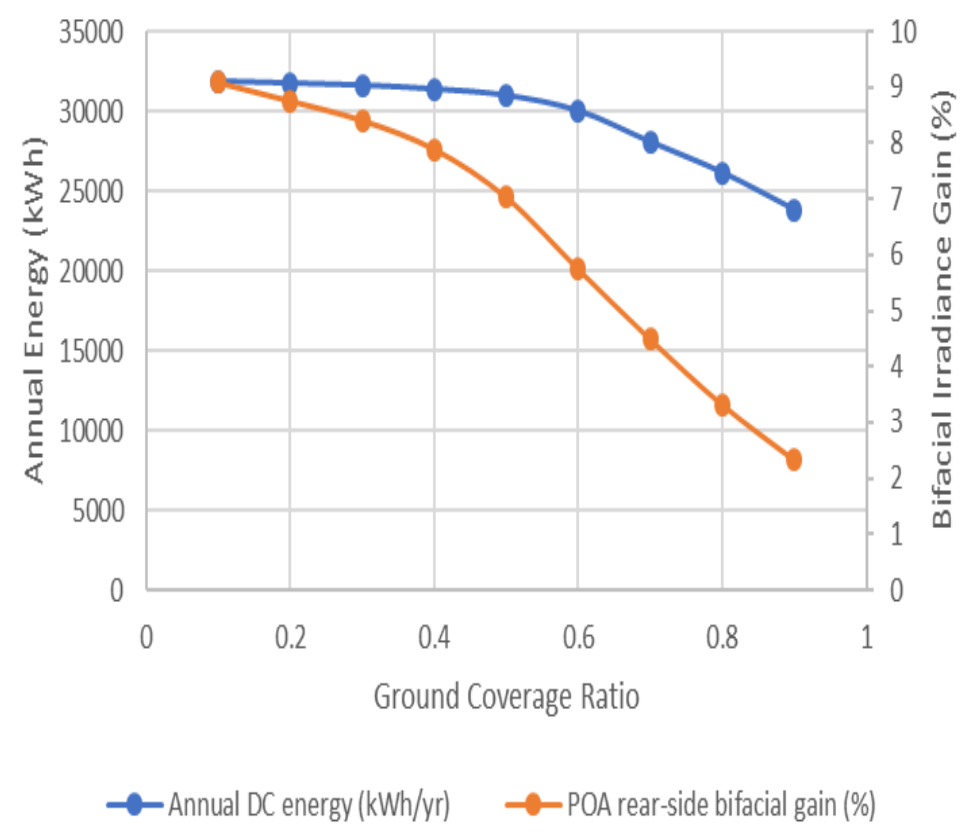

Figure 27. Ground coverage optimization

Mounting bifacial modules higher above the ground result in gain caused by additional ground reflection but must be balanced by the cost and complexity of increasing the mounting structures. Spacing rows out by decreasing the ground-coverage ratio results in less row-to-row shading and a higher bifacial gain but must be balanced by land cost and availability constraints.

Several key design variables have been examined in detail. Practically, there are more design decisions to consider, including module and inverter selection based on cost, efficiency, and compatibility. When optimizing one variable, it is also possible that previously optimized variables need to be updated, leading to the goal of a fully integrated optimization that considers all relevant variables and globally optimizes them. An example of doing this for azimuth, $\mathrm{DC} / \mathrm{AC}$ ratio, and tilt simultaneously is illustrated in Table 5.

Table 5. Multivariate Optimization

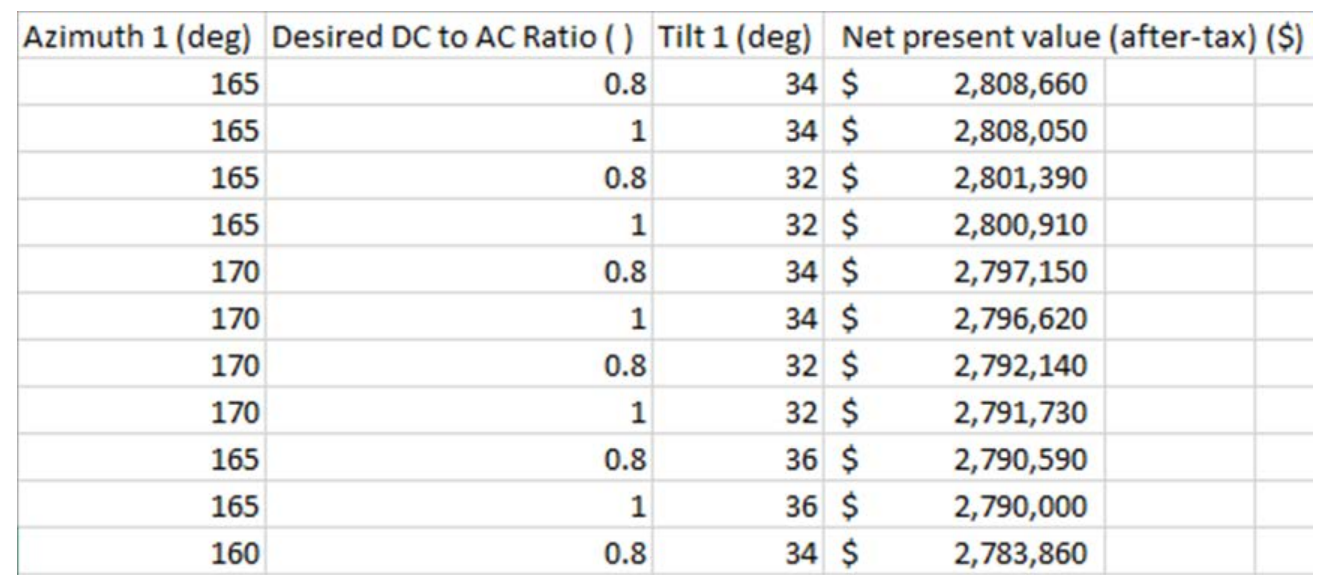




\subsection{Gaps and Limitations in Solar Plant Optimization Models}

Presently, limitations in solar plant optimization are focused on new technologies for which performance models are still emerging and undergoing validation. Bifacial PVs are an emerging area of interest. These modules capture irradiance on both the front and rear side of the module. Optimizing the layout to maximize the total panel power, given constraints on land area, mounting and tracking systems, characterizing the total system production can be challenging. Bifacial modules have not yet been installed in large numbers, but as the technology matures, more systems are expected to emerge (Deline et al. 2017).

Another challenge for solar plant optimization is designing control systems either with or without storage to meet more stringent grid interconnection requirements. PV plants have traditionally not required much, if any, plant level control, simply outputting power to the grid as it is produced. But in high-penetration PV scenarios, integration with the grid may require more stringent control, including the ability to mitigate large ramps up or down, or control voltage and frequency (Gevorgian and O'Neill 2016a; Gevorgian and O'Neill 2016b).

\subsection{Solar PV Plus Storage}

Solar plus storage plants are not hybrid power plants, as only one generation source is present. However, they are a step in the direction toward hybrid power plants and have recently received a significant amount of attention from the industrial development community. Solar PV plus storage plants are typically designed to maximize the value to the system owner while operating within requirements set forth by the utility for grid interconnection. Resilience to utility power outages has been another design objective of interest, primarily for isolated grids or commercial buildings (Laws et al. 2018). While multiple design objectives and value streams have been discussed (Eyer et al. 2010) for these systems, utility-scale PV plus storage systems primarily rely on energy value (typically through PPAs) and capacity value with some ancillary service markets available. Denholm et al. (2017) provided four categories of solar with storage power plants: (1) no point of common coupling, (2) AC coupled only, (3) DC coupled with a bidirectional inverter, and (4) DC tightly coupled with a DC-AC-only converter. In the last two cases, the distinguishing factor is whether the storage system can store both grid and PV electricity or only the PV-generated electricity, see Figure 28 (Denholm et al. 2017). 


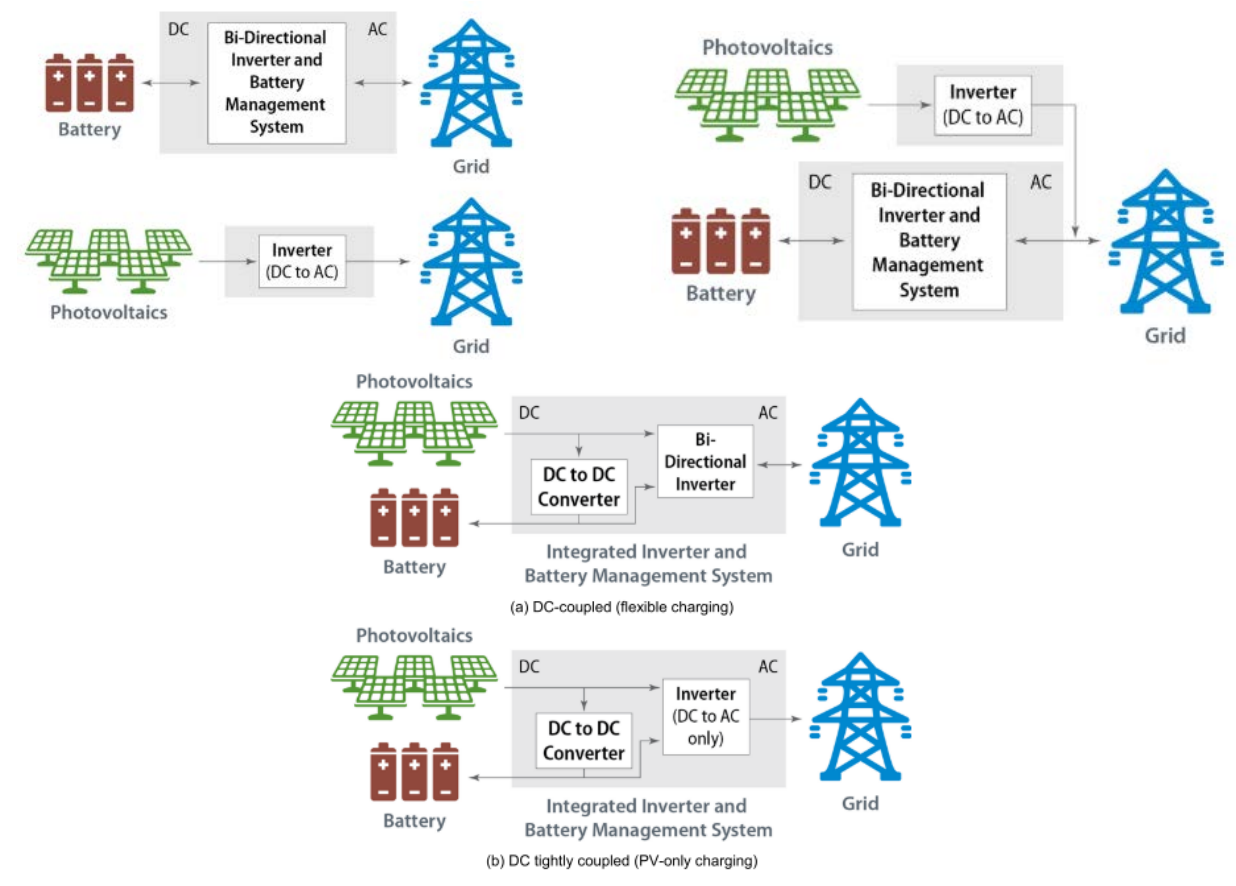

Figure 28. Coupling architectures of solar with storage systems (left) independent coupling, (center) AC coupling, (right) DC coupling. Source: Denholm et al. (2017)

Design of solar plus storage plants is tightly coupled with the optimal sizing and operation described in Section 3. In addition to the design variables previously discussed for stand-alone solar plants, fundamental design decisions for solar PV plus storage plants include:

- Solar DC capacity. The number of modules in the system, which is driven by cost and the desired operation of a plant. If it is valuable to maximize the interconnection capacity factor, the system may be oversized on the DC side to generate more power during offpeak hours and clip or store the power during hours of overproduction, relative to the inverter capacity.

- Solar AC capacity. The inverter capacity in the system. Typically, less than the DC capacity in the system and driven by the cost of modules, inverters, and the energy sell rate. Limits the amount of power that can be exported to the grid.

- Storage power. The maximum sustained power capacity from the storage system for charging and discharging. Governs how much power can be captured from excess PV production or how much power can be delivered to the grid.

- Storage duration. The amount of time the battery can discharge at the maximum sustained power capacity. Different use cases require different storage durations. Storage duration is important for determining capacity value (Denholm and Margolis 2018).

- Coupling architecture. Multiple distinct architectures have emerged in solar plus storage system design, each of which has advantages and disadvantages. Recent analysis on solar plus storage configuration cost, operation, and value has been completed $(\mathrm{Fu}$, Remo, and Margolis 2018; DiOrio et al. 2020; Denholm et al. 2017). 
- AC coupled. In an AC-coupled system, the battery is connected to the PV on the AC-side, requiring its own bidirectional inverter to charge and discharge.

- DC coupled. In a DC-coupled system, the battery is connected to the PV on the DC side through a DC/DC charge controller, allowing the battery to charge from otherwise clipped PV power and to share the PV inverter.

- Charging source. Under existing rules (Elgqvist et al. 2018), the storage component of a solar plus storage system can capture the federal investment tax credit (ITC) if it charges from PV. The system can qualify for a reduced portion of the credit if some charging is done by the grid.

Gaps in modeling solar plus storage systems for large-scale systems include correctly capturing battery degradation as a function of cycling and calendar life, modeling battery dispatch while conforming to commercially available controller limitations and modeling different configuration options within the same modeling platform.

\subsection{Hybrid Power Plant Design}

The physical design of a hybrid power plant entails all the complexity of the design of single technology plants, as described earlier, with additional complexity from the interaction between the technologies. In terms of a spectrum of such designs, one extreme are virtual hybrid power plants that are not co-located and share no infrastructure. Design of these plants is akin to doing individual wind plant optimizations, as described earlier. On the other extreme, a hybrid power plant of interwoven wind and solar assets can be envisioned; where there is potential shading of the solar panels by the turbines and where the electrical collection on a DC bus interconnects both solar panels and wind turbines interchangeably with, potentially, storage as well. In between, hybrid power plants may share only some interconnection to the larger grid system or a coupling only on the AC-side of the network. Little research exists to date on physical design of hybrid power plants, and the next section provides a basic overview of prior work.

\subsubsection{Research in and Software Tools for Physical Design Optimization of Hybrid Power Plants}

The following discussion will focus on solar PV and wind energy-based hybrid power plant design optimization, with a follow-up discussion about extensions to other types of hybrid power plants.

As mentioned in Section 3, most of the research to date on hybrid power plant design optimization has focused on technology selection and capacity sizing of the different technology elements (see again Nema et al. [2009] and Badwawi et al. [2016] for extensive reviews). The applications focus largely on distributed energy systems or even off-grid, stand-alone systems. This uses different optimization approaches and problem formulations, as compared to utilityscale solar (with or without storage) and wind power plants. However, moving toward the question of physical design of hybrid power plants, including wind and solar PV, there are aspects of each approach that can be leveraged as well as new challenges that must be addressed. Figure 29 provides an overview of the main elements feeding into the hybrid power plant design optimization process. 


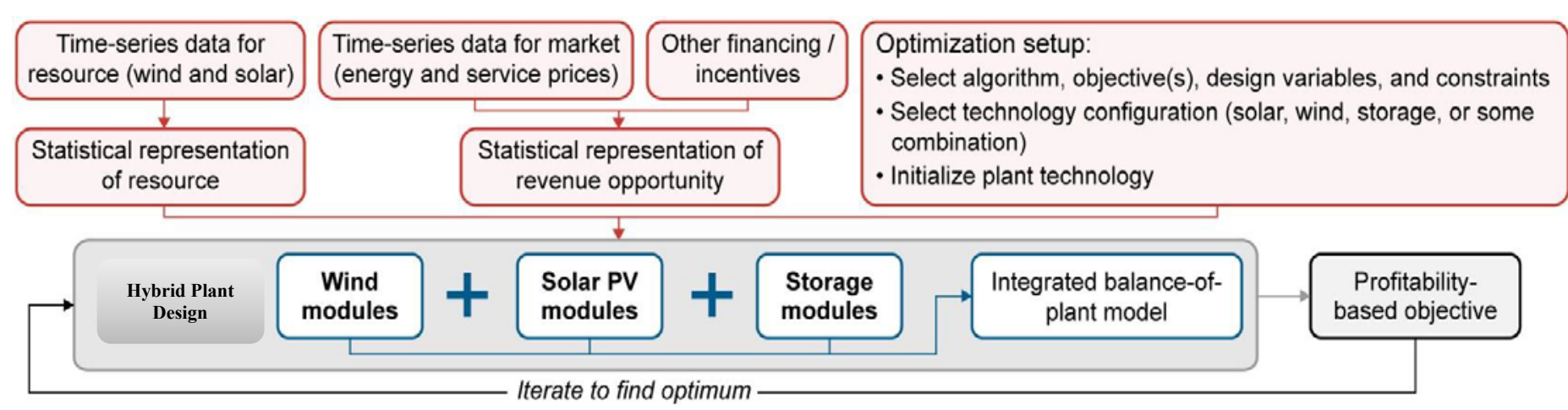

Figure 29. Generic elements of a hybrid wind and solar PV design optimization problem formulation. Source: NREL

The main components of the optimization include the resource and revenue opportunity space, technology performance and cost modules for each generation technology, the BOS plant infrastructure, and operations and maintenance. The overall optimization problem formulation using these components is then specified in terms of design variables, constraints, objective(s), and workflow architecture. Each of these major elements of the design process is next discussed in more detail, comparing and contrasting approaches for technology selection and sizing with physical design needs.

\subsubsection{Resource and Revenue Considerations}

The most critical design inputs for considering hybrid power plant design at a given site are a characterization of the potential resource from the different energy technologies and the potential revenue streams available, based on the local market conditions. For resources, the joint probability distribution of the solar and wind energy resource at a particular site is needed. Significant work has gone into the characterization of solar and wind energy resources around the globe to produce both statistical data as well as to provide historical and synthetic time-series data that can be used for site resource assessment (Draxl et al. 2015; Global Wind Atlas 2018; Blair et al. 2017). However, little work to date has been done to explicitly derive joint probability distributions across resources. Sizing tools, such as REopt, use time-series data (at a range of temporal resolutions) and so on, implicitly account for the complementarities of the resources at a given site. For solar plant design, SAM similarly uses representative time-series data to do full production analysis over time with some levels of automation in the design process. For wind power plants, on the other hand, the complex nature of the internal flow of the plant and turbine responses require the use of distilled statistics around the wind resource in the form of wind roses to make the optimization problem of the layout design tractable.

For physical design of hybrid power plants that integrate wind, solar PV, and potentially storage, a harmonization across these approaches is needed. This could take the form, as in WISDEM, of using joint probability density functions (PDFs) for wind energy and extending these to more dimensions to create a PDF across the resources either annually or broken down by season or by month. Such analysis could include auto-correlation aspects within or across the resources as well. Another approach could be to use time-series binning similar to REopt but to include the dimension of wind direction and other key parameters that are used in physical design of wind power plants. However, the resolution of such binning practices would need to be very low to 
limit the number of input cases to something tractable for the optimization. As an alternative, representative time slices could be used to bookend a range of exemplary performance cases, and again these could be subdivided by time of year. Finally, some combination of these approaches could be used (i.e., a general joint PDF for certain revenue streams and representative time slices to address others).

The time dependence of the resource availability is particularly important to hybrid power plant design for considering the revenue potential for the plant. Assuming the plant is small relative to the overall system, the market conditions can be treated as exogenous (though they will likely change over time, introducing a source of uncertainty into the optimization process, which will be discussed later in the optimization problem formulation). The approach in hybrid power plant sizing tools such as REopt, which have historically focused more on distributed generation, is to use actual time-series data for available capacity, energy, and service revenue streams (Cutler et al. 2017). For utility-scale solar and wind energy, SAM takes a similar approach for distributed generation and for utility-scale systems assumes a PPA type of structure with potentially added revenues related to time-of-delivery factors (Blair et al. 2017). WISDEM and most wind power plant design optimization tools assume a very simple PPA structure with no variation in revenue over time, and often the objective function for the design is thus reduced to LCOE, which still creates a complex optimization for the detailed design consideration, (as in Fleming et al. 2015).

For hybrid power plant design, time slices of data may be intractable; conversely, LCOE is oversimplified and would not lead to the optimal design from an overall profitability perspective. In conjunction with the resource data, the options again span from a completely statistical approach of complex joint PDFs for wind, solar, and revenue opportunities to a completely timeseries-driven approach (either with binning or representative time slices). The former may be very difficult to construct in and of itself, and then still difficult to apply within a design optimization context, while the latter may produce too many cases to perform a tractable optimization. It is possible that some combined approach, which uses a limited set of cases based on statistics and time-series data, would be tractable from a computational standpoint and also drive to designs that have significantly improved profitability over classic LCOE-optimized power plants.

\subsubsection{Wind, Solar, and Storage Modeling}

Detailed overviews of the approach to solar and wind power plants in SAM and WISDEM, respectively, were provided in the previous section. The key differences between basic sizing of capacity and detailed physical design are in the level of fidelity for the technical representation of the system. While on the one hand, models used for solar and wind power plant design optimization are not seen as high fidelity from the perspective of detailed technical analysis of those systems - for instance, they do not address the dynamic behavior of the systems - they are far more detailed than the models for the technology used in sizing, which largely exclude the physical couplings within the plant (e.g., shading between solar panels or wake losses from upstream to downstream turbine rows). To do physical design, these elements are essential and must be included in the hybrid power plant design optimization.

The introduction of wind and solar technologies at a single site introduces additional couplings that must be considered. De Azevedo and Mohammed (2015) developed a relatively detailed model of the effects of tower shadow from the wind turbines that was time invariant. Modeling 
of the shading of the panels from the turbines and their blades need to be considered for closely co-located wind turbines and solar panels. In addition, there may be additional need to address the shadow flicker from the turbines in operation. Shadow flicker caused by dynamic shading from rotating turbine blades is already a significant design consideration in terms of visual impacts from wind power plants, but now it is necessary to consider the additional impact of the dynamic shading on the actual plant performance of any impacted solar panels. Otherwise, the interaction of the technologies is limited to the actual electrical system.

\subsubsection{Integrated BOS Model (and Operations)}

Coupling of hybrid systems within the electrical system and its collective performance and associated control strategies is one of the most important considerations for ongoing research and design optimization of hybrid power plants. Operation and control of hybrid power plants will be discussed in more detail in the next section. From a design perspective, the selection of the overall topology of the plant should come first, which may include coupling of the various technologies on the AC or DC side of the system. Given the fundamental impact of the decision, it is likely that this will be decided prior to initiating the detailed design. Based on this, then, there will be different resulting potential strategies for developing the collection system for the full hybrid power plant including solar, wind, and storage technologies. Potential architectures (extending those discussed for solar PV with storage plants, as described in Denholm et al. [2017]) include:

1. No point of common coupling: all subsystems have independent interconnection to the larger grid system.

2. AC coupling of all technologies: subsystems have a point of common coupling on the AC side within the power plant, which allows for energy management of the battery system in response to solar and wind subsystem performance. This allows wind and storage technologies to more easily supply or consume reactive power as needed.

3. DC coupling (loose or tight) of the solar with storage and either no point of common coupling or AC coupling of the wind plant: this option reflects existing wind energy power plant technologies where significant retrofits would need to be done to allow DC coupling, whereas a more straightforward coupling can be done for solar and storage.

4. DC coupling (loose or tight) of all technologies: this option reflects the ability to couple all technologies in the plant on a DC bus, which would require wind turbines to separate the current functionality of fully rated converter types between the AC/DC inversion and $\mathrm{DC} / \mathrm{AC}$ inversion.

5. Another important distinction here is whether the power plant is land-based or offshore. For the previous discussion, we are assuming land-based systems, because offshore hybrid power plants would likely involve other technology combinations (for example, wind and wave energy).

Once the architecture is selected, the optimization of the infrastructure must be done in coordination with the rest of the plant design. For example, for LCOE optimization it is critical to balance the cost and performance of the electrical collection system (minimizing losses as well as equipment and installation costs) with the performance and costs of the generation and storage assets (maximizing revenue through energy production with minimal losses from wake effects 
and shading). For the latter, turbines should be spaced quite far apart to minimize the losses from turbines shading the panels and from producing wake losses, whereas from the former perspective, infrastructure costs can be lowered by reducing the intertechnology spacing as much as possible. Moving to broader profitability objectives associated with hybrid power plants, this is further complicated by the need to enable the plant to maximize its various revenue streams over time while also still minimizing capital and operational expenditures. This topic is directly tied to the plant control and operation, and the design needs to consider these downstream operational considerations, which are still an active area of research themselves, as will be discussed in the next section.

Beyond the electrical infrastructure, there are other potential design considerations around roads, development processes, installation, operations and maintenance, and other areas where there may be synergies if addressed as part of the upfront design process.

\subsubsection{Optimization Problem Formulation}

An optimization problem formulation includes the specifics of design variables, nondesign input parameters, constraints, and objectives, as well as the overall architecture of the workflow and the algorithms used. Wind power plant design problems are multidisciplinary design optimization problems that are difficult because of the size of the problems (potential number of design variables and constraints) and their scope (the number of different disciplines involved). Integrated wind and solar power plant design together (potentially with storage) further complicates this.

First, the design variables must be specified. For sizing models, the design variables are focused on technology selection (potentially within a category; i.e., what types of solar panels, wind turbines, or battery storage) as well as the capacity sizing of those assets. Further, REopt provides a recommended optimal operating strategy of those assets over time (Cutler et al. 2017). However, for physical design, the focus is less on the selection of the technology elements (those may come from REopt, for example) and more on the exact configuration of those elements in the plant, as previously discussed, the placement of wind turbines and panels. The number and type of these elements could also be part of the detailed optimization rather than part of the sizing step. In addition, the optimization of the electrical infrastructure includes the overall network topology of the collection system. Beyond the hardware, control parameters associated with the technologies may also be included in the design optimization, such as the wake steering example described in detail earlier. For a hybrid power plant where the dynamic operation of the whole system is the source of value creation, the control strategy in the upfront design process is critical. However, given that research on hybrid power plant control is still in early stages of development, it may limit the ability of adequately addressing control strategy in the system design.

One designer's constraints are another designer's objectives. There are often multiple objectives in a system design process, and some can be treated as constraints in a single objective optimization problem. Typically, the overall objective has to do with the highest-level aggregation of system performance and cost into a single global metric: LCOE (as in WISDEM), or other profitability metrics such as NPV, payback period, and more (as in SAM and REopt). Constraints can be numerous and may include the plant perimeter, exclusion zones within the 
plant, minimum or maximum spacing, limitations on the technology usage (i.e., loading of turbines at a specific location), and more.

Finally, the optimization workflow and algorithms must be considered. In a well-architected optimization problem formulation, the workflow and selection of algorithms are tied to the specific application and its characteristics. In a problem with a few low-fidelity models, few design variables and constraints (and where the models are well constructed without significant sources of discontinuities, and so on), then a monolithic workflow (solving all disciplines at once with a single global objective) with a gradient-based optimizer will work well. For a model with many disciplines with loose coupling and lots of design variables and constraints, a workflow that includes suboptimizations may be more appropriate. If there is potential for many local solutions or if the models are not differentiable, then a gradient-free or multistart approach may also be preferred. The effectiveness of different methods is closely tied to the structure of the problem and the embedded models.

For technology selection and sizing of hybrid power plants, as in REopt, problem formulations are typically available that can be classified as mixed integer linear programming, similar to what is used by unit commitment and dispatch models at a systems operation level. These problems are typically solved as one monolithic workflow rather than involving embedded suboptimizations. On the other hand, wind plant layout design optimization is highly nonlinear and can thus be classified as a nonlinear programming (NLP) or mixed-integer nonlinear programming (MINLP). In addition, depending on the submodels involved, wind plant layout optimization problems are typically not fully differentiable across all models, and gradient-free methods, including heuristic and metaheuristic methods, are often used (though there is a growing body of research that applies gradient-based methods to wind plant design; see Ning et al. [2019] for more detail on both). Finally, as shown in the workflow from Perez SanchezMoreno et al. (2017), often there are design subprocesses in wind plant optimization that can be decoupled and allow for suboptimization of some subsystems (in that case the electrical collection system design and the monopile sizing). For solar power plant design, approaches (like that taken in SAM) often do not use explicit optimization, because the smaller number of design levers and the relative ease with which design subprocesses can be decoupled lends itself to a manual design approach (see the previous case study for solar PV power plant design).

For optimization problems, the most complex aspect of the problem formulation drives the design of the workflow and choice of algorithms. Thus, because wind power plant design problems are NLP or MINLP, then hybrid power plant physical design optimization will fall into one of those categories as well. Depending on whether discrete choices are included (such as number of turbines, solar panels, and collection cable strings), then the problem will be MINLP and require either gradient-free techniques or some mixture of gradient-based and gradient-free techniques (see Graf et al. [2016] for an example of the latter where turbine types [discrete variables] and locations [continuous variables] were included in the optimization).

Table 6 provides an overall summary of the typical approaches and opportunities for hybrid power plant physical design optimization. 
Table 6. Overall Characteristics of Technology Selection, Sizing, and Design of Wind, Solar, and Wind-Solar Hybrid Power Plants

\begin{tabular}{|c|c|c|c|}
\hline $\begin{array}{l}\text { Design Process } \\
\text { Elements }\end{array}$ & $\begin{array}{l}\text { Current Practice for } \\
\text { Single Technology } \\
\text { and Hybrid Power } \\
\text { Plant Sizing }\end{array}$ & $\begin{array}{l}\text { Current Practice for } \\
\text { Single Technology } \\
\text { Physical Design } \\
\text { Optimization }\end{array}$ & $\begin{array}{l}\text { Potential Approach for } \\
\text { Hybrid Power Plant } \\
\text { Physical Design } \\
\text { Optimization }\end{array}$ \\
\hline Input Data: Resource & $\begin{array}{l}\text { Time-series data with } \\
\text { variable bin resolution } \\
\text { (for a representative } \\
\text { year) }\end{array}$ & $\begin{array}{l}\text { Statistical model of key } \\
\text { resource parameters } \\
\text { (i.e., for wind: speed and } \\
\text { direction joint PDF) }\end{array}$ & $\begin{array}{l}\text { Limited cases that reflect } \\
\text { temporal dependencies } \\
\text { but also bulk statistics }\end{array}$ \\
\hline Input Data: Resource & $\begin{array}{l}\text { Time-series data with } \\
\text { variable bin resolution } \\
\text { (for a representative } \\
\text { year) }\end{array}$ & $\begin{array}{l}\text { Single power purchase } \\
\text { price (with limited } \\
\text { options of extension) }\end{array}$ & $\begin{array}{l}\text { Limited cases that reflect } \\
\text { temporal dependencies } \\
\text { but also bulk statistics }\end{array}$ \\
\hline $\begin{array}{l}\text { Technical Models: } \\
\text { Solar, Storage, and } \\
\text { Wind }\end{array}$ & $\begin{array}{l}\text { Simplified parametric } \\
\text { representations of } \\
\text { technology } \\
\text { performance and cost }\end{array}$ & $\begin{array}{l}\text { Detailed physical models } \\
\text { of the technologies for } \\
\text { cost and performance }\end{array}$ & $\begin{array}{l}\text { Detailed physical models } \\
\text { of the technologies for } \\
\text { cost and performance } \\
\text { including interaction } \\
\text { effects (i.e., turbine } \\
\text { shading of panels) }\end{array}$ \\
\hline $\begin{array}{l}\text { Technical Models: } \\
\text { Balance of Plant and } \\
\text { Operations }\end{array}$ & $\begin{array}{l}\text { No or highly simplified } \\
\text { parametric } \\
\text { representation of } \\
\text { infrastructure and } \\
\text { operational costs }\end{array}$ & $\begin{array}{l}\text { Broad range of fidelity in } \\
\text { terms of modeling the } \\
\text { infrastructure and plant } \\
\text { operations }\end{array}$ & $\begin{array}{l}\text { Important to adapt } \\
\text { existing single } \\
\text { technology models for } \\
\text { hybrid power plant } \\
\text { implementations with } \\
\text { various topologies of } \\
\text { coupling in the plant } \\
\text { collection system }\end{array}$ \\
\hline $\begin{array}{l}\text { Optimization } \\
\text { Problem } \\
\text { Formulation: Design } \\
\text { Variables }\end{array}$ & $\begin{array}{l}\text { Technology types, } \\
\text { capacity sizing and } \\
\text { operational strategy }\end{array}$ & $\begin{array}{l}\text { Technology types, } \\
\text { number, placement, } \\
\text { interconnection } \\
\text { topology, control } \\
\text { strategy, and more }\end{array}$ & $\begin{array}{l}\text { Technology types, } \\
\text { number, placement, } \\
\text { interconnection } \\
\text { topology, control } \\
\text { strategy, and more (for } \\
\text { all technologies) }\end{array}$ \\
\hline $\begin{array}{l}\text { Optimization } \\
\text { Problem: Design } \\
\text { Constraints and } \\
\text { Objectives }\end{array}$ & $\begin{array}{l}\text { Objectives on } \\
\text { profitability (like NPV) } \\
\text { as well as potentially } \\
\text { resiliency and other } \\
\text { factors. Constraints on } \\
\text { sizing and operation of } \\
\text { the different technology } \\
\text { components. }\end{array}$ & $\begin{array}{l}\text { Objectives on LCOE } \\
\text { typically. Locational and } \\
\text { technology usage } \\
\text { constraints. }\end{array}$ & $\begin{array}{l}\text { Objectives on } \\
\text { profitability (like NPV). } \\
\text { Locational and } \\
\text { technology usage } \\
\text { constraints. }\end{array}$ \\
\hline $\begin{array}{l}\text { Optimization } \\
\text { Problem } \\
\text { Formulation: } \\
\text { Workflow } \\
\text { Architecture and } \\
\text { Algorithms }\end{array}$ & Monolithic MILP & $\begin{array}{l}\text { Monolithic (mostly) NLP } \\
\text { or MINLP (can include } \\
\text { suboptimizations that } \\
\text { are typically NLP) (both } \\
\text { gradient-based and } \\
\text { gradient-free) }\end{array}$ & $\begin{array}{l}\text { Monolithic (mostly) NLP } \\
\text { or MINLP (can include } \\
\text { suboptimizations that } \\
\text { are typically NLP) (both } \\
\text { gradient-based and } \\
\text { gradient-free) }\end{array}$ \\
\hline
\end{tabular}

Finally, the entire previous discussion assumed that the optimization involved deterministic information. However, uncertainty is rampant in almost all design optimization problems and is highly relevant for technology selection and sizing and physical design of hybrid power plants. Sources of uncertainty include the resources themselves, the potential revenue streams, and aspects 
of technology performance and cost over time. Including all sources of uncertainty would result in intractable problem formulations, but robust designs will likely require addressing some of the aspects of uncertainty in the design process. Such problems, known as optimization under uncertainty (OUU), or robust design optimization problems, include an uncertainty analysis and quantification method within the optimization to produce statistics that can be used to evaluate the objective function and/or various system constraints (see Quick et al. [2017] for an example of OUU applied to wind power plant control strategies). OUU applied to design optimization for renewable systems is an active area of research, and while it is necessary first to address issues associated with hybrid power plant physical design from a deterministic perspective, it will be important to quickly bring uncertainty into the design process to ensure the overall success of the developed designs.

\subsubsection{Other Hybrid Power Plants}

The previous discussion focused entirely on solar PV and wind power plants and hybrids created from the integration of these technologies (also including battery storage technology). However, there a wide variety of potential utility-scale hybrid power plant configurations, as discussed previously, that may include hydropower of various forms (including pumped hydropower), geothermal, CSP, biomass, and others. Hybrid power plants may even include nonrenewablebased electricity generation facilities such as natural gas, coal, or even nuclear power plants. Examples of some promising combinations (CSP and geothermal, solar PV and CSP, wind and pumped hydro, and wind-diesel power plants) were discussed in the previous section. In contrast to solar PV and wind energy, some of these technologies (including hydropower and geothermal power plants) are very site-specific and do not lend themselves as easily to general optimization frameworks. However, if coupling solar PV and wind energy to these plants, their performance parameters in terms of enabling energy shifting, increasing capacity value, or providing services, can be brought as inputs into the overall optimization process for the solar PV and wind power plant elements. In addition, there may be economies of scope to gain from integrated collection systems, operations, and other plant features that are worth investigating. These various combinations deserve a comprehensive analysis in and of themselves and present a good opportunity for follow-up studies. 


\section{Hybrid Power Plants Control and Operation}

In order to ensure that hybrid power plants meet performance and profitability objectives once they are deployed, it is important to understand their potential from a controls and operation perspective. Wind power plant controls has been a very active area of research over the last several years, and now there is a growing interest in hybrid power plant operations, which includes solar, and potentially storage technology, as well. The physical design of hybrid power plants needs to consider how that plant will perform with respect to controls and operation once built.

\subsection{State of the Art in Wind Power Plant Control}

Wind turbines are sited together for economic advantages, including reduced deployment costs, reduced grid interconnection costs, reduced land use/environmental impacts, and operation and maintenance costs (Boersma et al. 2017). However, siting turbines close together has adverse effects, including aerodynamic interactions between turbines. These aerodynamic interactions are known as wakes. Turbines operating in wakes experience reduced velocities and higher levels of turbulence generated by upstream turbines. This leads to lower power production and increased structural loading at downstream turbines.

Turbines operate individually to optimize their own performance by maximizing power and minimizing loads individually without considering these aerodynamic interactions. However, this type of operation has been shown to be suboptimal for the wind plant. Wind plant level controls aims to operate upstream turbines suboptimally to improve the performance of the wind plant. This includes increasing the power production in a wind plant, reducing dynamic structural loads on turbines, and providing grid services including active power control, frequency control, and power reference tracking.

The most popular type of wind plant controls is maximizing power output of a wind plant. One variant of this type of control that has gained increasing attention in recent years is wake steering. Wake steering is achieved by purposely misaligning the upstream turbine with respect to the inflow wind direction. This action deflects the wake away from downstream turbines and is achieved by yawing, tilting, or pitching the upstream turbine (Fleming et al. 2014). Figure 30 shows an example of a normal operating wind plant (top) and a wind plant with turbines operating in yaw misaligned conditions. In this example, the power may be improved by over $10 \%$.

Next, many wind plant owner/operators are seeking out ways to extend the lifetime of turbines. The lifetime of the turbine is determined by dynamic/fatigue-critical loads (Kanev, Savenjie, and Engels 2018; Soleimanzadeh et al. 2011). The upstream turbine can be operated to minimize turbulence in the wake at downstream turbines, thus reducing the aerodynamic loading on downstream turbines. This type of control is known as axial induction control and is achieved by adjusting the generator torque or the blade pitch angle of the turbines, which are standard inputs to the individual turbine controller. 
Finally, wind-plant-level controls can be used to provide grid services that balance total power generated with the variable electrical demand. As wind penetration increases, wind power plants will need to be able to provide these grid services. These services include frequency control, active power control, and so on. Wind can also provide inertia to the grid caused by the large rotating rotor. These services improve the performance of the grid and increase the reliability of the grid, especially in the face of large amounts of variable resources on the grid. Automatic generator control (AGC) has been studied extensively in the literature (van Wingerden et al. 2017). Typically, this means following a power reference signal provided by a transmission system operator. Several studies have shown that wind plants can follow these power reference signals as a whole (van Wingerden et al. 2017; Vali et al. 2018; Bay et al. 2018), demonstrating that when needed, wind plants can provide these services reliably. Wind plants have fast response times, unlike large baseloads like coal and nuclear, which makes wind, along with solar, an ideal candidate for providing frequency response services. The success of these strategies hinges on the ability to reliably estimate the total power available in a wind plant as well as the power available in the near future. Several studies have been conducted on how to optimally distribute the setpoints to each turbine to meet the power reference signal commanded by the transmission system operator.

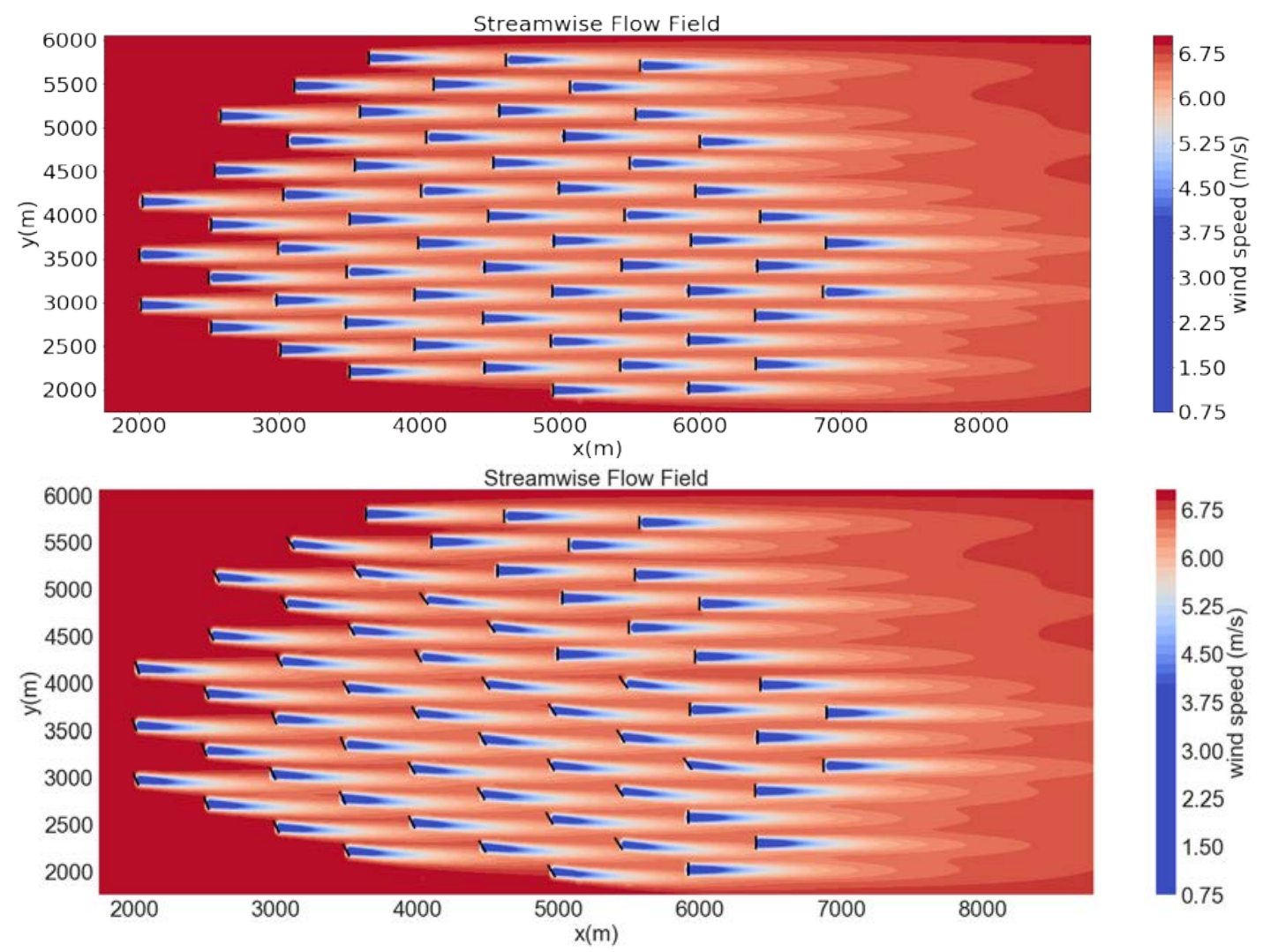

Figure 30. Example of wind-plant-level controls. The top plot shows turbines operating under normal conditions (i.e., each turbine is operating individually to maximize its performance). The bottom plot shows some of the turbines operating in misaligned conditions. These conditions are suboptimal for the individual turbine, but the power production of the whole wind plant can be increased by more than $10 \%$. 


\subsection{State of the Art in Solar Power Plant Control}

Solar plant control has traditionally not been a focus in commonly available tools (e.g., PVSyst, PV*SOL, SAM), with the exception of the ability to simulate curtailment or restrict plant AC output to be less than the grid interconnection limit, with the general assumption that the system output does not substantially affect the condition of the grid; however, plant control has become more important because increasing amounts of photovoltaic generation are connected to the grid (Ela et al. 2013a). Recent work (Gevorgian et al. 2016a) demonstrated active power controls for a utility-scale PV plant in Puerto Rico, illustrating the ability of PV plants to provide ancillary services for an isolated island grid.

At the individual solar panel level, solar panels have been designed with fixed-tilt, one-axis, and two-axis capabilities. The axes allow for solar panels to track the sun, depending on the time of day and time of the year. Two-axis capabilities provide the best performance in terms of power production, but they do also require the most mechanical movement, inviting more operation and maintenance costs.

In terms of solar-plant-level controls, similar studies have been conducted from the grid perspective. Like wind, as solar penetration increases, solar will also be required to provide grid services to improve the reliability of the grid. These solar plants consist of power electronics, specifically inverters, that can contribute to the grid stability and reliability, while decreasing the impact of the variability of solar on the grid. This test demonstrated several types of grid services including AGC, droop response, and fast frequency response. The solar-plant-level controls leverage classic feedback mechanisms to drive the error between the power reference signal and the power output of the solar plant to zero. The main benefit of solar generation, PV in particular, is that it does not have any rotating mechanical parts that can respond very fast to disturbances on the grid, which can increase the reliability of the grid.

\subsection{Hybrid Power Plant Control}

\subsubsection{Solar PV Plus Storage}

Solar PV plus storage control is a topic that has received considerable attention in recent years. One body of work has focused on developing methods to optimally size and control these hybrid plants based on assumed value streams and system operational limits, running from residentialto utility-scale systems. Recent work has explored optimization of distributed PV plus storage systems with dispatchable loads in residential buildings (O'Shaughnessy et al. 2018), whereas other work has focused on technical and economic performance of large-scale solar plus storage plants using a price-taker model (Denholm et al. 2017). Optimal plant control from the perspective of maximizing profit for the system owner has frequently been modeled with mathematical optimization approaches, as described in multiple sources (Nottrott, Kleissl, and Washom 2013; Hanna et al. 2014; Ru, Kleissl, and Martinez 2012; Zhang et al. 2015; Babacan et al. 2017). Other work has focused on representing nonlinear system effects and developing simulation or rule-based approaches to achieve an optimal dispatch (DiOrio et al. 2020; Riffonneau et al. 2011). 


\subsubsection{Research in and Software Tools for Hybrid Power Plant Operation and Control}

Finally, as mentioned throughout this report, by co-locating wind and solar, variability caused by variable resources has the potential to decrease, meaning the wind is strongest at night and is the lowest in the middle of the day when the sun is shining the brightest. Leveraging these variable resources together can improve the economics and reliability of the electric grid.

Most studies that have been conducted have focused on how to electrically integrate and control the technologies, wind, solar, and storage (Gevorgian, Burra, and Marjaria 2018). There are two main topologies that have gained traction in recent years. The first topology is to convert each technology, wind, solar, and storage to a DC bus that is then converted back to $\mathrm{AC}$ when interfacing with the grid. The second topology converts all technologies to $\mathrm{AC}$ and connects to an $\mathrm{AC}$ bus that interfaces directly with the grid. The fundamental difference between wind and solar at the electrical level in that wind inherently produces $\mathrm{AC}$ power, and solar/storage inherently produce $\mathrm{DC}$ power. This provides many decisions to be made on the electrical infrastructure of combining these technologies and has not been incorporated extensively in optimization studies. There are many options for interconnecting a hybrid power plant to the larger electrical grid system and the positioning of inverters that convert DC to AC for interconnection to the broader electricity system.

Regardless of the electrical infrastructure, control strategies have been developed for gridconnected hybrid systems and stand-alone (i.e., islanded grid) scenarios. Under both scenarios, the hybrid power plants are controlled to provide grid services to reduce the effects of variability on the grid to improve its reliability by providing AGC, fast frequency response, and droop control. In this case, the benefits of wind (i.e., inertial response) and the benefits of solar (i.e., fast response times) can be exploited to further improve the performance of the hybrid power plant with respect to the grid. Accurate forecasting plays an important role in being able to deploy these hybrid power plants effectively. These forecasts allow for the hybrid plants to be optimally scheduled from five minutes to a day in advance. As forecast accuracy increases, the adverse effects of variability will decrease, and the grid will be able to better plan for when the wind is not blowing and the sun is not shining.

It is likely that many hybrid power plants will have wind, solar, and storage co-located to minimize electrical infrastructure and deployment costs. Many of the studies described earlier have focused on the electrical infrastructure interactions between technologies. Further work will need to be performed to look at the physical interactions between co-located technologies, including shadow and/or flicker generated by turbines, impacting solar panel performance, or thermal heating and convection that can impact the inflow to turbines. These technologies will have to be modeled together to understand the implications of co-locating technologies. In addition, control strategies can be designed to mitigate any adverse effects of one technology on another. For example, if a rotating turbine is producing flicker that directly impacts several solar panels, the wind turbine operation can be altered or stopped to accommodate the operation of the solar panels. 


\section{Insights from NREL Workshop on Hybrid Power Plant Design, Development, and Operation}

A dominant theme throughout the entire 2-day workshop was lack of consensus around whether hybrid power plants were necessary at all and, if they are, under what resource and market conditions they make sense. It was clear that across the spectrum of stakeholders (including researchers, consultants, developer/owner/operators, and manufacturers) that there were no clear answers to these questions. Some primary sources of skepticism around the need for hybrid power plants included:

- Market challenges:

- Achieve significant revenue from capacity value or ancillary services.

- How should utilities assess capacity value from hybrid assets?

- How should utilities include forecasting of hybrid power plant energy in their commitment and dispatch operations?

- How will storage be treated from the utility perspective (for example, Federal Energy Regulatory Commission 841 in the United States directs system operators to develop rules for storage to participate in capacity, energy, and service markets)?

- Interconnection levels and associated costs

- System operators may not view hybrid power plants as single units and instead treat the overall plant rating as the sum of the capacity for generation assets (Federal Energy Regulatory Commission 845 seeks to address this in the United States by allowing all generation facilities to request less than their fully rated capacity).

- Hybrid power plants are only valuable in markets with very large renewable shares where capacity and energy shifting have value.

- Even in deregulated markets today with large amounts of renewables, there is little benefit of "energy arbitrage" through differential prices by time of day or over the course of a week.

- Even if "energy arbitrage" opportunities are present, the value of colocation of assets versus virtual hybrid power plant operation is questionable.

- Policy incentives (such as production tax credits and investment tax credits) typically reward individual technology systems incentives, and some revenue from these sources could be forfeited if assets are combined.

- Technology challenges:

- Need for one-off design solutions on a case-by-case basis (based on market and resource context) limits opportunities for industrialization and economies of scale.

- Too many business models are required for developers to be interested in fully committing to hybrid power plant solutions. 
- Lots of potential technology solutions (i.e., collection system topology, types of turbines and solar PV, types of storage) without a clear winner limits the ability for learning curve improvements to performance and cost.

- Risk caused by resource uncertainty may be as bad or worse for hybrid than single technology plants.

- From a wind energy perspective, hybrid power plants (with or without storage) may not be able to reduce uncertainty in preconstruction energy estimation (i.e., the P80 or P90), which drives financial costs of the project.

- Solar power plants have lower cost of capital today, and financing of hybrid power plants may be worse when combined than if financed separately.

- There is a lack of validation of hybrid power plants overall.

- Most hybrid power plant designs are still in early demonstration phases, meaning that their long-term viability from an energy and capacity perspective is not yet proven.

- Even more significant are questions around hybrid power plants providing ancillary services and performance in the short term with transients and dynamic interaction with the larger grid system, especially with the inverters themselves for protection and faults (i.e., being able to meet various grid codes).

However, all this skepticism also indicated a need for comprehensive research to better understand under what conditions hybrid power plants do make economic sense. In addition, the various impediments provide guidance about what research questions and specific topics of study will be important to address to credibly demonstrate the potential value of hybrid power plants.

Regardless of the type of technologies, an important message from the industry attendees at the workshop was to remember that hybrid power plants start with the business model, not the design. In other words, markets are key to the viability of all power plants, including hybrid power plants. From this perspective, there was significant skepticism from the attendees that colocation and shared resources were any better than either virtual hybrid power plants or even the larger system operation of the grid balancing across individual technology assets in the most cost-effective manner. Thus, the onus on the research community is to investigate whether hybrid power plants can, in fact, create a business opportunity where the whole is greater than the sum of the parts, and second, under what conditions that is the case. This can be done through coordinated research that looks at sizing, design, operation, and control of hybrid power plants to rigorously assess their potential under a variety of resource and market conditions.

\subsection{Specific Questions on Sizing and Design}

Despite the skepticism, attendees showed interest in better understanding the potential of hybrid power plants of all types, with solar PV and wind (with or without storage) being of highest priority (and solar PV with storage being of even higher importance). However, there was also 
significant interest in those technologies also combined with CSP, geothermal, hydropower (including pumped hydropower), broader consideration of nonbattery storage technologies (i.e., flywheels, compressed air, electric vehicles, demand response, etc.), and even nonelectricitybased hybrid power plants that involve fuel production or other energy products. In addition, there was interest in the opportunities for solar PV and hydropower together, especially if the solar PV were floating or installed above the hydro resource, which would reduce land-area taken by the solar panels and also help prevent evaporation of water assets; moreover, the water could also be used to support cooling of the panels. Finally, those from the geothermal community were particularly interested in opportunities of geothermal with CSP alone or also integrated with solar PV.

From a design perspective, the discussion for hybrid power plants focused on two broad areas. First, what are the opportunities and challenges associated with integrated design of hybrid power plants that include different technologies? And second, what are the opportunities for modifying and innovating design of specific technology elements within hybrid power plants for improved overall system level performance and cost? Again, the discussions were focused primarily on wind and solar PV hybrid power plants with some consideration of additional technologies. The resulting findings will be useful in terms of informing research at the level of sizing and design of hybrid power plants. The specific topics identified by the participants that merit further consideration including the following:

- Economies of scope:

- Integration of development activities, such as permitting of all types, project management, contracting, and other project overhead

- Single point of interconnection and reduced costs associated with interconnection request as well as overall costs for interconnection (if requested capacity is less than sum of individual generation asset-rated capacities)

- Depending on topology and overall layout, reduced cable lengths and costs of collection system and reduced costs overall for power electronics

- Reduced sizing and cost of power plant substation

- Reduced infrastructure costs for roads, maintenance buildings, and other balance of plant costs

- Reduced maintenance costs through coordination of maintenance across all technology assets.

- Technology performance and cost:

- Storage could relieve congestion at an interconnection point to get more overall energy to the grid from a given site

- Maintenance costs of the wind turbines may be reduced if storage reduces need for wind turbine control actuation (i.e., pitch and yaw) to reduce bearing and actuator wear and tear.

- Design innovation: 
- Turbine design could shift from type IV to type III with power electronics of broader collection system managing interface to larger grid

- Explore a variety of collection system topologies (AC coupled, DC coupled) and innovations related to inverters within the system.

However, the design of hybrid power plants also needs to consider several challenges as well:

- Shading if the assets are co-located: both static and dynamic (flicker) shading of the PV panels by the wind turbines needs to be considered, along with the effects that any dynamic oscillations may have on inverters and overall system performance

- If there are land constraints, how do we jointly optimize the sizing of different assets and their layout, because there may be considerable interaction effects between the two?

- Battery performance degradation over time is a general area of concern and could be worsened if the direct interaction with solar PV and wind assets (compared to more stable interaction with a larger grid system) results in higher frequency and amplitude duty cycles.

The listed opportunities and challenges are not exhaustive but reflect some of the key concerns on the minds of stakeholders actively engaged with hybrid power plant development. 


\section{Conclusions}

Hybrid power plants show promise to provide significant value to the electric grid system with high shares of variable renewable energy generation such as wind and solar PV. However, there still are many questions about whether hybrid power plants make sense versus leaving it to the larger grid system to ensure low cost and reliable supply by engaging directly with all individual assets. This report summarized literature on state-of-the-art research concerning hybrid power plants from multiple perspectives, including: (1) resource and market opportunities, (2) technology selection and sizing, (3) physical design, and (4) operation and control. The emphasis was placed on wind and solar hybrid power plants (with or without storage), but additional technologies were considered and merit further investigation.

In addition, findings from a National Renewable Energy Laboratory workshop, in December 2018 titled "Design and Development of Hybrid Power Plants", on these same topics was provided, and the combination of information can be used to help provide a general recommendation for research. The recommended research actions included 1) surveying market and resource condition to identify hybrid power plant opportunities, 2) investigation of detailed hybrid power plant design, and 3) investigation of control and operation of hybrid power plants for grid code compliance, ancillary services and operation in electricity markets.

Each of the three action areas will require significant research activity that can be further bolstered by collaboration between the national laboratories and industry stakeholders. This will in turn progress the successful commercialization of hybrid power plants that can increase the potential for deployment of renewable energy in the United States and globally. 


\section{References}

Ackermann, Thomas, Thibault Prevost, Vijay Vittal, Andrew J. Roscoe, Julia Matevosyan, and Nicholas Miller. 2017. "Paving the Way: A Future Without Inertia Is Closer Than You Think." IEEE Power and Energy Magazine 15: 61-69. https://ieeexplore.iee.org/document/8070502.

Adcock, Christiane, and Ryan N. King. (2018) "Data-Driven Wind Farm Optimization Incorporating Effects of Turbulence Intensity." 2018 Annual American Control Conference (ACC), June 27-29 http://ieeexplore.ieee.org/stamp/stamp.jsp?tp=\&arnumber=8431727\&isnumber=8430677.

Ahlstrom, Mark, Erik Ela, Jenny Riesz, Jonathan O’Sullivan, Benjamin F. Hobbs, Mark O'Malley, Michael Milligan, Paul Sotkiewicz, and Jim Caldwell. 2015. "The Evolution of the Market: Designing a Market for High Levels of Variable Generation." IEEE Power and Energy Magazine 13 (6): 60-66. https://ieeexplore.ieee.org/document/7299794/?part=1.

Babacan, O., Ratnam, E. L., Disfani, V. R., \& Kleissl, J. (2017). Distributed energy storage system scheduling considering tariff structure, energy arbitrage and solar PV penetration. Applied Energy, 205, 1384-1393.

Badwawi, Rashid Al, Mohammad Abusara, and Tapas Mallick. (2016). "A Review of Hybrid Solar PV and Wind Energy System.” Smart Science 3(3): 127-138. https://doi.org/10.1080/23080477.2015.11665647

Bay, Christopher J., Jennifer Annoni, Timothy Taylor, Lucy Pao, and Kathryn Johnson. 2018. "Active Power Control for Wind Farms Using Distributed Model Predictive Control and Nearest Neighbor Communication." 2018 Annual American Control Conference (ACC), June 27-29. http://ieeexplore.ieee.org/stamp/stamp.jsp?tp=\&arnumber=8431764\&isnumber=8430677.

Baring-Gould, E. Ian, Lawrence Flowers, Per Lundsager, Lawrence Mott, Mari Shirazi, Juergen Zimmermann. 2003. "Worldwide Status of Wind/Diesel Applications. (Viewgraphs only)."

Windpower 2003 Conference Proceedings (CD-ROM), Austin, Texas, May 18-21, 2003: 17 pp. Washington, DC: American Wind Energy Association; Omni Press.

Baring-Gould, Ian, and Martina Dabo. 2009. "Technology, Performance, and Market Report of Wind-Diesel Applications for Remote and Island Communities: Preprint." National Renewable Energy Laboratory. NREL/CP-500-44679. https://www.nrel.gov/docs/fy09osti/44679.pdf.

Blair, Nate, Nicholas DiOrio, Janine Freeman, Paul Gilman, Steven Janzou, Ty Neises, and Michael Wagner. 2017. "System Advisor Model (SAM) General Description (Version 2017.9.5)." National Renewable Energy Laboratory. NREL/TP-6A20-70414. https://www.nrel.gov/docs/fy18osti/70414.pdf.

Bloom, Aaron, Udi Helman, Hannele Holtinnen, Kate Summers, Jordan Bakke, Gregory Brinkman, G., and Anthony Lopez. 2017. "It's Indisputable. Five Facts about Planning and Operating Modern Power Systems." IEEE Power and Energy Magazine 15(6): 22-30. http://ieeexplore.ieee.org/stamp/stamp.jsp?tp=\&arnumber=8070499\&isnumber=8070475. 
Bloomberg New Energy Finance. 2018. New Energy Outlook 2018 (Technical Report). https://about.bnef.com/new-energy-outlook/.

Boersma, Sjoerd, Bart M. Doekemeijer, Pieter M. O. Gebraad, Paul A. Fleming, Jennifer Annoni, Andrew Scholbrock, J. A. Frederik, and Jan-Willem Van Wingerden. "A Tutorial on Control-Oriented Modeling and Control of Wind Farms." 2017 American Control Conference $(A C C)$, Seattle, Washington, May 24-26, 2017. https://ieeexplore.ieee.org/document/7962923.

BP Energy Economics. 2018. BP Energy Outlook: 2018 edition (Technical Report).

https://www.bp.com/content/dam/bp/en/corporate/pdf/energy-economics/energy-outlook/bpenergy-outlook-2018.pdf.

Coburn, Alice, Eilin Walsh, Patrick J. Solan, and Kevin P. McDonnell. (2014). "Combining Wind and Pumped Hydro Energy Storage for Renewable Energy Generation in Ireland." Journal of Wind Energy, 2014: 1-6. https://doi.org/10.1155/2014/415898.

Cole, W. J., Frazier, A., Donohoo-Vallett, P., Mai, T. T., \& Das, P. (2018). 2018 Standard Scenarios Report: A US Electricity Sector Outlook (No. NREL/TP-6A20-71913). National Renewable Energy Lab.(NREL), Golden, CO (United States).

Cutler, Dylan, Dan Olis, Emma Elgqvist, Xiangkun Li, Nick Laws, Nick DiOrio, Andy Walker, and Kate Anderson. 2017. "REopt ${ }^{\mathrm{TM}}$ : A Platform for Energy System Integration and Optimization.” Golden, CO: National Renewable Energy Laboratory. NREL/TP-7A40-70022. https://www.nrel.gov/docs/fy17osti/70022.pdf

De Azevedo, Ricardo, and Osama Mohammed. 2015. "Profit-Maximizing Utility-Scale Hybrid Wind-PV Farm Modeling and Optimization. IEEE SoutheastCon, April 9-12, 2015. https://doi.org/10.1109/SECON.2015.7132892.

Deline, Chris, Sara MacAlpine, Bill Marion, Fatima Toor, Amir Asgharzadeh, and Joshua S. Stein. 2017. "Assessment of Bifacial Photovoltaic Module Power Rating Methodologies - Inside and Out" IEEE Journal of Photovoltaics 7 (2): 575-580.

https://ieeexplore.ieee.org/document/7835135.

Deign, Jason. 2018. "Xcel Attracts 'Unprecedented' Low Prices for Solar and Wind Paired with Storage." GTM. January 8, 2018. https://www.greentechmedia.com/articles/read/record-lowsolar-plus-storage-price-in-xcel-solicitation.

Denholm, Paul, Josh Eichman, and Robert Margolis. 2017. "Evaluating the Technical and Economic Performance of PV Plus Storage Power Plants." Golden, CO: National Renewable Energy Laboratory. NREL/TP-6A20-68737. https://www.nrel.gov/docs/fy17osti/68737.pdf

Denholm, Paul L., and Robert M. Margolis. 2018. "The Potential for Energy Storage to Provide Peaking Capacity in California Under Increased Penetration of Solar Photovoltaics." Golden, CO: National Renewable Energy Laboratory. 6A20-70905, 1427348.

https://doi.org/10.2172/1427348. 
Denholm, Paul, Yinong Dun, and Trieu Mai. 2019. "An Introduction to Grid Services: Concepts, Technical Requirements, and Provision from Wind." Golden, CO: National Renewable Energy Laboratory. NREL/TP-6A20-72578. https:/www.nrel.gov/docs/fy19osti/72578.pdf.

DiOrio, Nicholas A., Janine M. Freeman, and Nate Blair. 2018. "DC-Connected Solar Plus Storage Modeling and Analysis for Behind-The-Meter Systems in the System Advisor Model." In 2018 IEEE 7th World Conference on Photovoltaic Energy Conversion (WCPEC) (A Joint Conference of 45th IEEE PVSC, 28th PVSEC \& 34th EU PVSEC), Waikoloa Village, Hawaii, June 10-15, 2018. https://doi.org/10.1109/PVSC.2018.8547329.

DiOrio, Nicholas A., and Will Hobbs. 2018. "Economic Dispatch for DC-Connected Battery Systems on Large PV Plants." Presented at the 2018 PV Systems Symposium, Albuquerque, NM, May 3, 2018. https://www.nrel.gov/docs/fy19osti/72513.pdf.

DiOrio, Nicholas, Paul Denholm, and William B. Hobbs. "A Model for Evaluating the Configuration and Dispatch of PV plus Battery Power Plants." Applied Energy 262 (March 2020): 114465. https://doi.org/10.1016/j.apenergy.2019.114465.

"Distributed Energy Resources - Customer Adoption Model (DER-CAM)." (n.d.). Microgrids at Berkeley Lab. | Accessed February 22, 2019. https://building-microgrid.lbl.gov/projects/der-cam.

Draxl, Caroline, Bri-Mathias Hodge, Andrew Clifton, and J. McCaa. 2015a. "Overview and Meteorological Validation of the Wind Integration National Dataset Toolkit." Golden, CO: National Renewable Energy Laboratory. NREL/TP-5000-61740. https://www.nrel.gov/docs/fy15osti/61740.pdf.

Draxl, Caroline, Bri-Mathias Hodge, Andrew Clifton, and J. McCaa. 2015b. "The Wind Integration National Dataset (WIND) Toolkit." Applied Energy 151: 355-366. https://doi.org/10.1016/j.apenergy.2015.03.121.

Dykes, Katherine, Maureen Hand, Tyler Stehly, Paul Veers, Mike Robinson, Eric Lantz, and Richard Tusing. 2017. "Enabling the SMART Wind Power Plant of the Future Through ScienceBased Innovation." Golden, CO: National Renewable Energy Laboratory. NREL/TP-500068123. https://www.nrel.gov/docs/fy17osti/68123.pdf.

Dykes, K. "Dynamics of technology innovation and diffusion with emphasis on wind energy." PhD dissertation. MIT, 2016.

Dykes, Katherine, Paul Veers, Eric Lantz, Hannele Holttinen, Ola Carlson, Aidan Tuohy, Anna Maria Sempreviva, Andrew Clifton, Javier Sanz Rodrigo, Derek Berry, Daniel Laird, Scott Carron, Patrick Moriarty, Melinda Marquis, Charles Meneveau, Joachim Peinke, Joshua Paquette, Nick Johnson, Lucy Pao, Paul Fleming, Carlo Bottasso, Ville Lehtomaki, Amy Robertson, Michael Muskulus, Jim Manwell, John Olav, Latha Sethuraman, Owen Roberts, and Jason Fields. 2019. "Results of IEA Wind TCP Workshop on a Grand Vision for Wind Energy Technology." IEA Technical Report 2019. https://www.nrel.gov/docs/fy19osti/72437.pdf. 
Dykes, Katherine, R. Meadows, Fort F. Felker, Peter Graf, M. Hand, Monte Lunacek, John Michalakes, Patrick Moriarty, W. Musial, and Paul Veers. 2011. "Applications of Systems Engineering to the Research, Design, and Development of Wind Energy Systems." Golden, CO:

Eberle, Annika, Owen Roberts, Alicia Key, Parangat Bhaskar, Katherine Dykes. 2019. NREL's Balance-of-System Cost Model for Land-Based Wind. Golden, CO: National Renewable Energy Laboratory (NREL). NREL/TP-6A20-72201. https://www.nrel.gov/docs/fy19osti/72201.pdf.

Eichman, Josh, and Francisco Flores-Espino. 2016. "California Power-to-Gas and Power-toHydrogen Near-Term Business Case Evaluation." Golden, CO: National Renewable Energy Laboratory (NREL). NREL/TP-5400-67384. https:/www.nrel.gov/docs/fy17osti/67384.pdf.

Ela, Erik, V. Diakov, E. Ibanez, and M. Heaney. 2013a. "Impacts of Variability and Uncertainty in Solar Photovoltaic Generation at Multiple Timescales." Golden, CO: National Renewable Energy Laboratory. NREL/TP-5500-58274, 1081387. https://doi.org/10.2172/1081387.

Ela, Erik, Brendan Kirby, A. Botterud, Cathy Milostan, Ibrahim Krad, and V. Koritarov. 2013 b. "Role of Pumped Storage Hydro Resources in Electricity Markets and System Operation." HydroVision International Denver, Colorado, July 23-26, 2013. NREL/CP-5500-58655. https://www.nrel.gov/docs/fy13osti/58655.pdf.

Elgqvist, Emma, Kate Anderson, and Edward Settle. 2018. "Federal Tax Incentives for Energy Storage Systems.” Golden, CO: National Renewable Energy Laboratory. NREL/FS-7A4070384. https://www.nrel.gov/docs/fy18osti/70384.pdf.

"Energy Transition Outlook 2018: A Global and Regional Forecast of the Energy Transition to 2050.” DNV GL. Last accessed Dec 17, 2018. https://eto.dnvgl.com/2018/.

Eyer, Jim, and Garth Corey. 2010. "Energy Storage for the Electricity Grid: Benefits and Market Potential Assessment Guide: A Study for the DOE Energy Storage Systems Program.”

Albuquerque, New Mexico: Sandia National Laboratory. SAND2010-0815.

https://doi.org/10.2172/1031895.

Fang, Xin, Bri-Mathias Hodge, and Fangxing Li. 2018a. "Capacity Market Model Considering Flexible Resource Requirements with High Penetration Renewables.” IEEE Power and Energy General Meeting, Portland, Oregon, August 5-10. NREL/CP-5D00-70162.

https://www.nrel.gov/docs/fy19osti/70162.pdf.

Fang, Xin, Bri-Mathias Hodge, Venkat Krishnan, and Fangxing Li. 2018b. "Potential of Wind Power to Provide Flexible Ramping Products and Operating Reserve.” IEEE Power and Energy General Meeting, Portland, Oregon, August 5-10. NREL/CP-5D00-70161. https://www.nrel.gov/docs/fy19osti/70161.pdf.

Feldman, David, and Robert Margolis. 2019. “Q2/Q3 2018 Solar Industry Update.” Golden, CO: National Renewable Energy Laboratory. NREL/PR-6A20-72180. https://www.nrel.gov/docs/fy19osti/72810.pdf 
Fleming, Paul A., Andrew Ning, Pieter M. O. Gebraad, and Katherine Dykes. 2015. "Wind Plant System Engineering Through Optimization of Layout and Yaw Control." Wind Energy 19 (2): 329-344. https://dx.doi.org/10.1002/we.1836.

Fleming, Paul A., Pieter M. O. Gebraad, Sang Lee, Jan-Willem van Wingerden, Kathryn Johnson, Matt Churchfield, John Michalakes, Phillippe Spalart, and Patrick Moriarty. 2014 "Evaluating Techniques for Redirecting Turbine Wakes Using SOWFA." Renewable Energy 70: (2014): 211-218. https://doi.org/10.1016/j.renene.2014.02.015.

Fu, Ran, Timothy Remo, and Robert Margolis. 2018. "2018 U.S. Utility-Scale PhotovoltaicsPlus-Energy Storage System Costs Benchmark." Golden, Colorado: National Renewable Energy Laboratory. NREL/TP-6A20-71714. https://www.nrel.gov/docs/fy19osti/71714.pdf.

Gebraad, Pieter, Jared J. Thomas, Andrew Ning, Paul Fleming, and Katherine Dykes.

"Maximization of the Annual Energy Production of Wind Power Plants by Optimization of Layout and Yaw-Based Wake Control." Wind Energy 20 (1): 97-107.

https://dx.doi.org/10.1002/we.1993

“Geothermal Prospector.” n.d. National Renewable Energy Laboratory. Accessed July 3, 2019. https://maps.nrel.gov/geothermal-prospector

Getman, Daniel, Arlene Anderson, and Chad Augustine. 2015. "Geothermal Prospector:

Supporting Geothermal Analysis Through Spatial Data Visualization and Querying Tools." Geothermal Resources Council 2015 Annual Meeting, Reno, Nevada, September 20-23. https://www.osti.gov/biblio/1253709.

Gevorgian, Vahan, and Barbara O'Neill. 2016a. "Advanced Grid-Friendly Controls Demonstration Project for Utility-Scale PV Power Plants.” 2016. Golden, Colorado: National Renewable Energy Laboratory. NREL/TP-5D00-65368.

https://www.nrel.gov/docs/fy16osti/65368.pdf.

Gevorgian, Vahan, and Barbara O'Neill. 2016b. "Demonstration of Active Power Controls by Utility-Scale PV Power Plant in an Island Grid: Preprint." $15^{\text {th }}$ International Workshop on LargeScale Integration of Wind Power into Power Systems as well as on Transmission Networks for Offshore Wind Power Plants, Vienna, Austria, November 15-17.

https://www.nrel.gov/docs/fy17osti/67255.pdf.

Gevorgian, Vahan, Rajni Burra, and Mahesh Morjaria. 2018. "Hybrid Utility-Scale PV-Wind Storage Plants for Dispatchability and Reliability Services.” Golden, Colorado: National Renewable Energy Laboratory. NREL/PR-5D00-71551. https://www.nrel.gov/docs/fy18osti/71551.pdf.

Gilman, Paul, Aron Dobos, Nicholas DiOrio, Janine Freeman, Steven Janzou, and David Ryberg. 2018. "SAM Photovoltaic Model Technical Reference Update." Golden, CO: National

Renewable Energy Laboratory. NREL/TP-6A20-67399.

https://www.nrel.gov/docs/fy18osti/67399.pdf. 
“Global Wind Atlas.” 2018. EnergyData.info. Accessed February 2020.

https://globalwindatlas.info/.

Graf, Peter, Katherine Dykes, George Scott, Jason Fields, Monte Lunacek, Julian Quick, and Pierre-Elouan Rethore. 2016. "Wind Farm Turbine Type and Placement Optimization." Journal of Physics: Conference Series 753 (062004): 1-15. https://dx.doi.org/10.1088/17426596/753/6/062004.

Haegel, Nancy M., Robert Margolis, Tonio Buonassisi, David Feldman, Armin Froitzheim, Raffi Garabedian, Martin Green, Stefan Glunz, Hans-Martin Henning, Burkhard Holder, Izumi Kaizuka, Benjamin Kroposki, Koji Matsubara, Shigeru Niki, Keiichiro Sakurai, Roland A. Schindler, William Tumas, Eicke R. Weber, Gregory Wilson, Michael Woodhouse, and Sarah Kurtz. 2017. "Terawatt-Scale Photovoltaics: Trajectories and Challenges." Science 356 (6334): 141-143.

http://science.sciencemag.org/content/356/6334/141.full?ijkey=q3.xaF3x8rF5M\&keytype=ref\&s iteid=sci.

Hanna, Ryan, J. Kleissl, Anders A. Nottrott, and M. Ferry. 2014. "Energy Dispatch Schedule Optimization for Demand Charge Reduction Using a Photovoltaic-Battery Storage System with Solar Forecasting." Solar Energy 103 (May): 269-87.

https://doi.org/10.1016/j.solener.2014.02.020.

Hassan, Sani, and Liana Cipcigan. 2017. "Optimal Battery Storage Operation for PV Systems with Tariff Incentives.” Cardiff University. https://doi.org/10.17035/d.2017.0038094155.

Helistö, Niina, Juha Kiviluoma, and Hannele Holttinen. 2017. "Sensitivity of Electricity Prices in Energy-Only Markets with Large Amounts of Zero Marginal Cost Generation.” $201714^{\text {th }}$ International Conference on the European Energy Market (EEM), Dresden, Germany, June 6-9. https://ieeexplore.ieee.org/document/7981893.

Hirth, Lion. 2013. "The Market Value of Variable Renewables: The Effect of Solar and Wind Power Variability on their Relative Price.” EUI Working Papers. Robert Schuman Centre for Advanced Studies. 2013/36: 1-51.

http://cadmus.eui.eu/bitstream/handle/1814/27135/RSCAS_2013 36.pdf?sequence.

Holttinen, Hannele, Juha Kiviluoma, Alain Forcione, Michael Milligan, Charles J. Smith, Jody Dillon, Jan Dobschinski, Serafin van Roon, Nicolaos Cutululis, Antje Orths, Peter Borre Eriksen, Enrico Maria Carlini, Ana Estanqueiro, Ricardo Bessa, Lennart Soder, Hossein Farahmand, Jose Rueda Torres, Bai Jianhua, Junji Kondoh, Ivan Pineda, and Goran Strbac. 2016. "Design and Operation of Power Systems with Large Amounts of Wind Power: Final Summary Report." IEA WIND Task 25, Phase Three 2012-2014. International Energy Agency. http://www.vtt.fi/inf/pdf/technology/2016/T268.pdfhttp://www.vtt.fi/inf/pdf/technology/2016/T2 68.pdfhttp://www.vtt.fi/inf/pdf/technology/2016/T268.pdf.

“HOMER ${ }^{\circledR}$ Products.” 2018. HOMER Energy. Accessed: February 22, 2019. https://www.homerenergy.com/products/index.html. 
Hou, Peng, Jiangsheng Zhu, Juichao MA, Guangya Yang, Weihao HU, and Zhe CHEN. 2019.

"A Review of Offshore Wind Farm Layout Optimization and Electrical System Design

Methods." Journal of Modern Power Systems and Clean Energy 7 (5): 1-12.

https://link.springer.com/article/10.1007/s40565-019-0550-5.

Huertas-Hernando, Daniel, Hossein Farahmand, Hannele Holttinen, Juha Kiviluoma, Erkka Rinne, Lennart Söder, Michael Milligan, Eduardo Ibanez, Sergio Martin Martínez, Emilio Gomez-Lazaro, Ana Estanqueiro, Luis Rodrigues, Luis Carr, Serafin van Roon, Antje Gesa Orths, Peter Børre Eriksen, Alain Forcione, and Nickie Menemenlis. 2017. "Hydro Power Flexibility for Power Systems with Variable Renewable Energy Sources: an IEA Task 25 Collaboration." WIREs Energy and Environment 6 (1): e220.

https://onlinelibrary.wiley.com/doi/abs/10.1002/wene. 220

Hughes, Thomas P. 1993. Networks of Power: Electrification in Western Society, 1880-1930. Baltimore, MD: Johns Hopkins University Press.

International Energy Agency (IEA). 2018. World Energy Outlook 2018 (Technical Report). https://www.iea.org/weo2018/.

Kanev, S. K., F. J. Savenije, and W. P. Engels. 2018. "Active Wake Control: An Approach to Optimize the Lifetime Operation of Wind Farms." Wind Energy 21 (7): 488-501.

https://onlinelibrary.wiley.com/doi/full/10.1002/we.2173.

Katsouris, Georgios. 2015. "Infield Cable Topology Optimization of Offshore Wind Farms." Master's thesis, Delft University of Technology.

Kleckner, Tom. 2017. "ERCOT Reaches 50\% Wind Penetration Mark." RTO Insider. March 26, 2017. https://www.rtoinsider.com/ercot-wind-penetration-40749/.

Krad, Ibrahim, Erik Ela, and Vladimir Koritarov. 2014. "Quantifying the Operational Benefits of Conventional and Advanced Pumped Storage Hydro on Reliability and Efficiency." IEEE Power and Energy Society General Meeting, National Harbor, MD, July 27-31.

https://doi.org/10.1109/PESGM.2014.6939040.

Kroposki, Benjamin, Emiliano Dall'Anese, Andrey Bernstein, Yingchen Zhang, and Bri-Mathias Hodge. 2017a. "Autonomous Energy Grids: Preprint." Presented at the Hawaii, International Conference on System Sciences in Waikoloa, Hawaii. Golden, Colorado: National Renewable Energy Laboratory. NREL/CP-5D00-68712. https://www.nrel.gov/docs/fy18osti/68712.pdf.

Kroposki, Benjamin, Brian Johnson, Yingchen Zhang, Vahan Gevorgian, Paul Denholm, BriMathias Hodge, and Bryan Hannegan. 2017b. "Achieving a 100\% Renewable Grid: Operating Electric Power Systems with Extremely High Levels of Variable Renewable Energy." IEEE Power and Energy Magazine 15 (2): 61-73. https://doi.org/10.1109/MPE.2016.2637122

Laws, Nicholas D., Kate Anderson, Nicholas A. DiOrio, Xiangkun Li, and Joyce McLaren. 2018. "Impacts of Valuing Resilience on Cost-Optimal PV and Storage Systems for Commercial Buildings." Renewable Energy 127 (November): 896-909. https://doi.org/10.1016/j.renene.2018.05.011. 
Lewis, Nathan S. 2007. "Toward Cost-Effective Solar Energy Use.” Science 315 (5813): 798801. https://doi.org/10.1126/science.1137014.

Lumbreras, Sara, and A. Ramos. 2012. "Offshore Wind Farm Electrical Design: A Review," Wind Energy16 (3): 459-473. https://onlinelibrary.wiley.com/doi/abs/10.1002/we.1498.

Ling-Ling, Huang, Chen Ning, Zhang Hongyue, and Fu Yang. 2012. "Optimization of LargeScale Offshore Wind Farm Electrical Collection Systems Based on Improved FCM." International Conference on Sustainable Power Generation and Supply, Hangzhou, China, September 8-9. https://digital-library.theiet.org/content/conferences/10.1049/cp.2012.1785.

Mai, Trieu T., Paige Jadun, Jeffrey S. Logan, Colin A. McMillan, Matteo Muratori, Daniel C. Steinberg, Laura J. Vimmerstedt, Benjamin Haley, Ryan Jones, and Brent Nelson. Electrification futures study: scenarios of electric technology adoption and power consumption for the United States. No. NREL/TP-6A20-71500. National Renewable Energy Lab.(NREL), Golden, CO (United States), 2018.

Manwell, J.; McGowan, J.; Rogers, A. Wind Energy Explained. 2009. John Wiley \& Sons. https://onlinelibrary.wiley.com/doi/book/10.1002/9781119994367

"Maps." (n.d.). Geospatial Data Science. National Renewable Energy Laboratory. Accessed July 3, 2019. https://www.nrel.gov/gis/maps.html.

Mashayekh, Salman, Michael Stadler, Gonçalo Cardoso, and Miguel Heleno. 2017. “A Mixed Integer Linear Programming Approach for Optimal DER Portfolio, Sizing, and Placement in Multi-Energy Microgrids." Applied Energy 187 (February): 154-68.

https://doi.org/10.1016/j.apenergy.2016.11.020.

Milligan, Michael, Bethany Frew, Brendan Kirby, Matt Schuerger, Kara Clark, Debbie Lew, Paul Denholm, Bob Zavakil, Mark O’Malley, and Bruce Tsuchida. 2015. "Alternatives No More: Wind and Solar Power Are Mainstays of a Clean, Reliable, Affordable Grid." IEEE Power and Energy Magazine, 13 (6): 78-87. https://doi.org/10.1109/MPE.2015.2462311

MISO. 2015. "Planning Year 2016-2017 Wind Capacity Credit.” Miso Energy. https://cdn.misoenergy.org/2016\%20Wind\%20Capacity\%20Report124858.pdf.

MWH. 2009. "Technical Analysis of Pumped Storage and Integration with Wind Power in the Pacific Northwest: Final Report.” U . S . Army Corps of Engineers Northwest Division Hydroelectric Design Center. https://www.hydro.org/wp-content/uploads/2017/08/PS-WindIntegration-Final-Report-without-Exhibits-MWH-3.pdf.

Nelson, Arthur. 2015. "Wind Power Generates 140\% of Denmark's Electricity Demand." The Guardian. July 10, 2015. https://www.theguardian.com/environment/2015/jul/10/denmark-windwindfarm-power-exceed-electricity-demand.

Nema, Pragya, Rajesh Nema, and Saroj Rangnekar. 2009. "A Current and Future State of Art Development of Hybrid Energy System Using Wind and PV-Solar: A Review. Renewable and Sustainable Energy Reviews, 13 (8): 2096-2103. https://doi.org/10.1016/j.rser.2008.10.006 
Norconsult. 2013. "Wind Power Based Pumped Storage: Pre-Feasibility Study." Retrieved from http://www.nordicenergy.org/wp-content/uploads/2013/11/Wind-Power-Based-PumpedStorage_Pre-Feasibility-Study_Suduroy-Faroe-Islands_2013.pdf

Nottrott, Anders A., Jan P. Kleiss1, and Byron Washom. 2013. "Energy Dispatch Schedule Optimization and Cost Benefit Analysis for Grid-Connected, Photovoltaic-Battery Storage Systems." Renewable Energy 55 (July): 230-40. https://doi.org/10.1016/j.renene.2012.12.036.

"NREL: Developer Network." n.d. National Renewable Energy Laboratory. Accessed July 3, 2019. https://developer.nrel.gov/.

NSRDB. n.d. "Advancing the Science of Solar Data | National Solar Radiation Database. National Renewable Energy Laboratory. Accessed July 3, 2019. https://nsrdb.nrel.gov/.

Nye, David E. 1992. Electrifying America: Social Meanings of a New Technology, 1880-1940. Cambridge, MA: The MIT Press.

O’Shaughnessy, Eric, Dylan Cutler, Kristen Ardani, and Robert Margolis. 2018. "Solar Plus: Optimization of Distributed Solar PV through Battery Storage and Dispatchable Load in Residential Buildings." Applied Energy 213 (March): 11-21. https://doi.org/10.1016/j.apenergy.2017.12.118.

Pali, Bahadur Singh, and Shelly Vadhera. 2018. "A Novel Pumped Hydro-Energy Storage Scheme with Wind Energy for Power Generation at Constant Voltage in Rural Areas." Renewable Energy 127 (November): 802-810. https://doi.org/10.1016/j.renene.2018.05.028

Perez-Moreno, Sebastian Sanchez, Katherine Dykes, Karl O. Merz, and Michiel B. Zaaijer. "Multidisciplinary Design Analysis and Optimisation of a Reference Offshore Wind Plant." 2018. Journal of Physics: Conference Series 1037: 1-15. https://doi.org/10.1088/1742$\underline{6596 / 1037 / 4 / 042004 .}$.

Petrollese, Mario, and Daniele Cocco. 2016. "Optimal Design of a Hybrid CSP-PV Plant for Achieving the Full Dispatchability of Solar Energy Power Plants.” Solar Energy 137 (November): 477-489. https://doi.org/10.1016/j.solener.2016.08.027

PJM Interconnection. 2017. "Proposed Enhancements to Energy Price Formation

“PV Software PV*SOL Premium.” n.d. Valentin Software. Accessed February 26, 2019. https://www.valentin-software.com/en/products/photovoltaics/57/pvsol-premium.

“PVSyst.” n.d. PVSyst (blog). Accessed February 26, 2019. https://www.pvsyst.com/.

Quick, Julian, Jennifer Annoni, Ryan King, Katherine Dykes, Paul Fleming, and Andrew Ning. 2017. "Optimization Under Uncertainty for Wake Steering Strategies: Preprint." Golden, Colorado: National Renewable Energy Laboratory. NREL/CP-5000-68185. https://www.nrel.gov/docs/fy17osti/68185.pdf 
Riffonneau, Yann, Seddik Bacha, Franck Barruel, and Stephane Ploix. 2011. "Optimal Power Flow Management for Grid Connected PV Systems with Batteries." IEEE Transactions on Sustainable Energy 2 (3): 309-20. https://doi.org/10.1109/TSTE.2011.2114901.

$\mathrm{Ru}, \mathrm{Yu}$, Jan Kleissl, and Sonia Martinez. 2013. "Storage Size Determination for Grid-Connected Photovoltaic Systems.” IEEE Transactions on Sustainable Energy 4 (1): 68-81. https://doi.org/10.1109/TSTE.2012.2199339.

Ruth, Mark, Dylan Cutler, Francisco Flores-Espino, Greg Stark, Thomas Jenkin, Travis Simpkins, and Jordan Macknick. 2016. "The Economic Potential of Two Nuclear-Renewable Hybrid Energy Systems.” Joint Institute for Strategic Energy Analysis. Golden, Colorado: National Renewable Energy Laboratory. NREL/TP-6A50-66073. https://www.nrel.gov/docs/fy16osti/66073.pdf.

Ruth, Mark, Dylan Cutler, Francisco Flores-Espino, and Greg Stark. 2017. "The Economic Potential of Nuclear-Renewable Hybrid Energy Systems Producing Hydrogen." Joint Institute for Strategic Energy Analysis. Golden, Colorado: National Renewable Energy Laboratory. NREL/TP-6A50-66764. http://www.nrel.gov/docs/fy17osti/66764.pdf.

N. M. Samu, S.-C. Kao, P. W. O'Connor, M. M. Johnson, R. Uria-Martinez, and R. A. McManamay, National Hydropower Plant Dataset, Version 2 (FY18Q3). Existing Hydropower Assets [series] FY18Q3. National Hydropower Asset Assessment Program. Oak Ridge National Laboratory, Oak Ridge, TN. https://dx.doi.org/10.21951/1454737

Sengupta, Manajit, Yu Xie, Anthony Lopez, Aron Habte, Galen Mclaurin, and James Shelby. 2018. "The National Solar Radiation Data Base (NSRDB)." Renewable and Sustainable Energy Reviews 89 (June): 51-60.

https://www.sciencedirect.com/science/article/pii/S136403211830087X?via\%3Dihub.

Seel, Joachim, Andrew D. Mills, Ryan H. Wiser. 2018. "Impacts of High Variable Renewable Energy Futures on Wholesale Electricity Prices, and on Electric-Sector Decision Making." (Technical Report). Lawrence Berkeley National Laboratory. LBNL-2001163. https://emp.lbl.gov/publications/impacts-high-variable-renewable.

Simpkins, Travis, Dylan Cutler, Kate Anderson, Dan Olis, Emma Elgqvist, Michael Callahan, and Andy Walker. 2014. "REopt: A Platform for Energy System Integration and Optimization." ASME $20148^{\text {th }}$ International Conference on Energy Sustainability Collocated with the ASME $201412^{\text {th }}$ International Conference on Fuel Cell Science, Engineering and Technology, Boston, MA, June 30-July 2. https://doi.org/10.1115/ES2014-6570.

Simpkins, Travis, Kate Anderson, Dylan Cutler, and Dan Olis. 2016. "Optimal Sizing of a SolarPlus-Storage System for Utility Bill Savings and Resiliency Benefits.” 2016 Power \& Energy Society Innovative Smart Grid Technologies Conference (ISGT), Minneapolis, MN, September 6-9. https://doi.org/10.1109/ISGT.2016.7781237.

Sinha, Sunanda, and S. S. Chandel. 2014. "Review of Software Tools for Hybrid Renewable Energy Systems." Renewable and Sustainable Energy Reviews 32 (April): 192-205. https://www.sciencedirect.com/science/article/pii/S136403211400046X?via\%3Dihub\#!. 
Sioshansi, Ramteen, Seyed Hossein Madaeni, and Paul Denholm. 2014 "A Dynamic Programming Approach to Estimate the Capacity Value of Energy Storage." IEEE Transactions on Power Systems 29 (1) 395-403. https://ieexplore.ieee.org/document/6601729.

Soleimanzadeh, Maryam, Arno J. Brand, and Rafael Wisniewski. 2011. "A Wind Farm Controller for Load and Power Optimization in a Farm." 2011 IEEE International Symposium on Computer-Aided Control System Design (CACSD), Denver, CO, September 28-30. https://ieeexplore.ieee.org/document/6044549.

Stark, Greg. 2018. "Market Opportunities and Challenges for Pumped Hydro in an Evolving Power Grid Preprint." 2018. HydroVision International, Charlotte, NC, June 26-28. (August). https://www.nrel.gov/docs/fy18osti/71675.pdf.

Stephens, Scott. 2018. "Economic analysis of Bifacial PV Systems.” bifiPV Workshop 2018. Lakewood, CO, September 10. http://npvworkshop.com/fileadmin/images/bifi/denver/presentations/3 Stephens_economic_analysis_of_systems_bifiPV2018.pdf

System Advisor Model (SAM). n.d. National Renewable Energy Laboratory. Accessed February 26, 2019. https://sam.nrel.gov/.

Testa, Antonio, Salvatore de Caro, S., R. La Torre, and Tommaso Scimone. 2010. "Optimal Design of Energy Storage Systems for Stand-Alone Hybrid Wind/PV Generators." SPEEDAM 2010, Pisa, Italy, June 14-16. https://doi.org/10.1109/SPEEDAM.2010.5542078.

Tillmann, Peter, Klaus Jäger, and Christiane Becker. "Minimising the levelised cost of electricity for bifacial solar panel arrays using Bayesian optimisation." Sustainable Energy \& Fuels 4.1 (2020): 254-264.

Turchi, Craig, Guangdong Zhu, Michael Wagner, Tom Williams, and Dan Wendt. 2014. "Geothermal / Solar Hybrid Designs: Use of Geothermal Energy for CSP Feedwater Heating." Geothermal Resources Council 2014 Annual Meeting, Portland, OR, September 28-October 1. https://www.osti.gov/biblio/1170300.

Vali, Mehdi, Vlaho Petrović, Sjoerd Boersma, Jan-Willem van Wingerden, Lucy Y. Pao, and Martin Kühn. 2018. "Model Predictive Active Power Control of Waked Wind Farms." 2018 Annual American Control Conference (ACC), Milwaukee, WI, June 27-29. https://ieeexplore.ieee.org/document/8431391.

van Wingerden, Jan-Willem, Lucy Pao, Jacob Aho, and Paul Fleming. "Active Power Control of Waked Wind Farms." 2017. IFAC-PapersOnLine 50 (1): 4484-4491. https://www.sciencedirect.com/science/article/pii/S240589631730722X?via\%3Dihub.

Whittingham, M. Stanley. 2012. "History, Evolution, and Future Status of Energy Storage." Proceedings of the IEEE Special Centennial Issue 100 (April): 1518-1534. https://ieeexplore.ieee.org/document/6184265. 
Wingfield, Derek. 2017. "SPP Sets North American Record for Wind Power." Southwest Power Pool. February 13, 2017. https://www.spp.org/newsroom/press-releases/spp-sets-north-americanrecord-for-wind-power/.

Wind Integration National Dataset Toolkit. n.d. Grid Modernization. National Renewable Energy Laboratory. Accessed July 3, 2019. https://www.nrel.gov/grid/wind-toolkit.html.

Wiser, Ryan, Andrew Mills, Joachim Seel, Todd Levin, and Audun Botterud. 2017. "Impacts of Variable Renewable Energy on Bulk Power System Assets, Pricing, and Costs.” Berkeley Laboratory and Argonne National Laboratory. Last accessed May 18, 2018. http://etapublications.lbl.gov/sites/default/files/lbnl_anl_impacts_of_variable_renewable_energy_final 0 . pdf.

Wiser, Ryan, and Mark Bolinger. 2018. "2017 Wind Technologies Market Report.” U.S. Department of Energy. Office of Energy Efficiency and Renewable Energy. DOE/EE-1798. https://www.energy.gov/eere/wind/downloads/2017-wind-technologies-market-report.

Zahedi, Ahmad. "Electric Vehicle as Distributed Energy Storage Resource for Future Smart Grid." 2012. 2012 22nd Australasian Universities Power Engineering Conference (AUPEC), Bali, Indonesia, September 26-29. https://ieeexplore.ieee.org/abstract/document/6360205.

Zhang, Yan, Tao Zhang, Rui Wang, Yajie Liu, and Bo Guo. 2015. "Optimal Operation of a Smart Residential Microgrid Based on Model Predictive Control by Considering Uncertainties and Storage Impacts." Solar Energy 122 (December): 1052-65.

https://doi.org/10.1016/j.solener.2015.10.027. 